\title{
Acute pancreatitis in adults and in children
}

\section{Akut pancreatitis jellemzése felnőttekben és gyermekekben}

\author{
Ph.D. Thesis
}

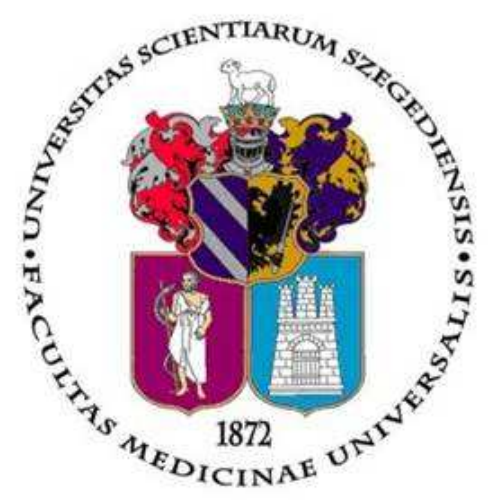

\section{Andrea Párniczky, M.D.}

Heim Pál Children's Hospital

Institute for Translational Medicine, University of Pécs

\section{Supervisors:}

\section{Prof. Péter Hegyi, M.D., Ph.D., D.Sc. ${ }^{1,2,3}$ \\ István Hritz, M.D., Ph.D. ${ }^{4}$}

${ }^{1}$ First Department of Medicine Faculty of Medicine University of Szeged, Szeged, Hungary ${ }^{2}$ MTA-SZTE Lendület Translational Gastroenterology Research Group, Szeged, Hungary ${ }^{3}$ Institute for Translational Medicine, University of Pécs, Hungary

${ }^{4}$ First Department of Surgery, Endoscopic Unit Semmelweis University, Budapest, Hungary

Szeged 


\section{TABLE OF CONTENTS}

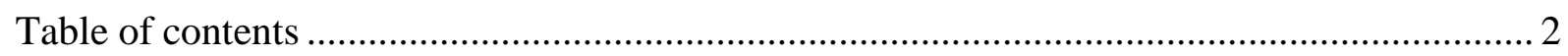

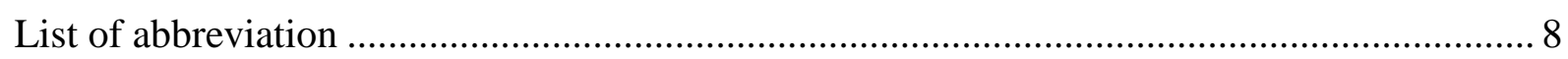

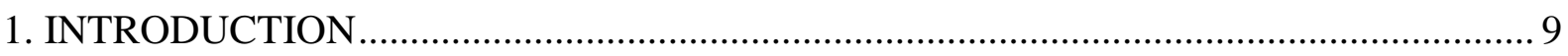

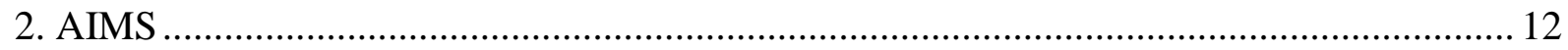

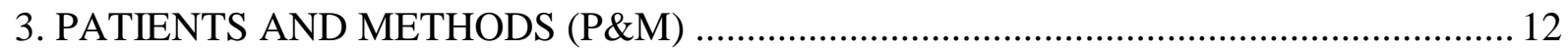

3.1. P\&M for Aim 1: Prospective, Multicentre, Nationwide Clinical Data from 600 Cases of

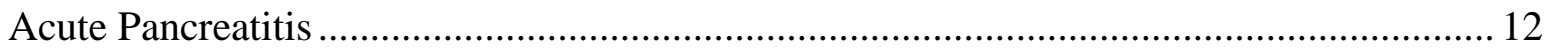

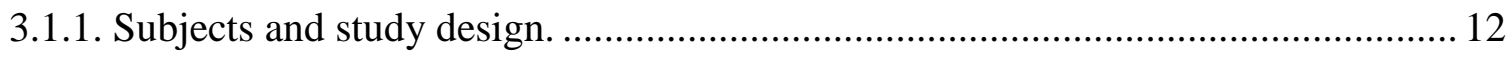

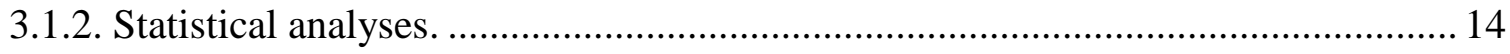

3.2. P\&M for Aim 2: Analysis of Pediatric Pancreatitis (APPLE Trial)............................. 15

3.3. P\&M for Aim 3: Variants in Chronic Pancreatitis ....................................................... 15

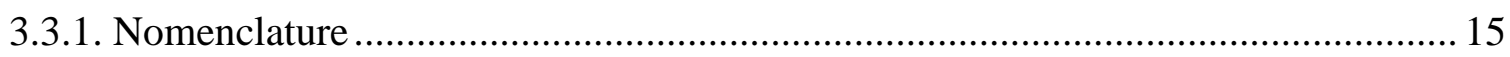

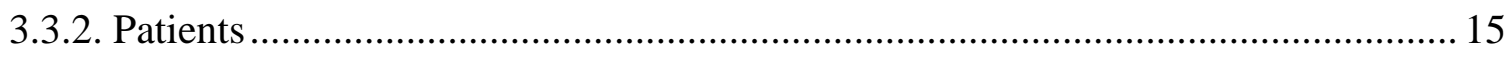

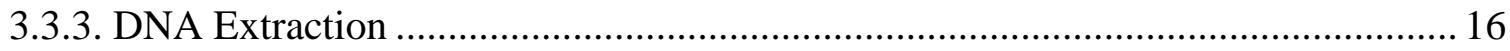

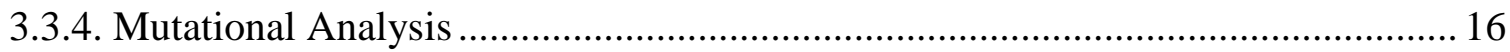

3.3.5. Construction of Luciferase Reporter Plasmids With SPINK1 Promoter................ 17

3.3.6. Dual Luciferase Reporter Gene Assay............................................................... 17

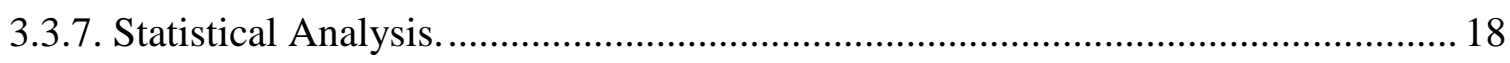

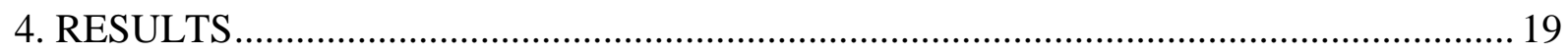

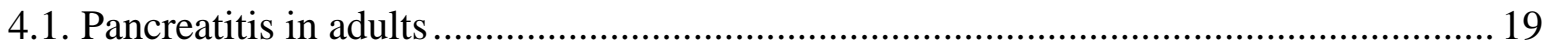

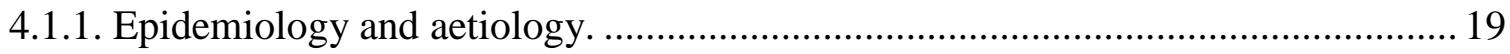

4.1.2. Diagnosis, anamnestic data and symptoms at admission...................................... 21

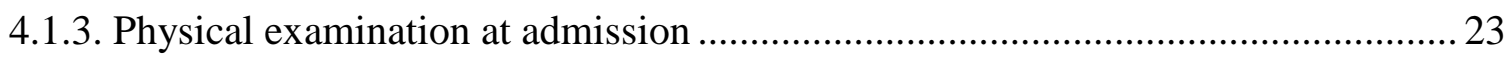

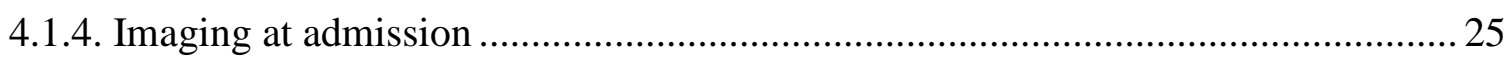

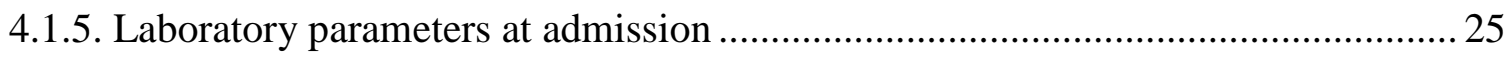

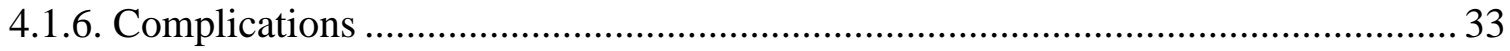

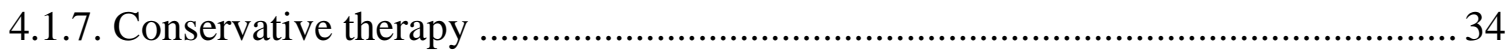

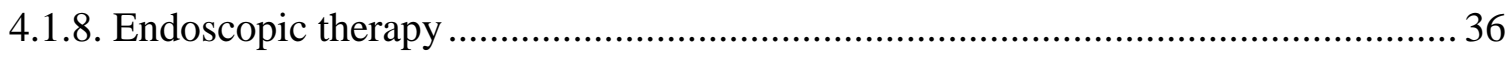

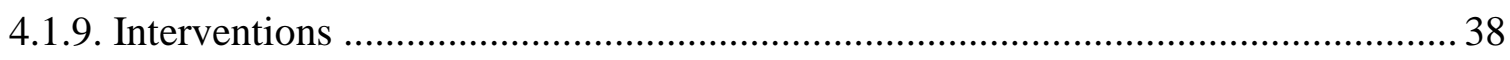

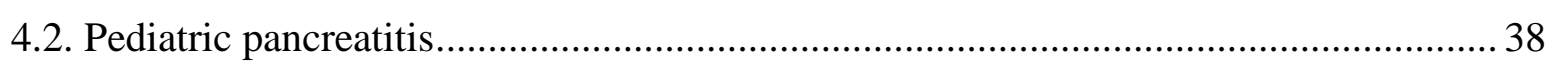

4.3. SPINK1 Promoter Variants in Chronic Pancreatitis..................................................... 39 
4.3.1. Sequence Analysis of the SPINK1 Promoter Region ........................................... 39

4.3.2. Sequence Analysis of the SPINK1 Coding Region ............................................. 40

4.3.3. Functional Analysis of Promoter Variants............................................................. 40

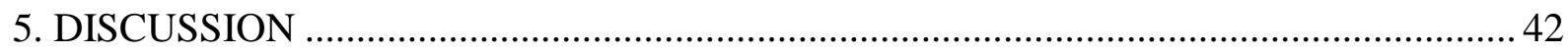

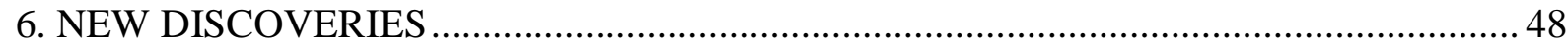

6.1. Prospective, Multicentre, Nationwide Clinical Data from 600 Cases of Acute

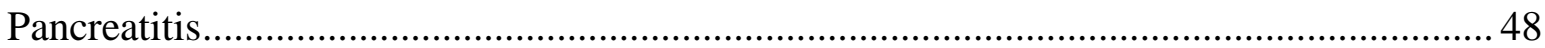

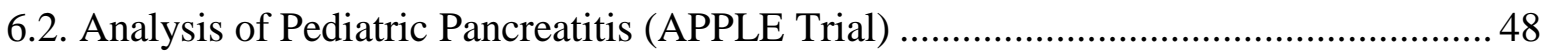

6.3. SPINK1 Promoter Variants in Chronic Pancreatitis..................................................... 48

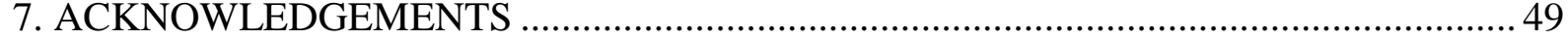

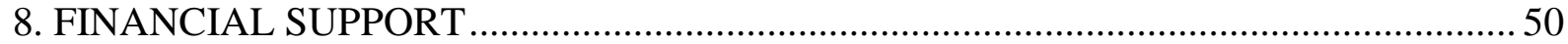

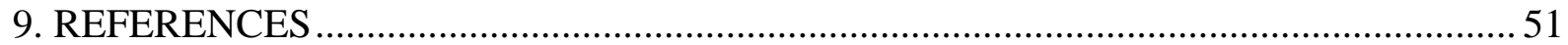




\section{Publications related to the subject of the thesis}

1. Párniczky A, Kui B, Szentesi A, Balázs A, Szűcs Á, Mosztbacher D, Czimmer J, Sarlós P, Bajor J, Gódi S, Vincze Á, Illés A, Szabó I, Pár G, Takács T, Czakó L, Szepes Z, Rakonczay Z, Izbéki F, Gervain J, Halász A, Novák J, Crai S, Hritz I, Góg C, Sümegi J, Golovics P, Varga M, Bod B, Hamvas J, Varga-Müller M, Papp Z, Sahin-Tóth M, Hegyi P; Hungarian Pancreatic Study Group. Prospective, Multicentre, Nationwide Clinical Data from 600 Cases of Acute Pancreatitis.

PLoS One. 2016 31;11(10):e0165309.

IF (2015/2016): 3.54

2. Párniczky A, Mosztbacher D, Zsoldos F, Tóth A, Lásztity N, Hegyi P; Hungarian Pancreatic Study Group and the International Association of Pancreatology.

Analysis of Pediatric Pancreatitis (APPLE Trial): Pre-Study Protocol of a Multinational Prospective Clinical Trial

Digestion. 2016 93(2):105-10.

IF (2015/2016): 1.06

3. Hegyi E, Geisz A, Sahin-Tóth M, Derikx MH, Németh BC, Balázs A, Hritz I, Izbéki F, Halász A, Párniczky A, Takács T, Kelemen D, Sarlós P, Hegyi P, Czakó L; Hungarian Pancreatic Study Group. SPINK1 Promoter Variants in Chronic Pancreatitis.

Pancreas. 2016 45(1):148-53.

IF (2015/2016): 2.738

\section{Publications not related to the subject of the thesis}

1. Párniczky A, Hegyi E, Tóth AZ, Szücs Á, Szentesi A, Vincze Á, Izbéki F, Németh BC, Hegyi P, Sahin-Tóth M.

Genetic Analysis of Human Chymotrypsin-Like Elastases 3A and 3B (CELA3A and CELA3B) to Assess the Role of Complex Formation between Proelastases and Procarboxypeptidases in Chronic Pancreatitis.

Int J Mol Sci. 2016 Dec 20;17(12). pii: E2148.

IF (2015/2016): 4.01

2. Párniczky A, Czakó L, Dubravcsik Z, Farkas G, Hegyi P, Hritz I, Kelemen D, Morvay Z, Oláh A, Pap Á, Sahin-Tóth M, Szabó F, Szentkereszti Z, Szmola R, Takács T, Tiszlavicz L, Veres G, Szücs Á, Lásztity N; Magyar Hasnyálmirigy Munkacsoport, Hungarian Pancreatic Study Group.

Pediatric pancreatitis. Evidence based management guidelines of the Hungarian Pancreatic Study Group.

Orv Hetil. 2015 Feb 22;156(8):308-25. Review. Hungarian.

IF (2015): 0.291

3. Mosztbacher D, Farkas N, Solymár M, Pár G, Bajor J, Szücs Á, Czimmer J, Márta K, Mikó A, Rumbus Z, Varjú P, Hegyi P, Párniczky A.

Restoration of energy level in the early phase of acute pediatric pancreatitis.

World J Gastroenterol. 2017 Feb 14;23(6):957-963.

IF (2015/2016): 3.8 
4. Szücs Á, Marjai T, Szentesi A, Farkas N, Párniczky A, Nagy G, Kui B, Takács T, Czakó L, Szepes Z, Németh BC, Vincze Á, Pár G, Szabó I, Sarlós P, Illés A, Gódi S, Izbéki F, Gervain J, Halász A, Farkas G, Leindler L, Kelemen D, Papp R, Szmola R, Varga M, Hamvas J, Novák J, Bod B, Sahin-Tóth M, Hegyi P; Hungarian Pancreatic Study Group.

Chronic pancreatitis: Multicentre prospective data collection and analysis by the Hungarian Pancreatic Study Group.

PLoS One. 2017 Feb 16;12(2):e0171420.

IF (2015/2016): 3.54

5. Rumbus Z, Matics R, Hegyi P, Zsiboras C, Szabo I, Illes A, Petervari E, Balasko M, Marta K, Miko A, Parniczky A, Tenk J, Rostas I, Solymar M, Garami A.

Fever Is Associated with Reduced, Hypothermia with Increased Mortality in Septic Patients: A Meta-Analysis of Clinical Trials.

PLoS One. 2017 Jan 12;12(1):e0170152.

IF (2015/2016): 3.54

6. Tenk J, Mátrai P, Hegyi P, Rostás I, Garami A, Szabó I, Solymár M, Pétervári E, Czimmer J, Márta K, Mikó A, Füredi N, Párniczky A, Zsiborás C, Balaskó M.

In Obesity, HPA Axis Activity Does Not Increase with BMI, but Declines with Aging: A MetaAnalysis of Clinical Studies.

PLoS One. 2016 Nov 21;11(11):e0166842.

IF (2015/2016): 3.54

7. Alfaro Cruz L, Parniczky A, Mayhew A, Hornung LN, Lin TK, Palermo JJ, Jackson K, Abu-El-Haija M.

Utility of Direct Pancreatic Function Testing in Children.

Pancreas. 2017 Feb;46(2):177-182.

IF (2015/2016): 2.738

8. Szentesi A, Tóth E, Bálint E, Fanczal J, Madácsy T, Laczkó D, Ignáth I, Balázs A, Pallagi P, Maléth J, Rakonczay Z Jr, Kui B, Illés D, Márta K, Blaskó Á, Demcsák A, Párniczky A, Pár G, Gódi S, Mosztbacher D, Szüics Á, Halász A, Izbéki F, Farkas N, Hegyi P; Hungarian Pancreatic Study Group..

Analysis of Research Activity in Gastroenterology: Pancreatitis Is in Real Danger.

PLoS One. 2016 Oct 24;11(10):e0165244.

IF (2015/2016): 3.54

9. Márta K, Farkas N, Szabó I, Illés A, Vincze Á, Pár G, Sarlós P, Bajor J, Szűcs Á, Czimmer J, Mosztbacher D, Párniczky A, Szemes K, Pécsi D, Hegyi P.

Meta-Analysis of Early Nutrition: The Benefits of Enteral Feeding Compared to a Nil Per Os Diet Not Only in Severe, but Also in Mild and Moderate Acute Pancreatitis.

Int J Mol Sci. 2016 Oct 20;17(10).

IF (2015/2016): 4.01

10. Balázs A, Németh BC, Ördög B, Hegyi E, Hritz I, Czakó L, Czimmer J, Gódi S, Csiszkó A, Rakonczay Z Jr, Párniczky A, Izbéki F, Halász A, Kahán Z, Hegyi P, Sahin-Tóth M; Hungarian Pancreatic Study Group.

A Common CCK-B Receptor Intronic Variant in Pancreatic Adenocarcinoma in a Hungarian Cohort. 
Pancreas. 2016 Apr;45(4):541-5.

IF (2015/2016): 2.738

11. Zsoldos F, Párniczky A, Mosztbacher D, Tóth A, Lásztity N, Hegyi P; Hungarian Pancreatic Study Group and the International Association of Pancreatology.

Pain in the Early Phase of Pediatric Pancreatitis (PINEAPPLE Trial): Pre-Study Protocol of a Multinational Prospective Clinical Trial.

Digestion. 2016;93(2):121-6.

IF (2015/2016): 1.06

12. Balázs A, Ruffert C, Hegyi E, Hritz I, Czakó L, Takács T, Szepes Z, Németh BC, Gervain J, Izbéki F, Halász A, Kelemen D, Szmola R, Novák J, Crai S, Illés A, Vincze Á, Molnár Z, Varga M, Bod B, Farkas G Jr, Sümegi J, Szepes A, Dubravcsik Z, Lásztity N, Párniczky A, Hamvas J, Andorka C, Veres G, Szentkereszty Z, Rakonczay Z Jr, Maléth J, Sahin-Tóth M, Rosendahl J, Hegyi P; Hungarian Pancreatic Study Group.

Genetic analysis of the bicarbonate secreting anion exchanger SLC26A6 in chronic pancreatitis. Pancreatology. 2015 Sep-Oct;15(5):508-13.

IF (2015): 2.406

13. Szmola R, Farkas G, Hegyi P, Czakó L, Dubravcsik Z, Hritz I, Kelemen D, Lásztity N, Morvay Z, Oláh A, Párniczky A, Rubovszky G, Sahin-Tóth M, Szentkereszti Z, Szücs Á, Takács T, Tiszlavicz L, Pap Á; Magyar Hasnyálmirigy Munkacsoport, Hungarian Pancreatic Study Group..

Pancreatic cancer. Evidence based management guidelines of the Hungarian Pancreatic Study Group.

Orv Hetil. 2015 Feb 22;156(8):326-39. Review. Hungarian.

IF (2015): 0.291

14. Dubravcsik Z, Farkas G, Hegyi P, Hritz I, Kelemen D, Lásztity N, Morvay Z, Oláh A, Pap Á, Párniczky A, Sahin-Tóth M, Szentkereszti Z, Szmola R, Takács T, Tiszlavicz L, Szücs Á, Czakó L; Magyar Hasnyálmirigy Munkacsoport, Hungarian Pancreatic Study Group.

Autoimmune pancreatitis. Evidence based management guidelines of the Hungarian Pancreatic Study Group.

Orv Hetil. 2015 Feb 22;156(8):292-307. Review. Hungarian.

IF (2015): 0.291

15. Takács T, Czakó L, Dubravcsik Z, Farkas G, Hegyi P, Hritz I, Kelemen D, Lásztity N, Morvay Z, Oláh A, Pap Á, Párniczky A, Patai Á, Sahin-Tóth M, Szentkereszti Z, Szmola R, Tiszlavicz L, Szücs Á; Magyar Hasnyálmirigy Munkacsoport. Hungarian Pancreatic Study Group.

Chronic pancreatitis. Evidence based management guidelines of the Hungarian Pancreatic Study Group.

Orv Hetil. 2015 Feb 15;156(7):262-88. Review. Hungarian.

IF (2015): 0.291

16. Hritz I, Czakó L, Dubravcsik Z, Farkas G, Kelemen D, Lásztity N, Morvay Z, Oláh A, Pap Á, Párniczky A, Sahin-Tóth M, Szentkereszti Z, Szmola R, Szücs Á, Takács T, Tiszlavicz L, Hegyi P; Magyar Hasnyálmirigy Munkacsoport,

Acute pancreatitis. Evidence-based practice guidelines, prepared by the Hungarian Pancreatic Study Group. 
Orv Hetil. 2015 Feb 15;156(7):244-61. Review. Hungarian.

IF (2015): 0.291

17. Balaskó M, Soós S, Párniczky A, Koncsecskó-Gáspár M, Székely M, Pétervári E. Anorexic effect of peripheral cholecystokinin (CCK) varies with age and body composition (short communication).

Acta Physiol Hung. 2012 Jun;99(2):166-72.

IF (2012): 0.43

18. E. Pétervári, M. Balaskó, M. Solymár, A. Párniczky, M. Székely, Z. Szelényi

CCK-8 induces fever-like regulated hyperthermia and symptoms of sickness behavior in mice: A biotelemetric study

J Therm Biol, 2012 July;37(4):297-301.

IF (2012): 1.84

19. Faluhelyi N, Matkovits A, Párniczky A, Csernus V.

The in vitro and in ovo effects of environmental illumination and temperature on the melatonin secretion from the embryonic chicken pineal gland.

Ann N Y Acad Sci. 2009 Apr;1163:383-5.

IF (2009): 1.07

$\begin{array}{llll}\text { Number of full publications: } & 22 & \text { (4 first author) } & \text { IF: } 8.9\end{array}$

Cumulative impact factor: $\quad \mathbf{4 7 . 0 5 5}$ 


\section{LIST OF ABBREVIATION}

\begin{tabular}{|c|c|}
\hline $\mathrm{AP}$ & acute pancreatitis \\
\hline $\mathrm{ACP}$ & alcoholic chronic pancreatitis \\
\hline ALP & alkaline phosphatase \\
\hline APA & American Pancreatic Association \\
\hline APPLE & Analysis of Pediatric Pancreatitis \\
\hline BISAP & Bedside Index of Severity in Acute Pancreatitis \\
\hline BMI & body mass index \\
\hline BUN & blood urea nitrogen \\
\hline $\mathrm{CP}$ & chronic pancreatitis \\
\hline CFTR & cystic fibrosis transmembrane conductance regulator \\
\hline CPAl & carboxypaptidase A1 \\
\hline $\mathrm{CRF}$ & clinical research form \\
\hline CRP & C-reactive protein \\
\hline CT & computertomography \\
\hline CTRC & chymotrypsin C \\
\hline EBM & evidence based medicine \\
\hline EDTA & ethylenediamine tetraacetic acid \\
\hline ERCP & endoscopic retrograde cholangiopancreatography \\
\hline ESGE & European Society of Gastointestinal Endoscopy \\
\hline EST & endoscopic sphinchterotomy \\
\hline GGT & gamma-glutamyl transferase \\
\hline HPSG & Hungarian Pancreatic Study Group \\
\hline IAP & International Association of Pancreatology \\
\hline ICMJE & International Committee of Medical Journal Editors \\
\hline $\begin{array}{l}\text { INSPPIRE } \\
\mathrm{K}\end{array}$ & $\begin{array}{l}\text { International Study Group of Pediatric Pancreatitis: In Search for a Cure } \\
\text { potassium }\end{array}$ \\
\hline LDH & lactate dehydrogenase \\
\hline $\mathrm{LOH}$ & length of hospitalization \\
\hline $\mathrm{Na}$ & sodium \\
\hline OR & odds ratio \\
\hline PCR & polymerase chain reaction \\
\hline PCT & procalcitonin \\
\hline PP & pediatric panreatitis \\
\hline PPI & proton pump inhibitor \\
\hline PRSS1 & protease serine 1 \\
\hline SGOT & glutamic oxaloacetic transaminase \\
\hline SGPT & glutamic pyruvic transaminase \\
\hline SPINK1 & serine peptidase inhibitor Kazal type 1 \\
\hline US & ultrasonography \\
\hline WBC & white blood cells \\
\hline WHO & World Health Organization \\
\hline
\end{tabular}




\section{INTRODUCTION}

Acute pancreatitis (AP) is a serious disease with high mortality (1). The reported incidence is variable in different countries (10-100/100,000 people) (2), and AP is a leading cause of acute hospitalization for gastrointestinal disorders (3). Published studies on the clinical characteristics of AP $(4,5)$ have mostly been based on retrospective cohorts or prospectively collected data from 200-300 cases $(4,5)$. Therefore, large, nationwide, prospectively collected cohorts are needed. Adherence to treatment guidelines has been documented to reduce mortality and/or severity of AP (1). Consequently, dissemination and validation of newly described guidelines are important. The IAP/APA guidelines were approved by 171 experts worldwide (6); however, the recommendations have not yet been validated in large prospective cohorts.

However, the situation in pediatric pancreatitis is different. In the past few years, studies have showed an increased number of AP in children (7-14). Based on the latest epidemiology report, there were over 50,000 new cases in the United States from 2000 to 2009 (13). The fact that the incidence of AP in adults is 4.8-38 per 100,000 and is 3.6-13.2 per 100,000 in children suggests that AP in children is as common as it is in adults (14). It is almost needless to say that children are not 'small adults'; however, the suggestions for the management of AP in children are mostly based on clinical trials performed on adults $(15,16)$. Analyzing the available PubMed data (Figure 1.), we can assume that there are around 10 times more articles available for AP in adults than there is for children. Therefore, it is not surprising that the International Study Group of Pediatric Pancreatitis: In Search for a Cure (INSPPIRE) highlighted the crucial necessity of multicenter prospective studies to better understand AP in children (16). The Hungarian Pancreatic Study Group (HPSG) was established in 2011 in order to improve the care of patients suffering from pancreatic diseases. To achieve our aims we (i) developed an electronic data registry and biobank for patients (www.pancreas.hu), (ii) published the currently available evidence-based medicine guidelines (15, 17-19), (iii) established specific study sessions including the pediatric section and (iv) organized multicentre clinical trials $(20,21)$. We created an international observational clinical trial (APPLE) to collect a critical mass of clinical data and biomedical research samples in a uniform prospective manner. Importantly, the study protocol is suitable for tracking both ongoing (APPLE-P) and earlier episodes (APPLE-R) of pancreatitis. 


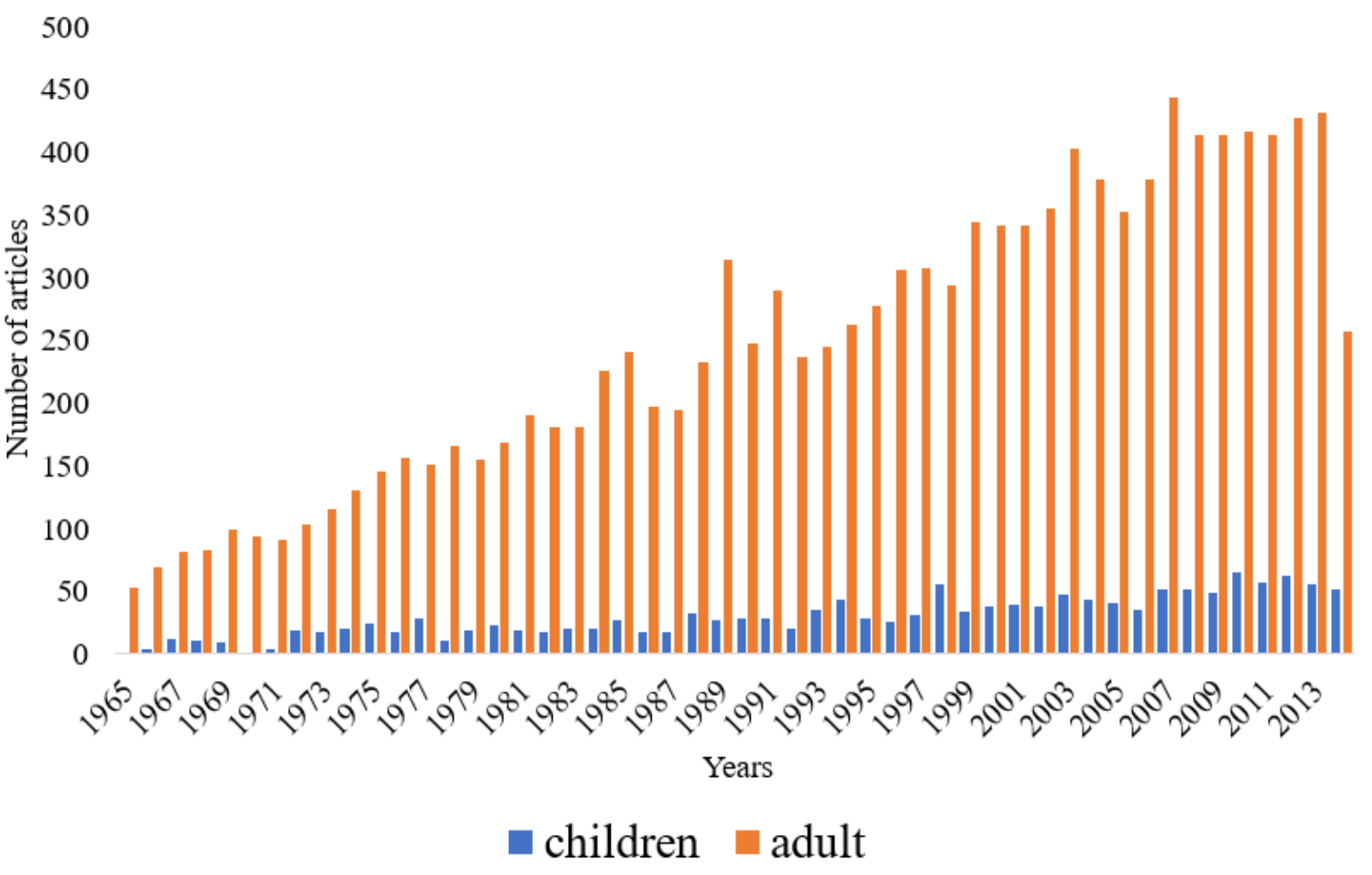

Figure 1. Annual distribution of available papers on AP in adults and children. Results of PubMed searching for 'acute pancreatitis, adult' and acute pancreatitis, children' in the last 50 years are shown.

Both in adults and children genetic alterations and environmental factors play crucial role in the pathogenesis of all forms of pancreatitis. Chronic pancreatitis (CP) is a continuing inflammatory disease of the pancreas leading to irreversible morphological changes and impairment of both exocrine and endocrine functions (22, 23). A genetic background for CP was first described in 1952 by demonstrating a pedigree of a family with hereditary chronic relapsing pancreatitis (24). During the past 20 years, the importance of genetic factors in the etiology of CP has been successively revealed and a mechanistic model in which premature trypsinogen activation plays a central pathogenic role has been established. Gain of-function mutations in the human cationic trypsinogen gene (PRSS1, OMIM *276000) increase premature trypsinogen activation and cause autosomal dominant hereditary pancreatitis or act as a risk factor for sporadic disease $(25,26)$. In addition, genetic alterations of a potent trypsin inhibitor, the serine protease inhibitor Kazal type 1 (SPINK1, OMIM *167790), the trypsindegrading enzyme chymotrypsin C (CTRC, OMIM*601405), carboxypeptidase A1 (CPA1, OMIM *114850), and the cystic fibrosis transmembrane conductance regulator (CFTR, OMIM *602421) may increase the risk for CP (27-34). SPINK1 encodes pancreatic secretory trypsin inhibitor (PSTI) synthesized in the pancreatic acinar cells. The physiological role of PSTI is to 
protect the pancreas against premature trypsinogen activation (35). Human SPINK1 is approximately $7.5 \mathrm{~kb}$ long and contains 4 exons (36). The gene product consists of 79 amino acids, including a 23-amino acid secretory signal peptide. Mutations in SPINK1 are associated with CP of various etiologies such as idiopathic, familial, tropical, and alcoholic (28, 29, 3741). The c.101A $>\mathrm{G}$ (p.N34S) variant associated haplotype, which also includes 4 intronic alterations, c.56-37T $>\mathrm{C}$ in intron $1, \mathrm{c} .87+268 \mathrm{~A}>\mathrm{G}$ in intron 2, and c.195-606G $>\mathrm{A}$ and c.19566_65insTTTT in intron 3, is the most common SPINK1 haplotype associated with CP $(28,29$, $37,39,40)$. According to a recent meta-analysis, this haplotype confers a 13-fold higher risk for idiopathic CP (ICP) (allele frequency of $9.2 \%$ in patients vs $0.7 \%$ in controls) and an approximately 5-fold increased risk for alcoholic CP (ACP) (40). Despite efforts to uncover the functional defect in the p.N34S-associated haplotype, the underlying molecular mechanisms remain unclear so far. However, several studies showed that there was no appreciable effect of this haplotype on the PSTI protein expression, trypsin inhibition activity, or intracellular folding (37, 42-47). In addition to the relatively common p.N34S mutation, a large number of different SPINK1 variants have also been reported (www.pancreasgenetics.org). Whereas, in some SPINK1 variants, the nature of the mutation may suggest an obligatory loss of SPINK1 expression because of mRNA splicing defects, early translation termination, loss of the initiator codon, or large genomic deletions $(28,43,48-50)$, the pathogenicity of missense mutations has to be often determined by functional analysis $(28,30,51,52)$. The promoter region located upstream of a gene plays an important role in transcriptional regulation. Mutations in the promoter may disrupt transcription by altering the recruitment of transcription factors. Consequently, promoter mutations can decrease or increase the amount of mRNA and hence the protein (53). To date, 16 different SPINK1 promoter variants have been reported in the literature (see also www.pancreasgenetics.org) (27, 28, 54-60). Functional characterization of 11 promoter alterations has been recently performed using the human COLO-357 cell line (57). Based on the findings of decreased activity, 3 variants (c. $-53 \mathrm{C}>\mathrm{T}$, c. $-142 \mathrm{~T}>\mathrm{C}$, and c. $-147 \mathrm{~A}>\mathrm{G}$ ) were suggested as CP-predisposing factors. Because no information is available regarding the incidence of SPINK1 promoter variants and their role in CP in the Hungarian population, our aim was to (a) identify potential pathogenic promoter variants of SPINK1 in CP patients, (b) determine their possible linkage with SPINK1 coding region variants, and (c) assess the relevance of the novel promoter variants in relation to disease. 


\section{AIMS}

\subsection{Specific aim 1.}

The main goals of our study were to analyse the course of AP in a prospectively collected cohort of patients from Hungarian centres and to validate the major recommendations in the IAP/APA evidence-based guidelines for the management of AP.

\subsection{Specific aim 2.}

To organize an international, observational clinical trial for pediatric pancreatitis to collect a critical mass of clinical data and biomedical research samples in uniform prospective manner (Analysis of Pediatric Pancreatitis-APPLE).

\subsection{Specific aim 3.}

Identify potential pathogenic promoter variants of SPINK1 in CP patients, determine their possible linkage with SPINK1 coding region variants, and assess the relevance of the novel promoter variants in relation to disease.

\section{PATIENTS AND METHODS (P\&M)}

\subsection{P\&M for Aim 1: Prospective, Multicentre, Nationwide Clinical Data from 600 Cases of Acute Pancreatitis}

\subsubsection{Subjects and study design.}

The study was approved by the Scientific and Research Ethics Committee of the Medical Research Council (22254-1/2012/EKU). All the participants provided written informed consent to participate in this study. The ethics committee have carefully checked and approved the consent procedure. The Hungarian Pancreatic Study Group (HPSG) was established in 2011 to improve patient care for pancreatic diseases (61-65). To achieve our aims, we developed a uniform prospective electronic data registry (www.pancreas.hu), which formed the base for our data collection. For this HPSG study cohort, 600 patients in Hungary were prospectively enrolled for two years between 1 January 2013 and 1 January 2015. Centre distribution is indicated in Figure 2. 


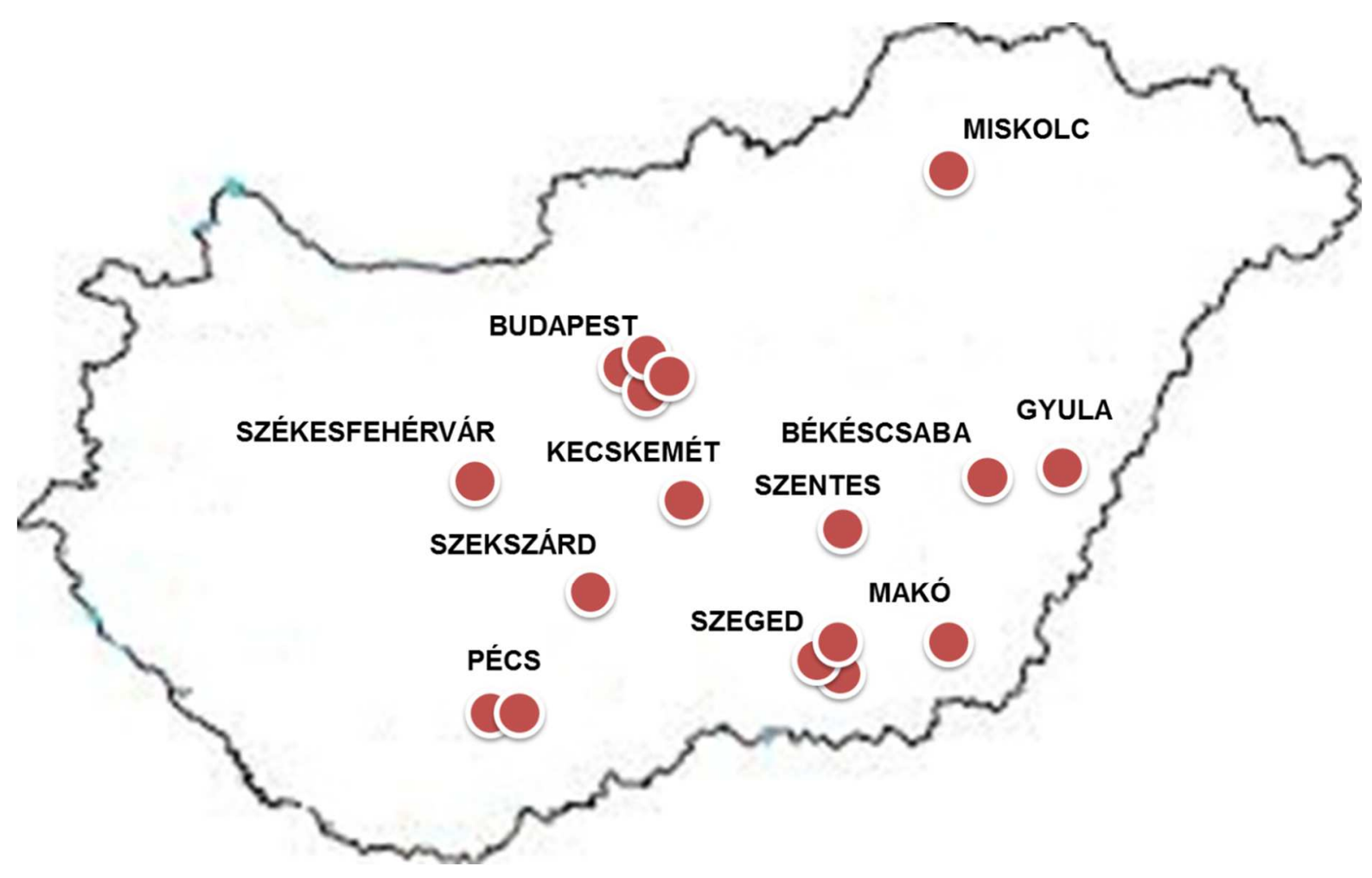

Figure 2. Distribution of participating centres

Diagnosis of AP was based on recommendation A1 in the IAP/APA guidelines (6). Two of the following alterations were confirmed in each patient: abdominal pain (clinical symptom), pancreatic enzyme elevation at least three times above the upper limit and morphological changes (imaging changes). Eighty-six different parameters were collected (http://journals.plos.org/plosone/article?id=10.1371/journal.pone.0165309 S2Fig). Overall, $77 \%$ of the requested data were provided by investigators. The missing data were either not measured (e.g. breath rate at admission) or not investigated (e.g. procalcitonin levels at admission). Only four of the collected parameters were not analysed due to a high amount of missing data (amount of smoking, amount of alcohol, Glasgow coma score and breath rate).

Please note that some of the presented data are difficult to measure (for example alcohol consumption, pain, type of pain, tenderness etc.) and have potential risk for bias, therefore these data need to be interpreted with caution. 


\begin{tabular}{|c|c|c|c|}
\hline ETIOLOGY \& EPIDEMIOLOGY & & LABORATORY PARAMETERS AT ADMISSION & \\
\hline Age & $100 \%$ & White blood cell acount (G/L) & $87 \%$ \\
\hline Sex & $100 \%$ & Haematocrite & $45 \%$ \\
\hline Etiology & $100 \%$ & Thrombocyte & $45 \%$ \\
\hline Days of hospitalization & $100 \%$ & Glucose & $72 \%$ \\
\hline Severity (mild/moderate/severe) & $100 \%$ & BUN & $77 \%$ \\
\hline Mortality & $100 \%$ & Creatitine & $77 \%$ \\
\hline DIAGNOSIS, ANAMNESTIC DATA \& SYMPTHOMS AT ADMISSION & & Sodium & $42 \%$ \\
\hline Abdominal pain & $100 \%$ & Potassium & $42 \%$ \\
\hline Onset of abdominal pain & $74 \%$ & Calcium & $22 \%$ \\
\hline Localization of abdominal pain & $91 \%$ & Cholesterol & $18 \%$ \\
\hline Characterisation of abdominal pain & $83 \%$ & Triglyceride & $19 \%$ \\
\hline Nausea/vomiting & $91 \%$ & Amylase & $90 \%$ \\
\hline Fever & $90 \%$ & Lipase & $53 \%$ \\
\hline Stool & $84 \%$ & SGOT & $47 \%$ \\
\hline Smoking & $94 \%$ & SGPT & $48 \%$ \\
\hline Amount of smoking & $24 \%$ & GGT & $80 \%$ \\
\hline Alcohol & $95 \%$ & direct bilirubin & $26 \%$ \\
\hline Amount of alcohol & $17 \%$ & ALP & $79 \%$ \\
\hline Earlier pancreatic disease & $96 \%$ & LDH & $19 \%$ \\
\hline Ealier AP & $97 \%$ & CRP & $73 \%$ \\
\hline Diabetes & $97 \%$ & Procalcitonin & $12 \%$ \\
\hline Pancreatic cancer & $95 \%$ & CONSERVATIVE THERAPY & \\
\hline Family history of pancreatic disease & $77 \%$ & Intravenosus fluid in the first 24 hours & $92 \%$ \\
\hline Pancreatic enzyme (amylase, lipase) & $100 \%$ & Enteral feeding (on demand) & $96 \%$ \\
\hline Pancreatic imaging & $100 \%$ & Parenteral feeding & $93 \%$ \\
\hline PHYSICAL EXAMINATION AT ADMISSION & & Antibiotic therapy & $94 \%$ \\
\hline Body mass index & $74 \%$ & Probiotics & $59 \%$ \\
\hline Blood pressure & $71 \%$ & PPI & $76 \%$ \\
\hline Heart rate & $60 \%$ & ENDOSCOPIC THERAPY & \\
\hline Abdominal tenderness & $97 \%$ & ERCP & $100 \%$ \\
\hline Abdominal guarding & $65 \%$ & Timing of ERCP & $85 \%$ \\
\hline Fever & $17 \%$ & Obstruction (bile duct dilation or bile stone) & $97 \%$ \\
\hline Breath rate & $3 \%$ & Predicted biliary AP $(2 / 3$ : ALP $>225 \mathrm{IU} / \mathrm{L}, \mathrm{SGPT}>225 \mathrm{IU} / \mathrm{L}$, bilirubin $>40 \mathrm{um}$ & $79 \%$ \\
\hline Glasgow coma scale & $8 \%$ & Suspected cholangitis (fever, WBC, CRP) & $90 \%$ \\
\hline IMAGING AT ADMISSION & & Severity in biliary AP & $100 \%$ \\
\hline Abdominal US & $96 \%$ & Biliary EST & $94 \%$ \\
\hline Abdominal CT & $96 \%$ & Biliary stent & $94 \%$ \\
\hline Pleural fluid/lung infiltration determined by US & $77 \%$ & Pancreatic EST & $92 \%$ \\
\hline Pleural fluid/lung infiltration determined by thoracic X-ray & $93 \%$ & Pancreatic stent & $94 \%$ \\
\hline Pleural fluid/lung infiltration determined by thoracic CT & $95 \%$ & INTERVENTION & \\
\hline COMPLICATION & & Intervetion & $100 \%$ \\
\hline Lung & $95 \%$ & Timing of intervention & $100 \%$ \\
\hline Kidney & $95 \%$ & Type of intervention & $100 \%$ \\
\hline Cardiac & $95 \%$ & Indication & $100 \%$ \\
\hline Brain & $94 \%$ & Severity of AP requiring intervention & $100 \%$ \\
\hline Pancreas & $98 \%$ & Outcome of AP after intervention & $100 \%$ \\
\hline
\end{tabular}

Figure 3. Prospectively collected parameters.

\subsubsection{Statistical analyses.}

A biostatistics consultancy (AdWare Research Ltd., Balatonfüred, Hungary) aided us in selecting and using the adequate methods for the statistical analyses. For descriptive statistics, the number of patients, mean, standard deviation (SD), minimum, median and maximum values were calculated for continuous variables, and the case number and percentage were computed for categorical values. For inferential statistics, the following statistical tests were used for determining statistical significance of differences between groups. To compare two groups of independent samples, the t-test was applied for normally distributed data and the MannWhitney $\mathrm{U}$ test for non-normal data. To compare more than two groups, one-way ANOVA with the Bonferroni adjustment method was used for normally distributed data with homogenous group-wise standard deviation; Brown-Forsythe Levene-type test was applied to test of variance 
homogeneity; the Welch test followed by the Games-Howell post hoc test for normally distributed data with heterogeneous group-wise standard deviation; and the Kruskal-Wallis test followed by the Bonferroni $\mathrm{p}$ value adjustment method for non-normal data. The association between categorical variables was examined with the Chi-square test and Fisher's exact test. For categorical variables the multiple comparison between groups were not applied. The relevant statistical tests are also described in the legends to the figures. Statistical analyses were prepared by SPSS 19.0.0. Brown-Forsyte Levene test was prepared by R Studio Version 0.99.896-@ 2009-2016 R studio, Inc., Lawstat package.

\subsection{P\&M for Aim 2: Analysis of Pediatric Pancreatitis (APPLE Trial): Pre- Study Protocol of a Multinational Prospective Clinical Trial}

The study protocols have been discussed in our international meeting held in Szeged in November 2014, where expert pediatric pancreatologists attended. The study has received the relevant ethical approval (No. ad.52499-3/2014) issued by the National Hungarian Ethical Authority (ETT TUKEB). The trial has been registered at the ISRCTN registry (ISRCTN89664974) which is a primary clinical trial registry recognized by Word Health Organization (WHO) and International Committee of Medical Journal Editors (ICMJE). Electronic clinical research forms have been developed (http://www.pancreas.hu/studies/apple). The IAP Scientific Committee has approved the study and advertised worldwide among its 4000 members. The study is open for all pediatric centers throughout the world, who can provide accurate data.

\subsection{P\&M for Aim 3: Variants in Chronic Pancreatitis}

\subsubsection{Nomenclature}

Nucleotide numbering reflects coding DNA numbering with +1 corresponding to the A of the ATG translation initiation codon in the SPINK1 reference sequence (RefSeq: NG_008356.1). Promoter variants were numbered relative to the first nucleotide $5^{\prime}$ of the ATG initiation codon, designated -1 .

\subsubsection{Patients}

Patients were recruited through the Hungarian National Pancreas Registry (www.pancreas.hu). All patients enrolled were Hungarian and gave their informed consent 
according to the ethical guidelines of the Declaration of Helsinki. The study was approved by the National Ethical Review Committee ETT-TUKEB (22254-1/2012). A total of 100 unrelated patients with CP (cases) and 100 subjects with no pancreatic disease (controls) were enrolled. Diagnosis of CP was based on 2 or more of the following findings: history of recurrent pancreatitis or recurrent abdominal pain typical for $\mathrm{CP}$, radiological findings of pancreatic calcifications by computed tomography and/or ultrasonography, and/or pathological findings such as pancreatic ductal irregularities and dilatations on endoscopic retrograde cholangiopancreatography or magnetic resonance cholangiopancreatography.9 Alcoholic CP was defined by consumption of more than $80 \mathrm{~g} / \mathrm{d}$ (men) ethanol or more than $60 \mathrm{~g} / \mathrm{d}$ (women) for at least 2 years. Idiopathic CP was diagnosed in the absence of a positive family history or known risk factors, such as alcohol abuse, medication, trauma, metabolic disorders, and infection.

\subsubsection{DNA Extraction}

Whole blood was collected in EDTA tubes and stored at $-80^{\circ} \mathrm{C}$. Genomic DNA was extracted from peripheral blood leukocytes using the QIAamp DNA Blood Mini Kit (Qiagen, Hilden, Germany).

\subsubsection{Mutational Analysis}

The p.N34S mutation was detected by polymerase chain reaction (PCR)-restriction fragment length polymorphism. Polymerase chain reaction was carried out in a total volume of $25 \mu \mathrm{L}$ using 0.5 U HotStarTaq DNA Polymerase (Qiagen), $1.5 \mathrm{mM} \mathrm{MgCl2,} 0.2 \mathrm{mM}$ of each dNTP, $0.5 \mu \mathrm{M}$ of each primer, and 10 to $50 \mathrm{ng}$ of genomic DNA template. Cycle conditions were 15 -minute initial heat activation at $95^{\circ} \mathrm{C} ; 36$ cycles of 3 -step cycling including 30 -second denaturation at $94^{\circ} \mathrm{C}, 30$-second annealing at $54^{\circ} \mathrm{C}$, and 1 -minute extension at $72^{\circ} \mathrm{C}$; and 10 minutes of final extension at $72^{\circ} \mathrm{C}$. The 560-bp PCR products were digested with restriction endonuclease Hpy166II (New England Biolabs, Ipswich, Mass). The wild-type allele yielded a 518-bp product, whereas the mutant allele resulted in 414-bp and 104-bp fragments. Polymerase chain reaction-restriction fragment length polymorphism products were electrophoretically separated on $2 \%$ agarose gels and stained with ethidium bromide. An approximately 1.2-kb SPINK1 region spanning from c.-1181 to c.31 was sequenced in the study population. The promoter region was amplified using 3 primer pairs (P1-P3) (Figure 25). Polymerase chain reaction was performed using 0.5 U HotStarTaq DNA Polymerase (Qiagen), $1.5 \mathrm{mM} \mathrm{MgCl}$, 
$0.2 \mathrm{mM}$ dNTP, $0.5 \mu \mathrm{M}$ primers, and 10 to $50 \mathrm{ng}$ of genomic DNA template in a volume of 25 $\mu \mathrm{L}$. Cycle conditions were 15 -minute initial heat activation at $95^{\circ} \mathrm{C} ; 40$ cycles of 3 -step cycling including 30-second denaturation at $94^{\circ} \mathrm{C}, 30$-second annealing at the indicated annealing temperature, and 1 -minute extension at $72^{\circ} \mathrm{C}$; and 5 minutes of final extension at $72^{\circ} \mathrm{C}$. In cases with promoter variants c. $-14 \mathrm{G}>\mathrm{A}$, c. $-108 \mathrm{G}>\mathrm{T}$, c. $-215 \mathrm{G}>\mathrm{A}$, and c. $-246 \mathrm{~A}>\mathrm{G}$, the entire SPINK1 coding region with exon-intron boundaries was sequenced to determine a possible linkage with other variants. Polymerase chain reaction was performed using 1.5 U HotStarTaq DNA Polymerase (Qiagen), $1.5 \mathrm{mM} \mathrm{MgCl} 2,0.2 \mathrm{mM} \mathrm{dNTP}, 0.5 \mu \mathrm{M}$ primers, and 10 to $50 \mathrm{ng}$ of genomic DNA template in a volume of $50 \mu \mathrm{L}$. Cycle conditions were 15 minutes of initial heat activation at $95^{\circ} \mathrm{C} ; 40$ cycles of 3 -step cycling including 30 -second denaturation at $94^{\circ} \mathrm{C}, 30$ second annealing at the indicated annealing temperature and 45 -second extension at $72{ }^{\circ} \mathrm{C}$; and 5 minutes of final extension at $72^{\circ} \mathrm{C}$.

\subsubsection{Construction of Luciferase Reporter Plasmids With SPINK1 Promoter}

A DNA fragment corresponding to the region between c.-541 and c. 35 of the SPINK1 genewas cloned into the pGL3-Basic vector (Promega, Madison, Wis) upstream of a firefly luciferase reporter gene (pGL3-SPINK1 plasmid) using restriction sites KpnI and HindIII. SPINK1 promoter variants were introduced into this construct by overlap extension PCR mutagenesis.

\subsubsection{Dual Luciferase Reporter Gene Assay}

Cells were washed with phosphate buffered saline, covered with $500 \mu \mathrm{L}$ passive lysis buffer (Promega), scraped from the culture plates, subjected to a freeze-thaw cycle in liquid nitrogen, and incubated at $22^{\circ} \mathrm{C}$ for 15 minutes. Cell debris was then removed by centrifugation (10,000 rpm, 30 seconds), and the supernatant was saved for analysis. Luciferase expression was measured using the Dual-Glo Luciferase Assay System (Promega). Aliquots (20 $\mu \mathrm{L})$ of cell extracts were mixed with $100 \mu \mathrm{L}$ Luciferase Assay. Reagent II, and the luminescence was measured with a Veritas luminometer (Turner Biosystems Inc, Sunnyvale, Calif). After recording the firefly luciferase activity, renilla luciferase was measured by adding $100 \mu \mathrm{L}$ Stop and Glo Reagent. Relative luciferase activity was determined by dividing the firefly and renilla luciferase luminescence results and expressing this firefly/renilla ratio as the percentage of the wild-type pGL3-SPINK1 value. Results were obtained from 3 to 8 independent transfection experiments. 


\subsubsection{Statistical Analysis}

The significance of the differences in allele frequencies between cases and controls was tested by 2-tailed Fisher exact test and was calculated using GraphPad Prism 6 (GraphPad Software, Calif). The significance between luciferase activities of SPINK1 promoter variants and wild typewas assessed by means of the Student $\mathrm{t}$ test; $\mathrm{P}<0.05$ was considered statistically significant. 


\section{RESULTS}

\subsection{Pancreatitis in adults}

\subsubsection{Epidemiology and aetiology}

In our cohort, $56 \%(n=335)$ of the patients were male, and $44 \%(n=265)$ were female (Figure 4A). With regard to the age distribution of the cases, AP incidence in the males increased between 33 and 38 years and remained high until 68 years, after which it sharply declined. In the females, the highest incidence was between 53 and 78 years (Figure 4B). The majority $(61.2 \%)$ of the cases were mild, $30 \%$ were moderate, and $8.8 \%$ were severe, according to the revised Atlanta classification (66) (Figure 4C). The incidence of severe AP demonstrated an age-dependent rise between 23 and 58 years. In contrast, the frequency of mild or moderate AP did not show a similar age distribution (Figure 4B), suggesting that age may be a risk factor for disease severity.
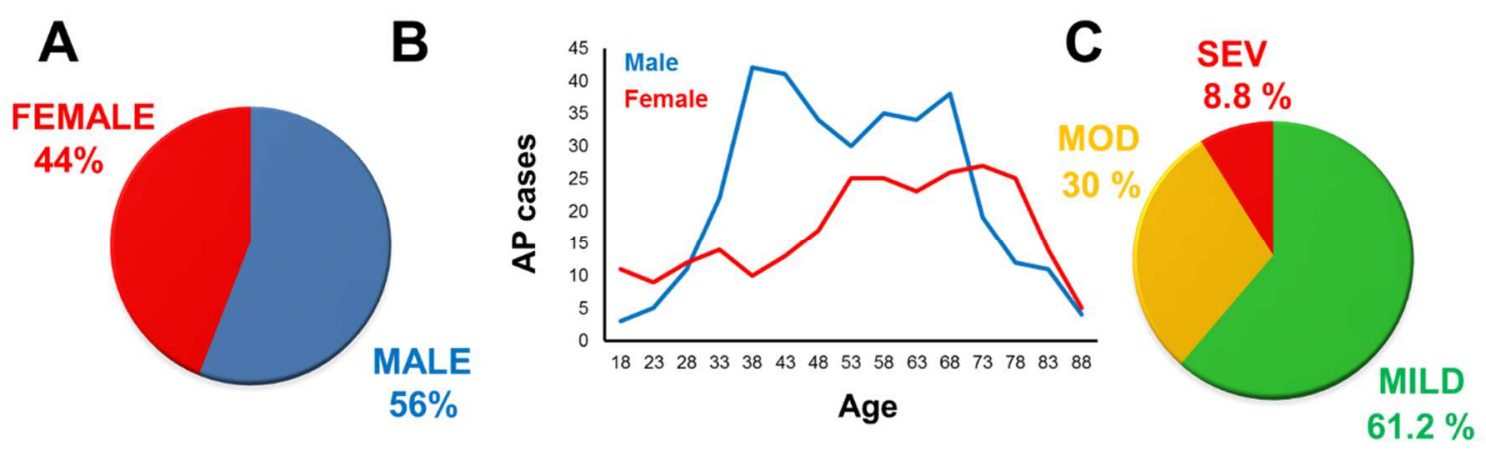

Figure 4. Epidemiology and aetiology. A. Sex distribution of AP cases. B. Age distribution of AP cases. C. AP severity groups. Mod: moderate; sev: severe.

Overall mortality was $2.83 \%$ (17 deaths/600 patients) in the cohort. Mortality was higher in severe AP $(28.3 \% ; \mathrm{p}<0.001)$ versus moderate $(0.6 \%)$ and mild AP $(0.3 \%)$ (Figure $5 \mathrm{~B})$. Analyses of age distribution for mortality revealed two peaks at 43 and 68 years (Figure 5A). There was no relevant difference in mortality between mild and moderate AP. The length of hospitalization showed significant differences between these groups (mild: $8.3 \pm 0.2$ days; moderate: $14.6 \pm 0.5$ days; severe: $26.2 \pm 3.1$ days; $\mathrm{p}<0.001$ ) (Figure 5C). Mortality peaked between days 1 and 4 (early mortality) and days 11 and 14 (late mortality) (Figure 6). The cost of treatment (calculating only the costs of medications, examinations and interventions) for mild AP was 
HUF 99,006 (approximately 330 euros); however, it increased to HUF 1,725,135 (approximately 5,750 euros) for severe AP, based on an average of 10 patients per group.
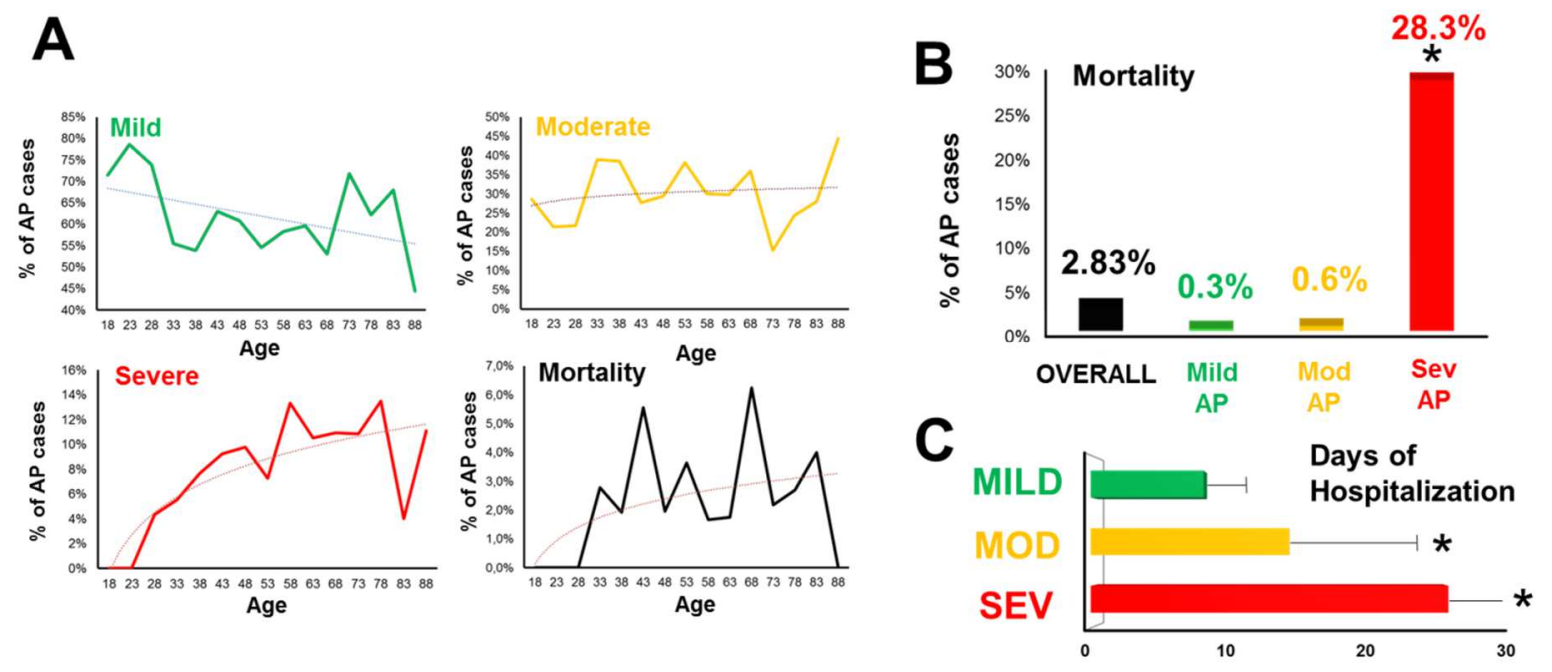

Figure 5. A. Age distribution of mild, moderate and severe AP cases and mortality. B. Overall mortality and distribution in the severity groups. $\mathrm{p}<0.001$ was between the severe and other groups according to Fisher's exact test. C. Days of hospitalization. Mann-Whitney U test with Bonferroni correction was used to compare the group pairs $(\mathrm{p}<0.001$ between groups).

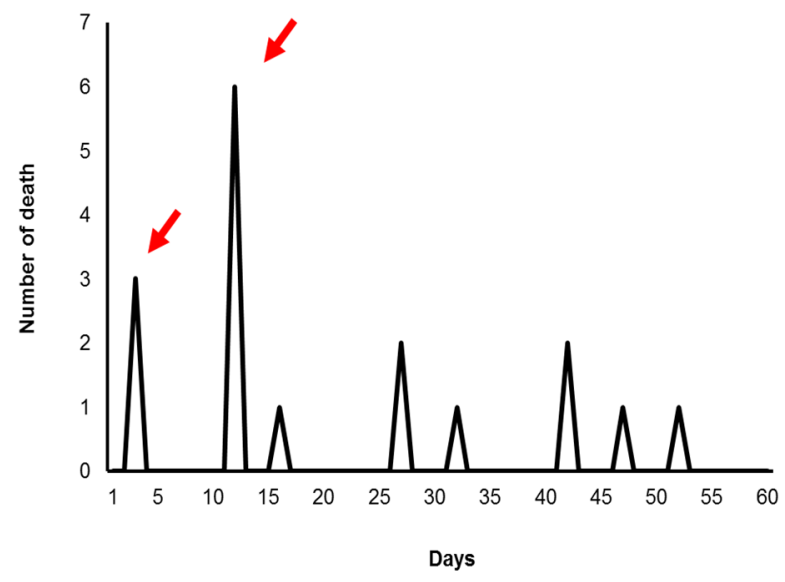

Figure 6.

Mortality peaks during AP.

The most common aetiology of AP was biliary disease (43.8\%) and alcohol abuse $(26.5 \%)$ (Figure 7). In females, the frequency of biliary AP was almost twice as high as in males (58.9\% vs. $31.9 \%)$. In contrast, alcoholic AP was almost four times more common in males $(39.1 \%)$ versus females (10.6\%). When alcohol plus high-fat diet was considered as a separate etiological group, the frequency was still higher among males $(11.9 \%)$ versus females $(6.4 \%)$. Hyperlipidaemia was more frequently observed in males $(8.1 \%)$ versus females $(3.8 \%)$. Relative to other aetiologies, the frequency of hyperlipidaemia was significantly lower in mild $\mathrm{AP}$, whereas it was higher in moderate and severe AP, indicating that hyperlipidaemia is a risk 
factor for severity. The number of idiopathic cases was comparable in males $(16.1 \%)$ and females (16.6\%) (Figure 7). Post-ERCP AP was significantly more prevalent in females (6\%) versus males $(1.8 \%)$. Although it is true that more female patients have ERCP than male patients (the difference is less than 3.3\%) but this rather reflects the risk difference. Notably, female gender is an independent risk factor for post-ERCP AP (ESGE Guideline 2014).

\begin{tabular}{|c|c|c|c|c|c|c|c|}
\hline & number & $\%$ & MALE & FEMALE & MILD & MOD & SEV \\
\hline Biliary & 263 & $43.83 \%$ & $31.94 \%$ & $58.87 \%{ }^{\mathrm{a}}$ & $64.26 \%$ & $28.52 \%$ & $7.22 \%$ \\
\hline Alcohol & 102 & $17.00 \%$ & $27.16 \%^{b}$ & $4.15 \%$ & $61.76 \%$ & $30.39 \%$ & $7.84 \%$ \\
\hline Alcohol + High fat & 57 & $9.50 \%$ & $11.94 \%^{\mathrm{c}}$ & $6.42 \%$ & $57.89 \%$ & $29.82 \%$ & $12.28 \%$ \\
\hline Idiopathic & 98 & $16.33 \%$ & $16.12 \%$ & $16.600 \%$ & $62.24 \%$ & $28.57 \%$ & $9.18 \%$ \\
\hline Hyperlipidaemia & 37 & $6.17 \%$ & $8.06 \%^{d}$ & $3.77 \%$ & $32.43 \%^{f}$ & $48.65 \%^{g}$ & $18.92 \%^{h}$ \\
\hline Post ERCP & 22 & $3.67 \%$ & $1.79 \%$ & $6.04 \%{ }^{e}$ & $68.18 \%$ & $22.73 \%$ & $9.09 \%$ \\
\hline \multirow[t]{2}{*}{ Other } & 21 & $3.50 \%$ & $2.99 \%$ & $4.15 \%$ & $66.67 \%$ & $28.57 \%$ & $4.76 \%$ \\
\hline & 600 & $100,00 \%$ & & & & & \\
\hline
\end{tabular}

Figure 7. Aetiology of AP. a: $p<0.001 ; \mathbf{b}: p<0.001 ; \mathbf{c}: p=0.022, \mathbf{d}: p=0.030 ; \mathbf{e}: p=0.006 ;$ f: $p<0.001$; g: $\mathrm{p}=0.011 ; \mathbf{h}: \mathrm{p}=0.025$ )

Anamnestic data collected at admission revealed that $21.2 \%$ of AP was recurrent (Figure 8) and $4.9 \%$ had a family history of AP. Neither mortality nor severity was affected by recurrence. History of alcohol consumption or smoking was associated with higher mortality in severe AP; however, this difference did not reach statistical significance due to the small number of such cases. The combined presence of both toxic factors did not raise mortality further (Figure 8).

\begin{tabular}{|c|c|c|c|} 
ANAMNESTIC DATA & $\%$ & SEV & MORT \\
\hline Alcohol & $39.4 \%$ & $13.0 \%$ & $40 \%$ \\
\hline Smoking & $26.9 \%$ & $6.0 \%$ & $44 \%$ \\
\hline Alcohol + Smoking & $25.8 \%$ & $6.7 \%$ & $44 \%$ \\
\hline Diabetes & $17.6 \%$ & $0.1 \%$ & $33 \%$ \\
\hline Acute Pancreatitis & $21.2 \%$ & $0.1 \%$ & $25 \%$ \\
\hline Chronic Pancreatitis & $5.1 \%$ & \multicolumn{2}{|}{} \\
\cline { 1 - 2 } Family History of AP & $4.9 \%$ & \multicolumn{1}{|}{} \\
\cline { 1 - 2 } Pancreatic Cancer & $0.3 \%$ & & \\
\cline { 1 - 2 } & \multicolumn{1}{|l}{}
\end{tabular}

Figure 8. Diagnosis, anamnestic data and symptoms at admission. A. Anamnestic data. The percentages of severe AP and mortality in severe AP are also shown in relation to alcohol consumption, smoking, diabetes and history of earlier AP.

\subsubsection{Diagnosis, anamnestic data and symptoms at admission}

The majority of AP patients usually presented at emergency departments 1-6 hours or 19-24 hours after the onset of abdominal pain (Figure 9). Not seeking medical attention during the first four days of AP strongly heightened the risk for severe AP and mortality (Figure 10C). 
Diagnosis of AP was based on the two-thirds rule as described in Methods. The large majority $(95.3 \%)$ of the patients suffered from abdominal pain, $85.4 \%$ experienced serum pancreatic enzyme elevation, and $64.2 \%$ had imaging alterations (oedema or peripancreatic fluid) (Figure 10D). In $44.9 \%$ of the cases, all three diagnostic criteria were present. In $80.7 \%$ of the cases, diagnosis of AP could be established on the basis of abdominal pain and a rise in pancreatic enzyme. Importantly, the lack of an increase in enzyme was a risk factor for severe pancreatitis, whereas the lack of abdominal pain demonstrated a risk for mortality. The absence of imaging alterations in the pancreas significantly decreased the risk of severe AP (Figure 10D).

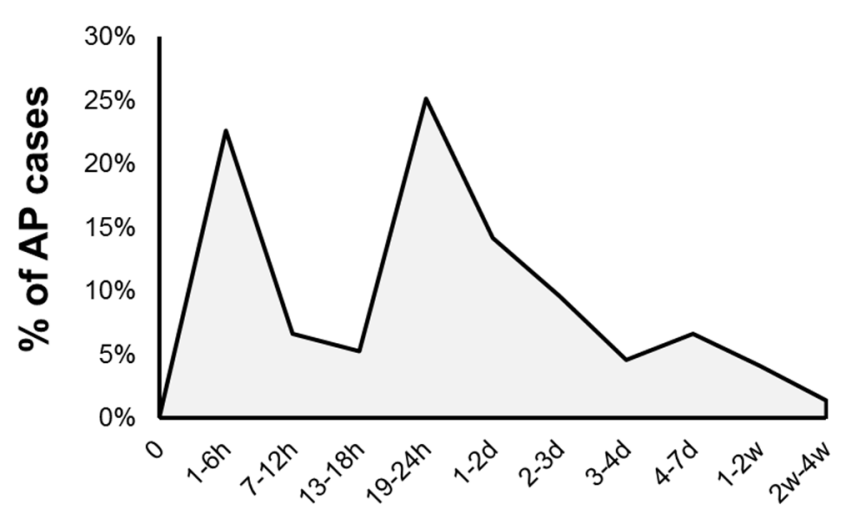

Figure 9. Relationship between time of onset of abdominal pain and presentation at ER units.

\section{ONSET OF ABDOMINAL PAIN}
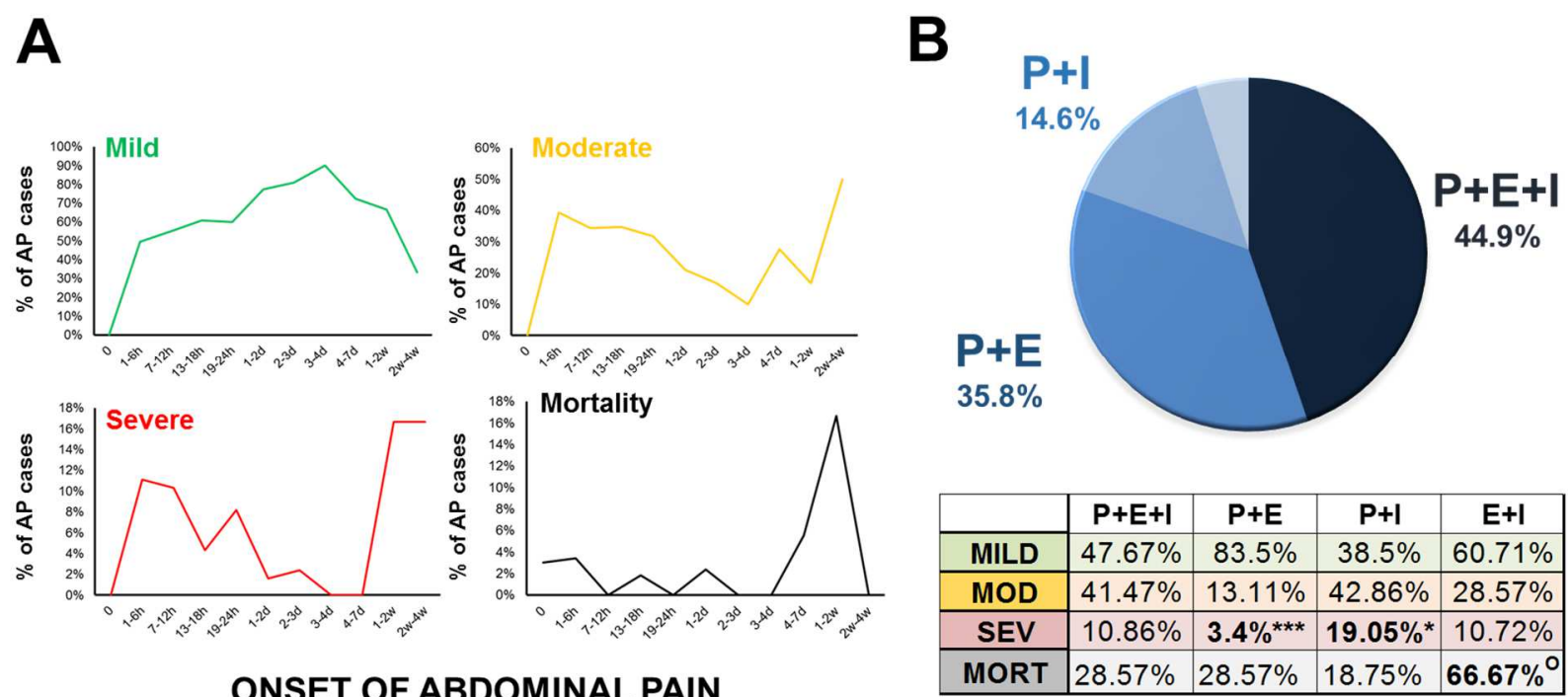

ONSET OF ABDOMINAL PAIN

Figure 10. A. Time of onset of abdominal pain and presentation at ER in the three severity groups and association with mortality in the severe group. B. Diagnosis. Distribution of diagnostic criteria in the overall cohort (pie chart) and in the three severity groups (table) and association with mortality in severe AP (table). P: pain; E: enzyme elevation; I: imaging alteration. ${ }^{\circ} \mathrm{p}=0.189$ (Fisher's exact test) $* \mathrm{p}=0.005$ (Chi-square test) $* * * \mathrm{p}<0.001$ (Chi-square test). 
The pain was mostly epigastric in origin as well as from cramping (Figure 11E). In addition to abdominal pain, nausea and/or vomiting were the other most frequent complaints (74.9\%) (Figure 11F). Importantly, mortality was not observed among patients without nausea and/or vomiting as AP symptoms. Other clinical symptoms and their relation with severity and mortality are described in Figure 11F.
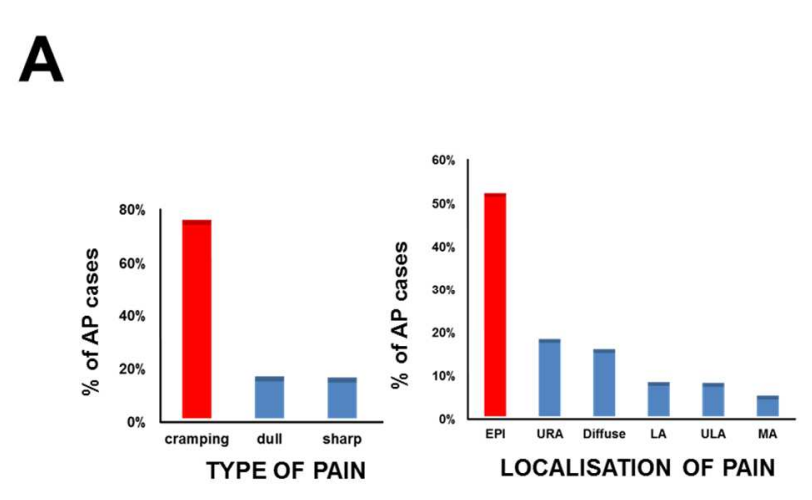

\begin{tabular}{|c|c|c|c|}
\hline & $\%$ & SEV & MORT \\
\hline \multicolumn{4}{|l|}{ Abdominal Pain } \\
\hline Yes & $95.3 \%$ & $9.0 \%$ & $26.0 \%$ \\
\hline No & $4.7 \%$ & $11.0 \%$ & $66.7 \%^{\circ}$ \\
\hline \multicolumn{4}{|l|}{ Nausea/Vomiting } \\
\hline Yes & $74.9 \%$ & $7.0 \%$ & $28.0 \%$ \\
\hline No & 25.1 & $8.0 \%$ & 0 \\
\hline \multicolumn{4}{|c|}{ Subfebrility/Fever } \\
\hline Yes & $22.0 \%$ & $11.6 \%$ & $21.0 \%$ \\
\hline No & $78.0 \%$ & $6.1 \%^{*}$ & $29.0 \%$ \\
\hline \multicolumn{4}{|l|}{ Stool } \\
\hline diarrhea & $16.7 \%$ & $10.0 \%$ & $38.0 \%$ \\
\hline constipation & $11.1 \%$ & $13.0 \%$ & $43.0 \%$ \\
\hline normal & $72.2 \%$ & $6.0 \%$ & $19.0 \%$ \\
\hline
\end{tabular}

Figure 11. A. Type and localisation of abdominal pain. EPI: epigastric pain; URA: upper right abdomen; ULA: upper left abdomen; MD: middle abdomen; L: lower abdomen; D: diffuse. $\mathbf{B}$. Symptoms in the entire cohort and in the severe AP group and association with mortality in the severe AP group. ${ }^{\circ} \mathrm{p}=0.189$ (Fisher's exact test) ${ }^{\mathrm{OO}} \mathrm{p}=0.051$ (Chi-square test) $* \mathrm{p}=0.029$ (Chi-square test).

Although a tendency for association was observed between the rise in BMI and severity of AP, a significant difference was not found when patients with different BMI levels were compared for severity or when the three severity groups were compared with respect to BMI averages (Figure 12A). With regard to the physical examination of the abdomen, tenderness was detected in $91.2 \%$ of the cases (Figure 12B). Importantly, abdominal tenderness developed in all the patients suffering from severe AP; however, the lack of this symptom was favourable for mortality. Abdominal guarding developed in $6.4 \%$ of the patients during AP, and this symptom was associated with increased mortality in severe AP (Figure 12B). Systolic blood pressure above $180 \mathrm{Hgmm}$ or elevation of heart rate above 100 was significantly connected with severe AP (Figure 12C).

There was a lack of measurement of breath rates among doctors regarding the possibility of lung injury. The number of documented respiratory rate measurements at admission was only $2.5 \%$. 
A

\begin{tabular}{|c|c|c|c|c|}
\hline BMI & AVERAGE & S.E.M. & $\%$ & SEV \\
\hline $13-18$ & 16.1 & 0.3 & $4 \%$ & \\
\hline $18-23$ & 20.8 & 0.1 & $20 \%$ & $6.7 \%$ \\
\hline 23-28 & 25.4 & 0.1 & $35 \%$ & $8.4 \%$ \\
\hline $28-33$ & 30.0 & 0.1 & $25 \%$ & $9.7 \%$ \\
\hline $33-38$ & 34.7 & 0.2 & $10 \%$ & $14.3 \%$ \\
\hline $38-43$ & 39.8 & 0.4 & $4 \%$ & \\
\hline $43-48$ & 44.6 & 0.5 & $2 \%$ & \\
\hline
\end{tabular}

\section{BMI}

B

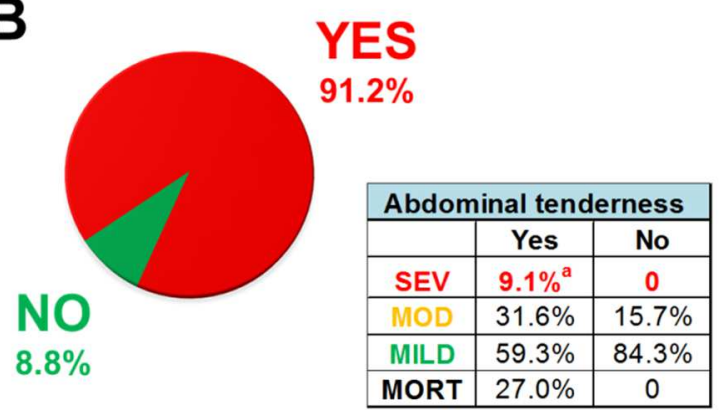

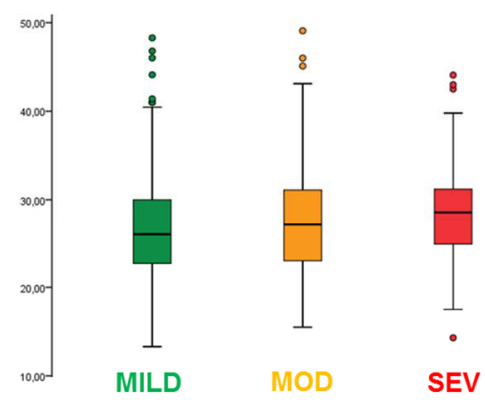

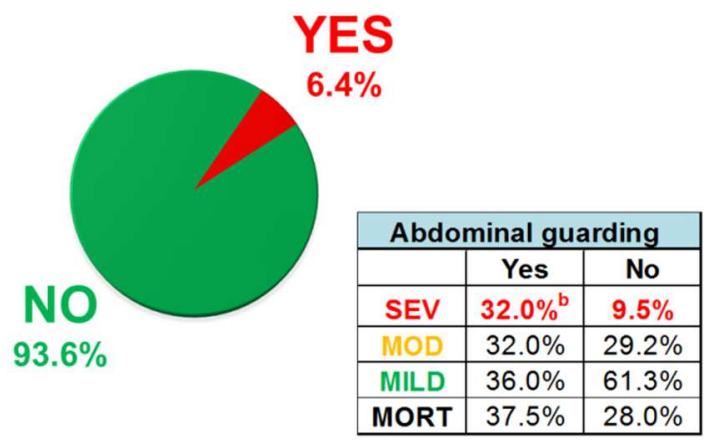

a b

C

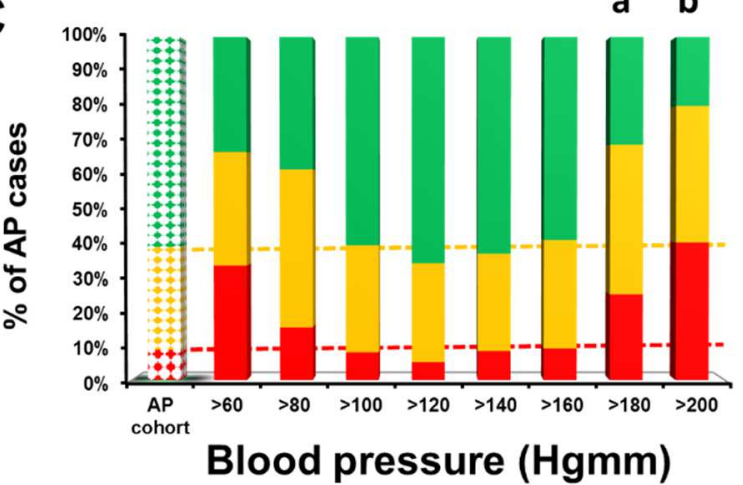

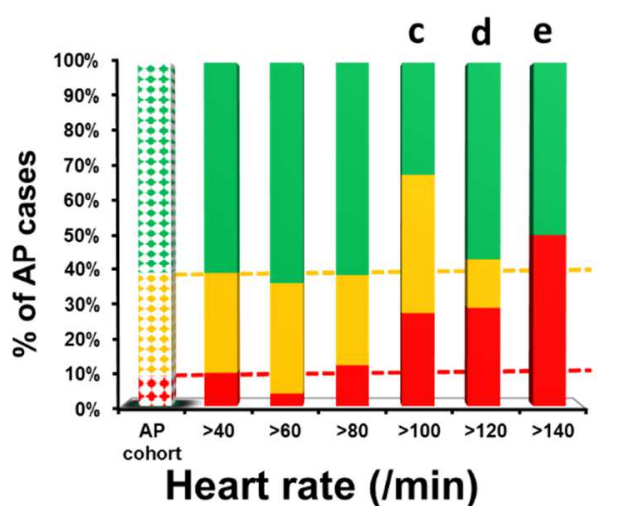

Figure 12. Physical examination at admission. A. Body Mass Index (BMI) in the three AP severity groups. BMI values for $90 \%$ of the cohort were between 18 and 38. Although the tendency suggests that a rise in BMI increases the risk for severe AP, statistical analyses showed no significant differences between the groups. B. Abdominal tenderness and guarding in the three AP severity groups. Both abdominal tenderness and guarding were more frequent in severe AP (a: $p=0.025 ; \mathbf{b}$ : $\mathrm{p}<0.001$; Chi-square test). Mortality in the severe AP group is shown. C. Systolic blood pressure and heart rate in the three AP severity groups. The first dotted column represents the entire cohort. Green: mild AP; yellow: moderate AP; red: severe AP. (a: $p=0.027$; b: $p=0.016$; $\mathbf{c}: p<0.001$; d: $p=0.071 ; \mathbf{e}: p=0.042$; Chi-square test). 


\subsubsection{Imaging at admission}

All the patients had either abdominal US or CT at admission. During abdominal US, only $74.3 \%$ of the investigators described the status of the lungs (Figure 13). Thoracic X-ray was performed in $37.7 \%$ of the cases and thoracic CT was conducted in $6.5 \%$ of them. Pleural fluid and/or pulmonary infiltrates were found in $6.7 \%$ of the US examinations, $26.6 \%$ of the Xrays and $75.6 \%$ of the $\mathrm{CT}$ scans. The distribution of positive findings among the different imaging modalities indicates that doctors are more likely to order chest X-rays or CTs when the clinical picture suggests moderate or severe AP. Importantly, mortality was not observed in the absence of lung injury at admission (Figure 13).

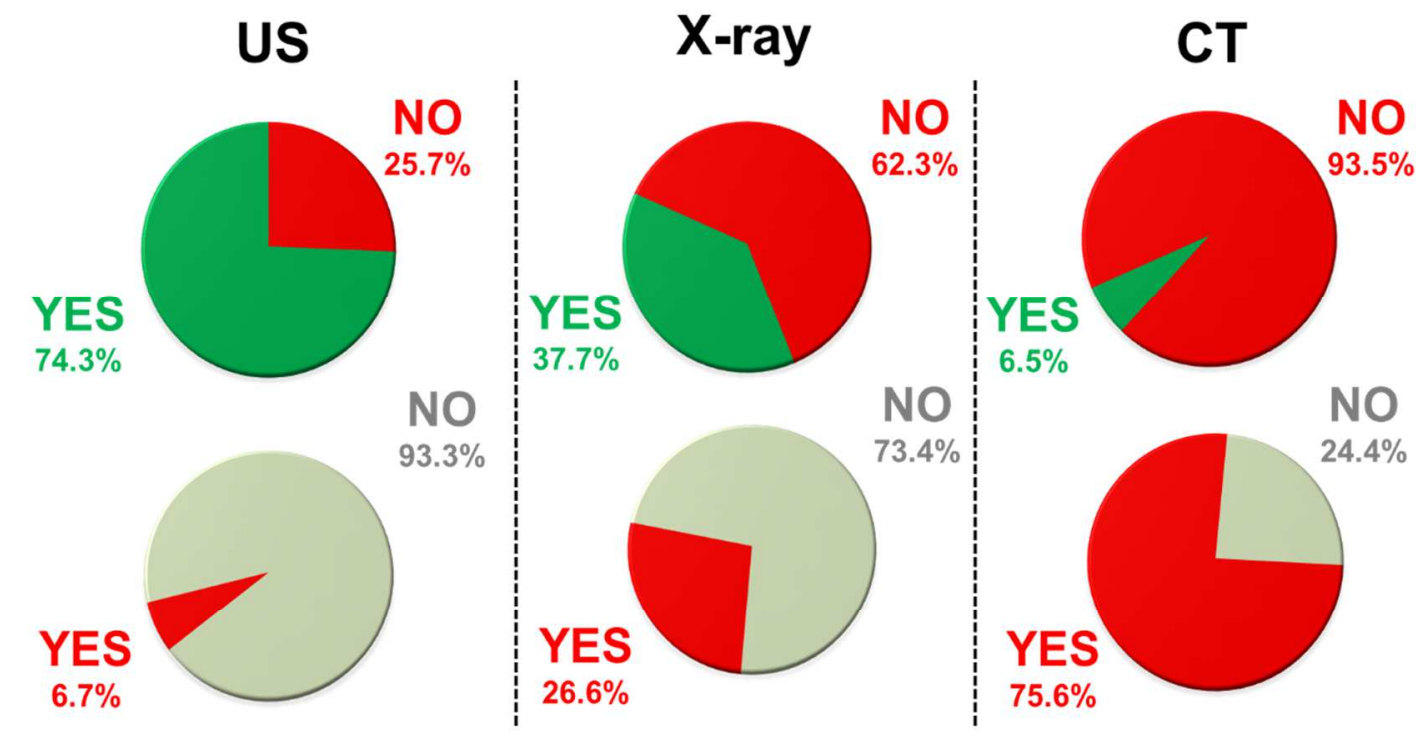

Severity and mortality with (yes) or without (no) pleural complications

\begin{tabular}{|c|c|c|c|c|}
\hline & MILD & MOD & SEV & MORT \\
\hline YES & $39.1 \%$ & $47.8 \%$ & $13.0 \%$ & $33.0 \%$ \\
\hline NO & $63.0 \%$ & $28.9 \%$ & $8.1 \%$ & 0 \\
\hline
\end{tabular}

\begin{tabular}{|c|c|c|c|c|}
\hline & MILD & MOD & SEV & MORT \\
\hline YES & $28.6 \%$ & $41.1 \%$ & $30.4 \%$ & $58.8 \%$ \\
\hline NO & $64.3 \%$ & $27.9 \%$ & $7.8 \%$ & 0 \\
\hline
\end{tabular}

\begin{tabular}{|c|c|c|c|c|}
\hline & MILD & MOD & SEV & MORT \\
\hline YES & $14.3 \%$ & $61.7 \%$ & $25.0 \%$ & $43.0 \%$ \\
\hline NO & $33.3 \%$ & $55.6 \%$ & $11.1 \%$ & 0 \\
\hline
\end{tabular}

Figure 13. Lung complications at admission. Investigators ordered tests for pleural fluid or lung infiltration by abdominal US in $74.3 \%$ of the cases, by chest X-ray in $37.7 \%$ and by thoracic CT in $6.5 \%$. The most positive results were found by thoracic CT (75.6\%) followed by X-ray $(26.6 \%)$ and abdominal US (6.7\%). Severity and mortality data were analysed in groups with and without pleural complications. Data suggest that doctors are more likely to test for lung complications when severe AP is predicted.

\subsubsection{Laboratory parameters at admission}

Laboratory parameters were evaluated using two methods. The distribution of distinct values (grouped in ranges) was calculated within the three AP severity groups (Figure 14-16, 
left panels), and average values were compared between the three severity groups (Figure 1416 , right panels).

A white blood cell (WBC) count above $23,000 / \mu \mathrm{L}$ was associated with severe AP (OR 3.2; 95\% CI 1.1-9.2). Furthermore, the average WBC counts differed significantly between the mild vs. moderate and the mild vs. severe AP groups (Figure 14A).

The level of C-reactive protein (CRP) above $200 \mathrm{mg} / \mathrm{L}$ was associated with severe AP (OR 2.8; 95\% CI 1.3-6.2). The average CRP levels differed significantly between the mild vs. moderate and the mild vs. severe AP groups (Figure 14B).

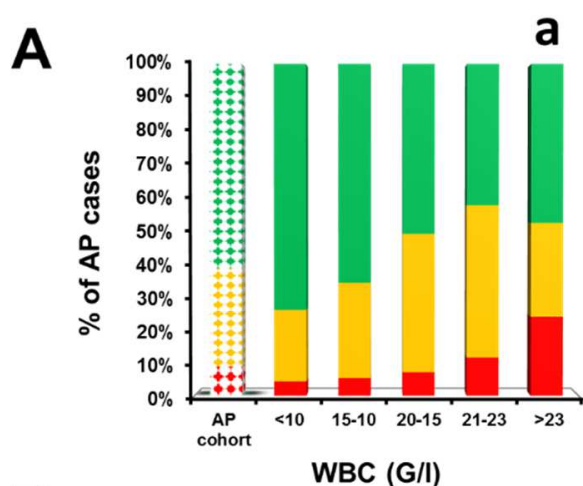

B

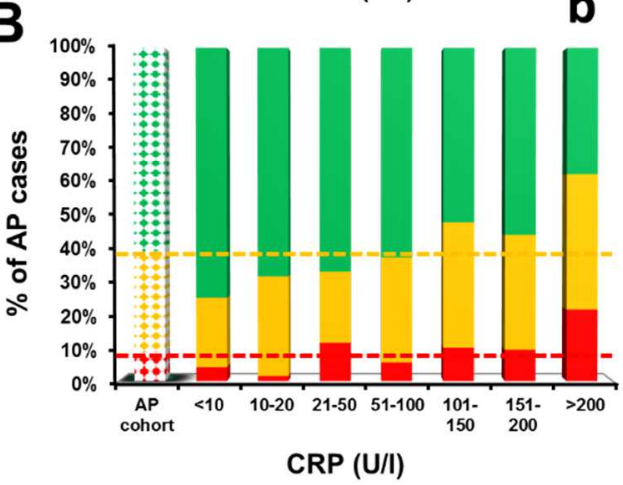

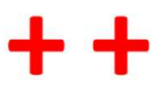

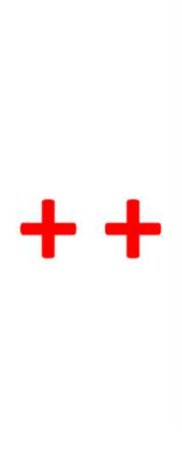

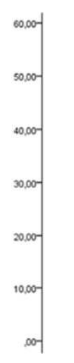
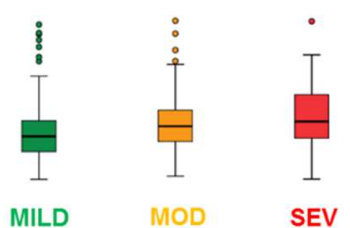

WBC (G/l)

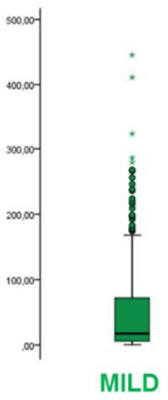

MILD

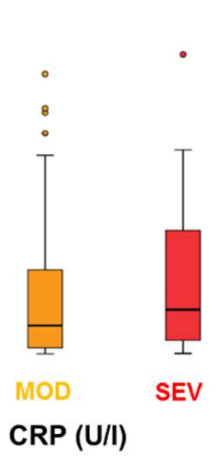

Figure 14. Laboratory parameters in AP. The only parameters shown are where statistical differences were found between the AP severity groups. Green: mild AP; yellow: moderate AP; red: severe AP; ns: no significant difference $(\mathrm{p}>0.05)$; +: significant difference $(\mathrm{p}<0.05)$. In the left-hand panel of graphs, laboratory parameters were analysed by distinct values, grouped in ranges. The first dotted column represents the AP severity groups of the entire cohort. Here, the Chi-square test was employed. In the right-hand panel of graphs, the average laboratory parameters were compared in the three AP severity groups. Here, we used the Kruskal-Wallis test and Mann-Whitney U test with a Bonferroni correction to compare the pairs of groups under examination. A. White blood cell count (WBC, $n=21-204$ ). A WBC count above $23,000 / \mu \mathrm{L}$ was associated with elevated risk of severe AP (a: $\mathrm{p}=0.020$ ), and the average WBC counts also showed significant differences between the mild versus moderate and mild versus severe AP groups $(\mathrm{p}<0.001)$. B. C-reactive protein $(C R P: n=32-$ 144). CRP above $200 \mathrm{mg} / \mathrm{L}$ was associated with severe AP (b: $p=0.007)$. In addition, average CRP levels differed significantly between the mild versus moderate and mild versus severe AP groups $(\mathrm{p}<0.001)$. 
Procalcitonin (PCT) levels above 10 U/L were associated with severe AP (OR 20.6; 95\% CI 3.7-115.4); however, the average PCT levels did not differ significantly between the three AP severity groups (Figure 15C).

Calcium levels below $2 \mathrm{mmol} / \mathrm{L}$ were associated with severe AP (OR 5.2; 95\% CI 1.517.7); however, average calcium levels did not differ significantly between the three AP severity groups (Figure 15D).

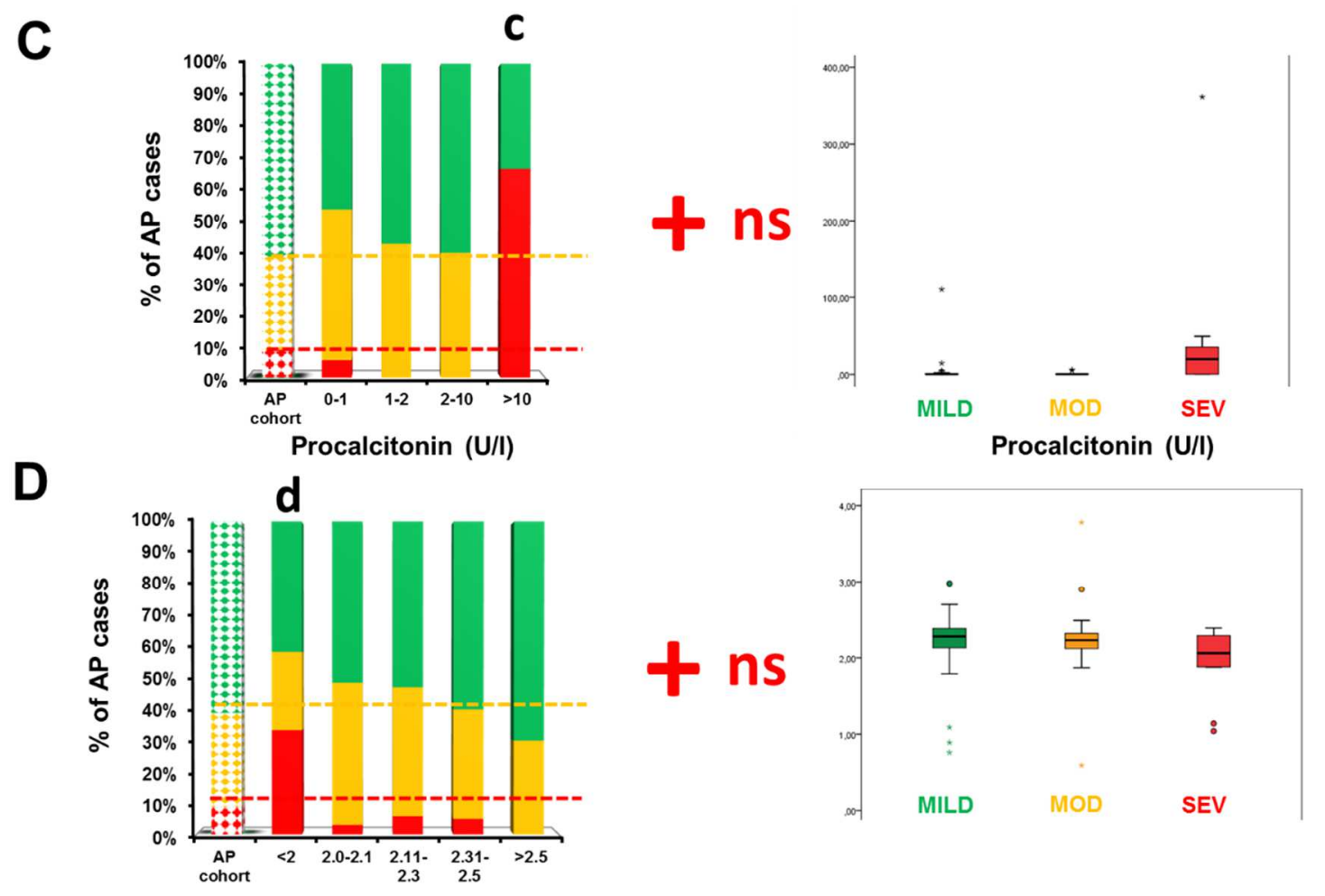

Figure 15. C. Procalcitonin (PCT, $n=5-54)$. PCT levels above $10 \mathrm{U} / \mathrm{L}$ were associated with elevated risk of severe AP (c: $\mathrm{p}<0.001)$; however, average PCT levels did not differ significantly between the three AP severity groups $(\mathrm{p}=0.143)$. D. Calcium $(\mathrm{Ca}, \mathrm{n}=12-40)$. Ca levels below $2 \mathrm{mmol} / \mathrm{L}$ were associated with a heightened risk of severe AP (d: $\mathrm{p}=0.004)$; however, the average calcium levels did not differ significantly between the three AP severity groups $(\mathrm{p}=0.077)$.

Triglyceride (Tg) levels above $40 \mathrm{mmol} / \mathrm{L}$ were associated with severe AP (OR 4.1; 95\% CI 1.3-13.6); however, average Tg levels did not differ significantly between the three AP severity groups (Figure 16E).

An association between discrete glucose levels and AP severity was not observed; however, the average glucose levels differed significantly between mild vs. moderate and mild vs. severe AP cases (Figure 16F). 
Haematocrit values, thrombocyte counts and serum levels of amylase, lipase, sodium $(\mathrm{Na})$, potassium $(\mathrm{K})$, lactate dehydrogenase $(\mathrm{LDH})$, cholesterol, (Figure 17A-H), glutamic oxaloacetic transaminase (SGOT), glutamic pyruvic transaminase (SGPT), alkaline phosphatase (ALP), gamma-glutamyl transferase (GGT), direct bilirubin (diBi), creatinine and blood urea nitrogen (BUN) (Figure 18A-G) showed no significant changes with severe AP regardless of the method of analysis.
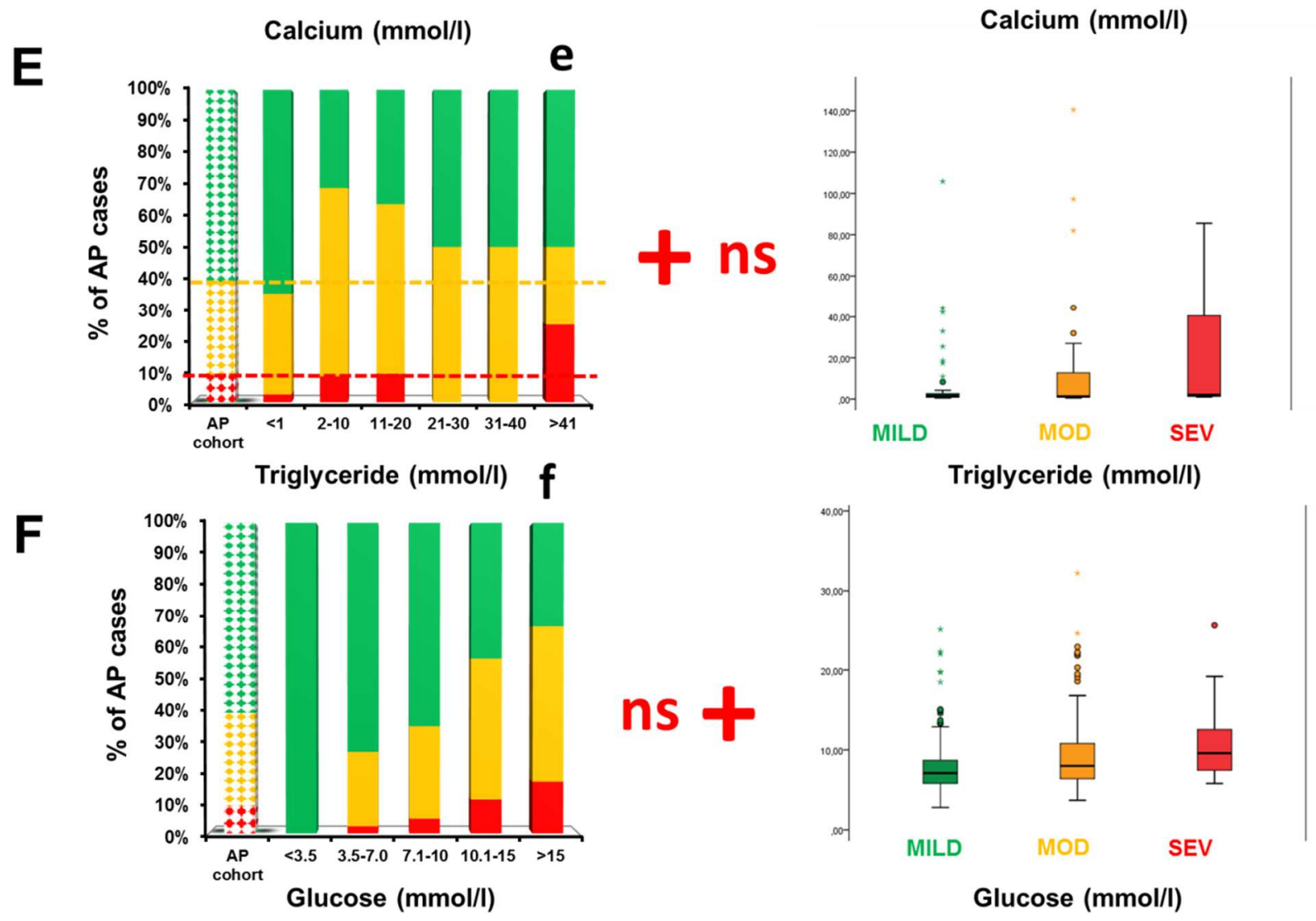

Figure 16. E. Triglycerides (Tg: $\mathrm{n}=10-48)$. Tg levels above $41 \mathrm{mmol} / \mathrm{L}$ were associated with greater risk of severe AP (e: $\mathrm{p}=0.012)$; however, average Tg levels did not differ significantly between the three AP severity groups ( $\mathrm{p}=0.153)$. F. Glucose. $(\mathrm{n}=3-175)$. Significant differences in severity associated with particular glucose levels were not found (f: $\mathrm{p}=0.191$ ); however, average glucose levels differed significantly between the mild versus moderate and mild versus severe AP groups $(\mathrm{p}<0.001)$. 
A

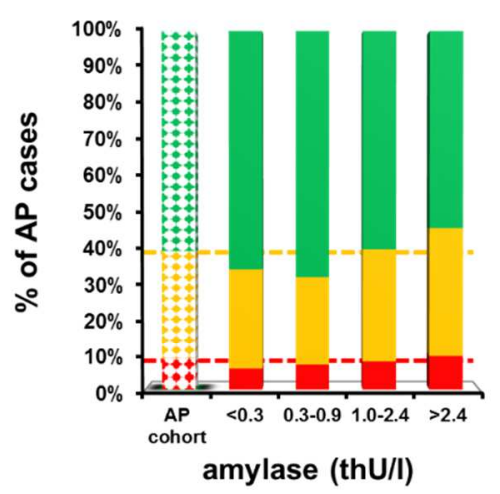

15000

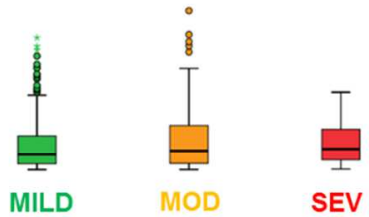

B

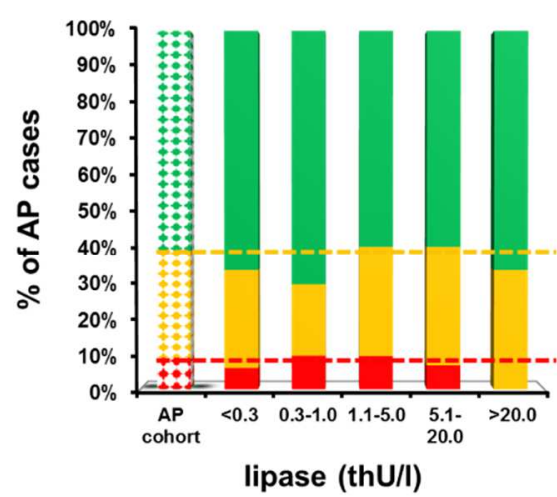

amylase (U/I)
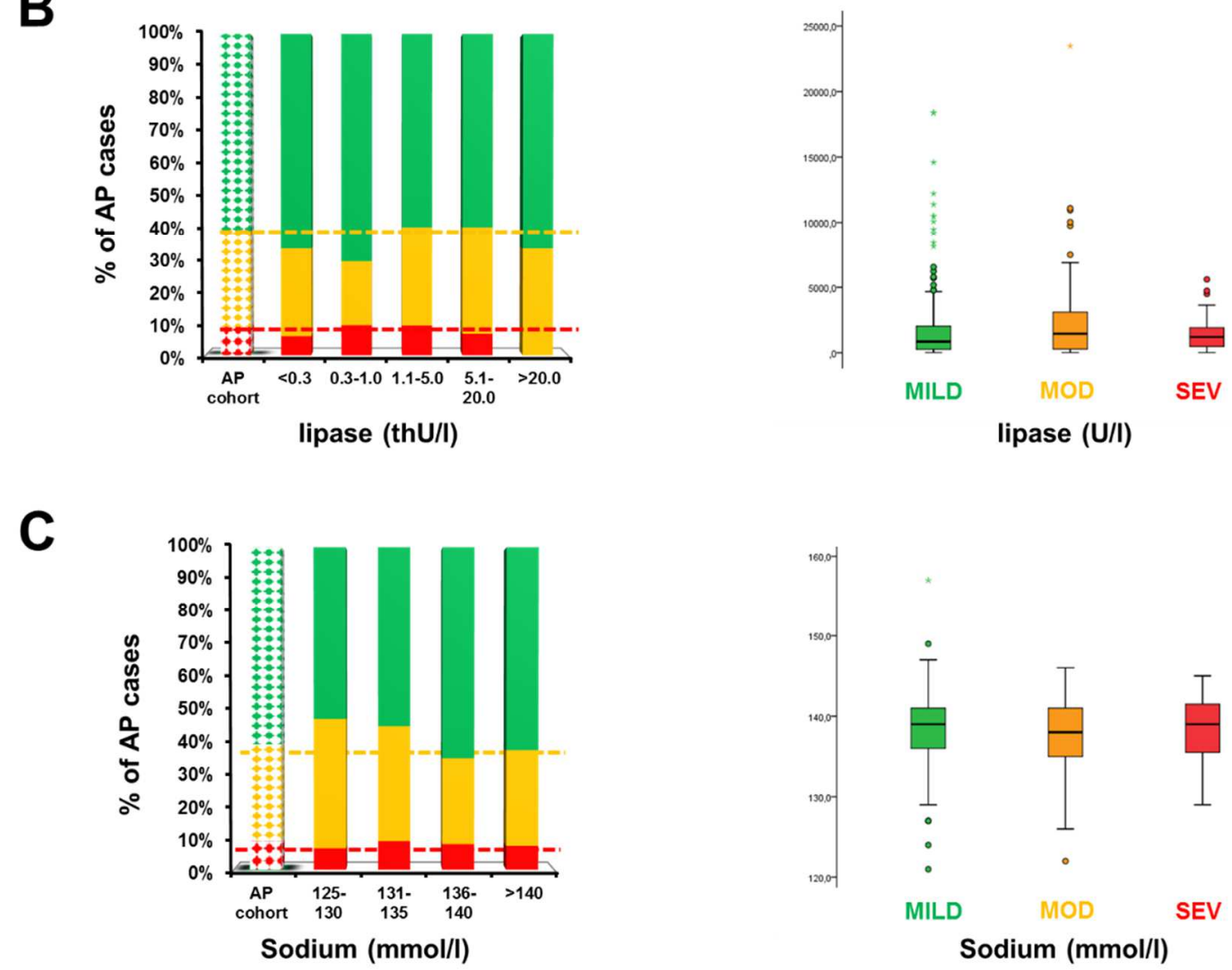

Figure 17. Laboratory parameters. On the left panel of graphs laboratory parameters were analysed by distinct values, grouped in ranges. The first dotted column represents the AP severity groups of the entire cohort. In the right-hand panel of graphs the average laboratory parameters were compared in the three AP severity groups. Here, we used the Kruskal-Wallis test to analyse the significance level and Mann-Whitney $U$ test with Bonferroni correction to compare the pairs of groups under examination. Green, mild AP, yellow, moderate AP, red, severe AP. A, Amylase $(n=64-165)$. B, Lipase $(n=12-130)$. C, Sodium $(\mathrm{Na}, \mathrm{n}=15-113)$. 
D
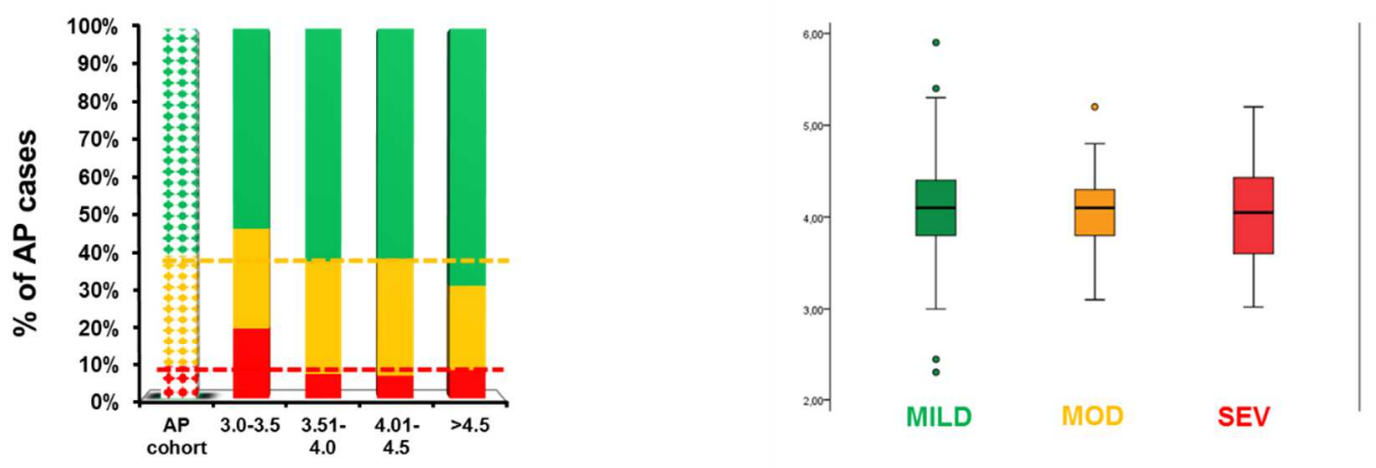

Potassium (mmol/l)

E

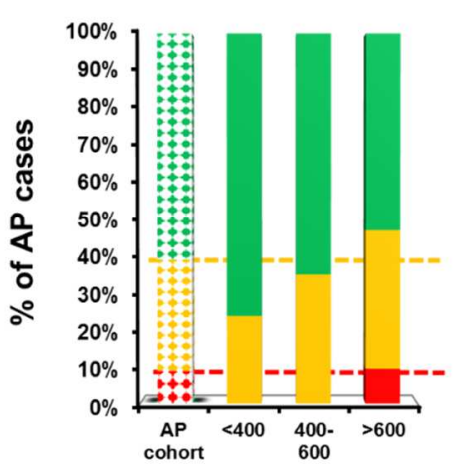

LDH (U/I)

$\mathbf{F}$

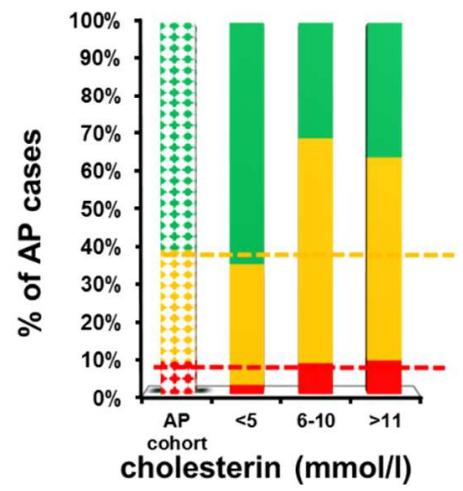

G
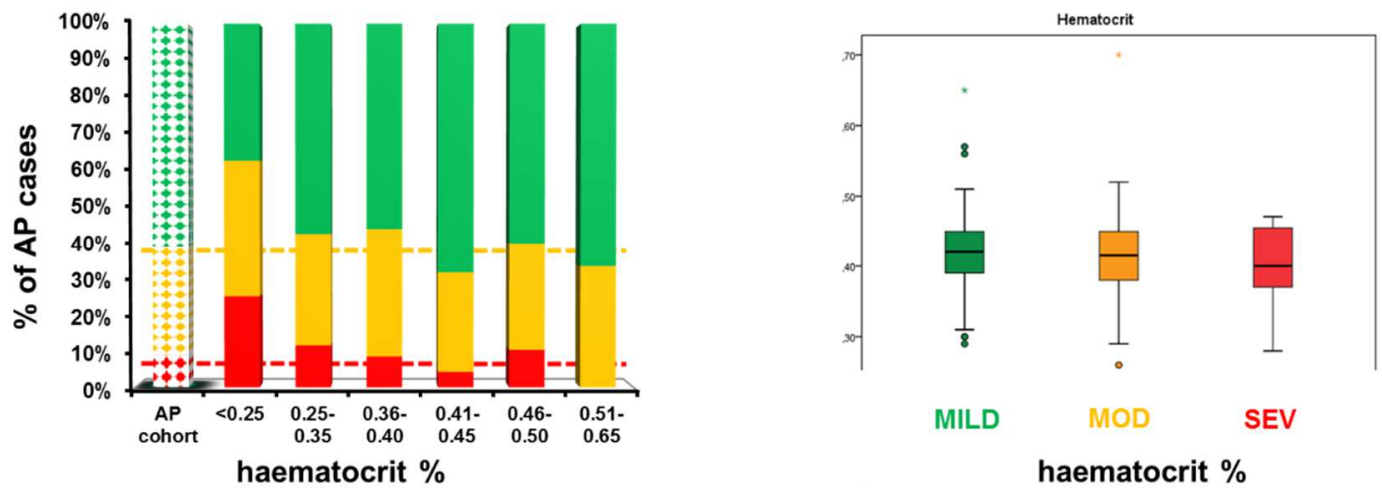

Figure 17. D, Potassium ( $\mathrm{n}=26-113)$. E, Lactate dehydrogenase (LDH, $\mathrm{n}=32-43)$. F, Cholesterol $(\mathrm{n}=15-59)$. G, Hematocrit $(\mathrm{n}=9-95)$. 
H
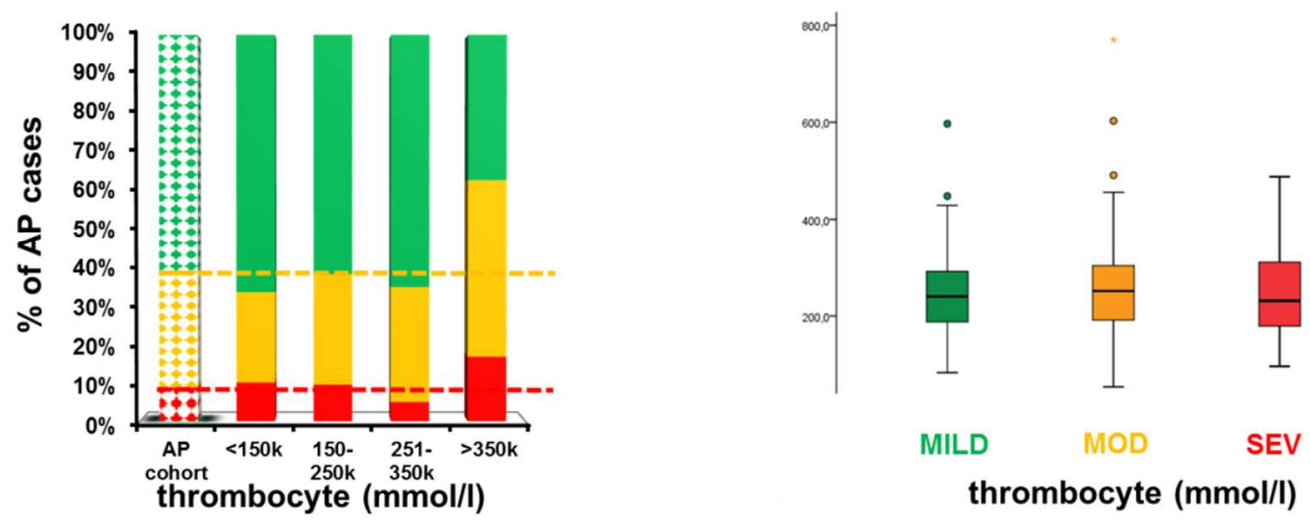

Figure 17. H, Thrombocyte count ( $n=24-116)$.

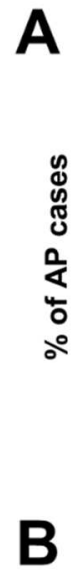
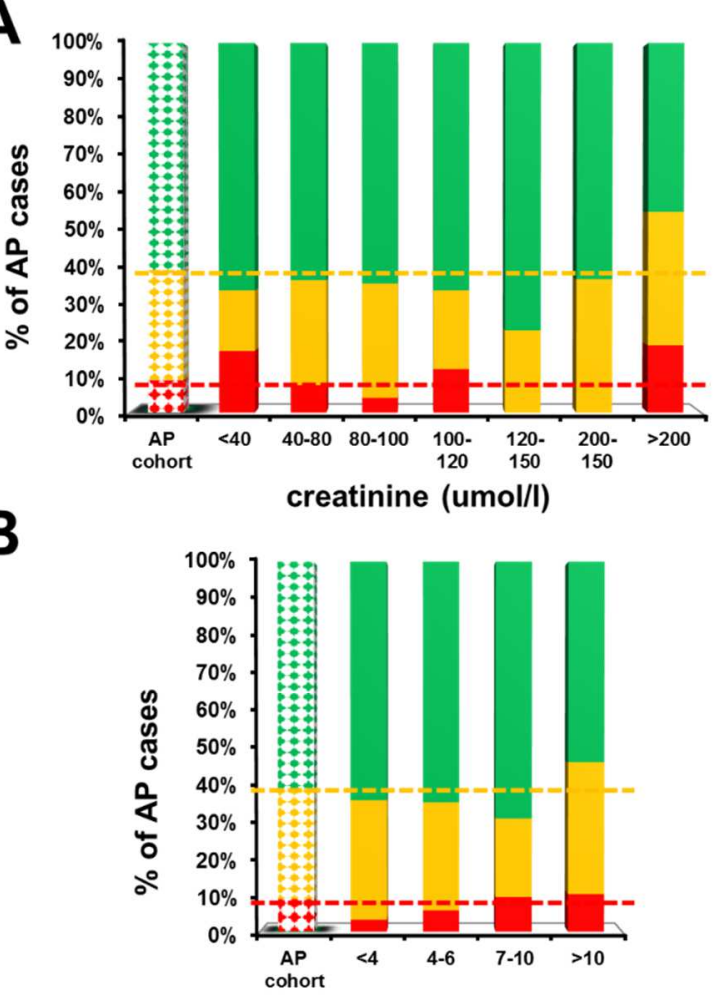

Blood urea nitrogen $(\mathrm{mmol} / \mathrm{l})$

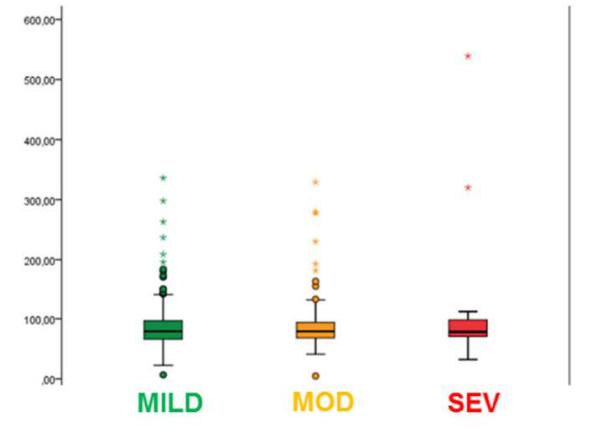

creatinine (umol/l)

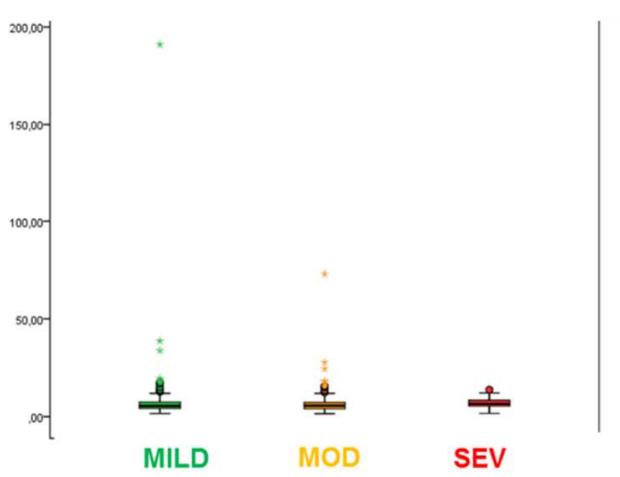

Blood urea nitrogen $(\mathrm{mmol} / \mathrm{l})$

Figure 18. Laboratory parameters. For description of statistical analyses see Supplementary Figure 5. A, Glutamic oxaloacetic transaminase (SGOT, $n=19-44$ ). B, Glutamic pyruvic transaminase (SGPT, $\mathrm{n}=46-88$ ). 


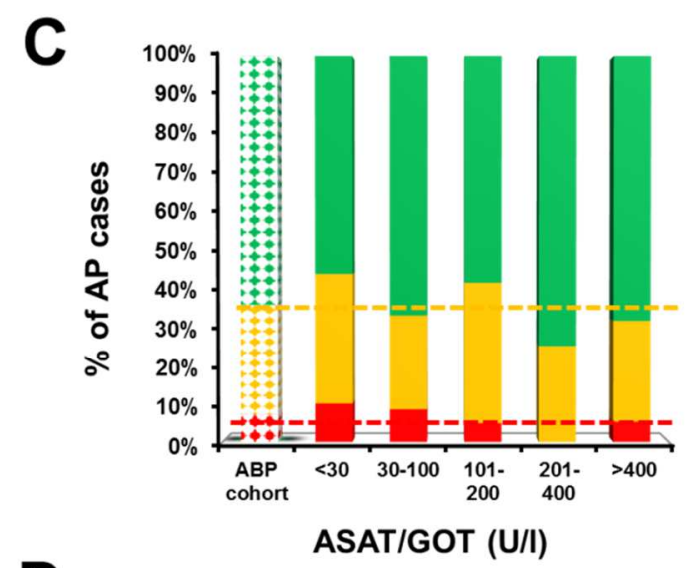

D
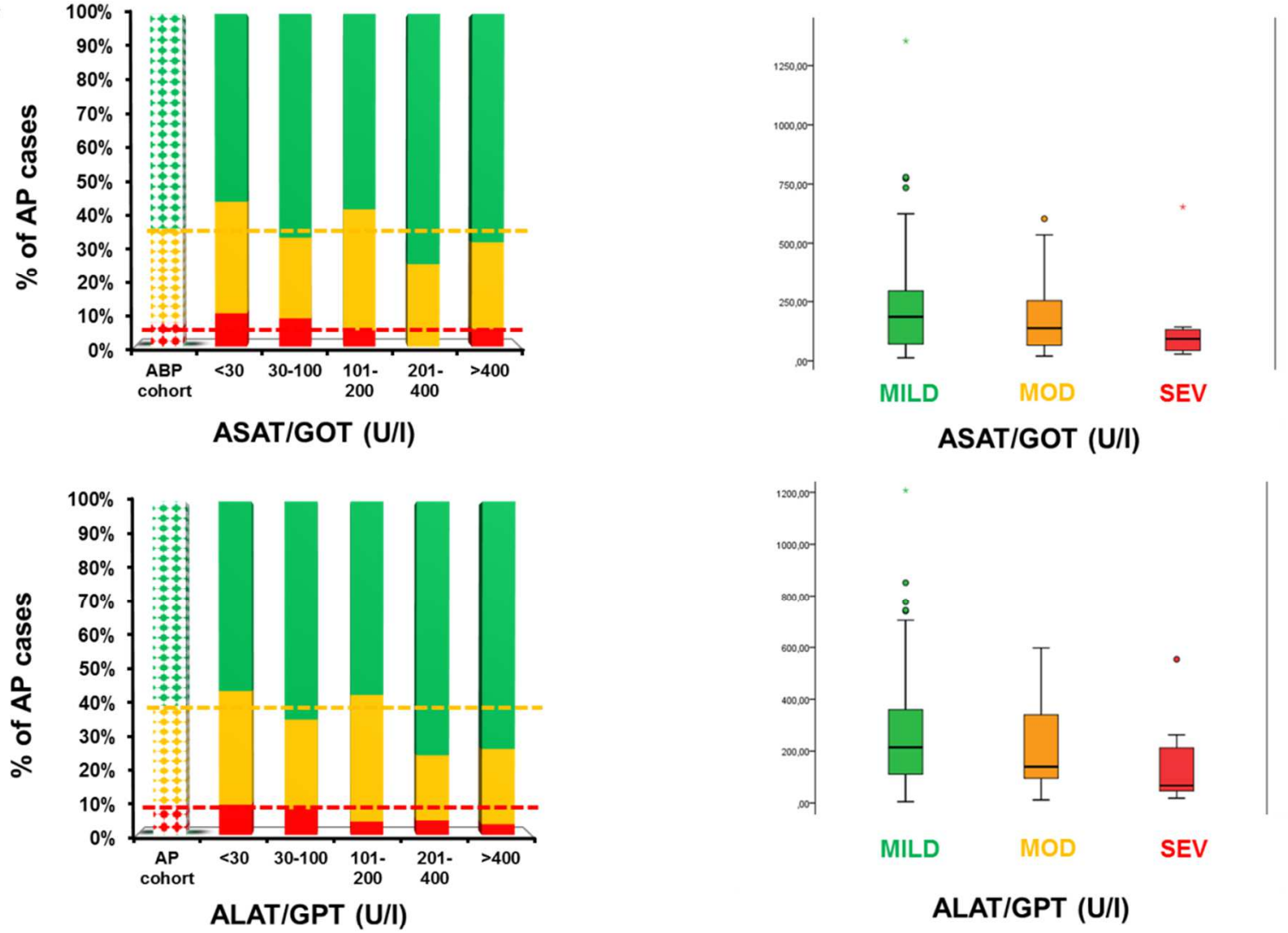

$\mathbf{E}$
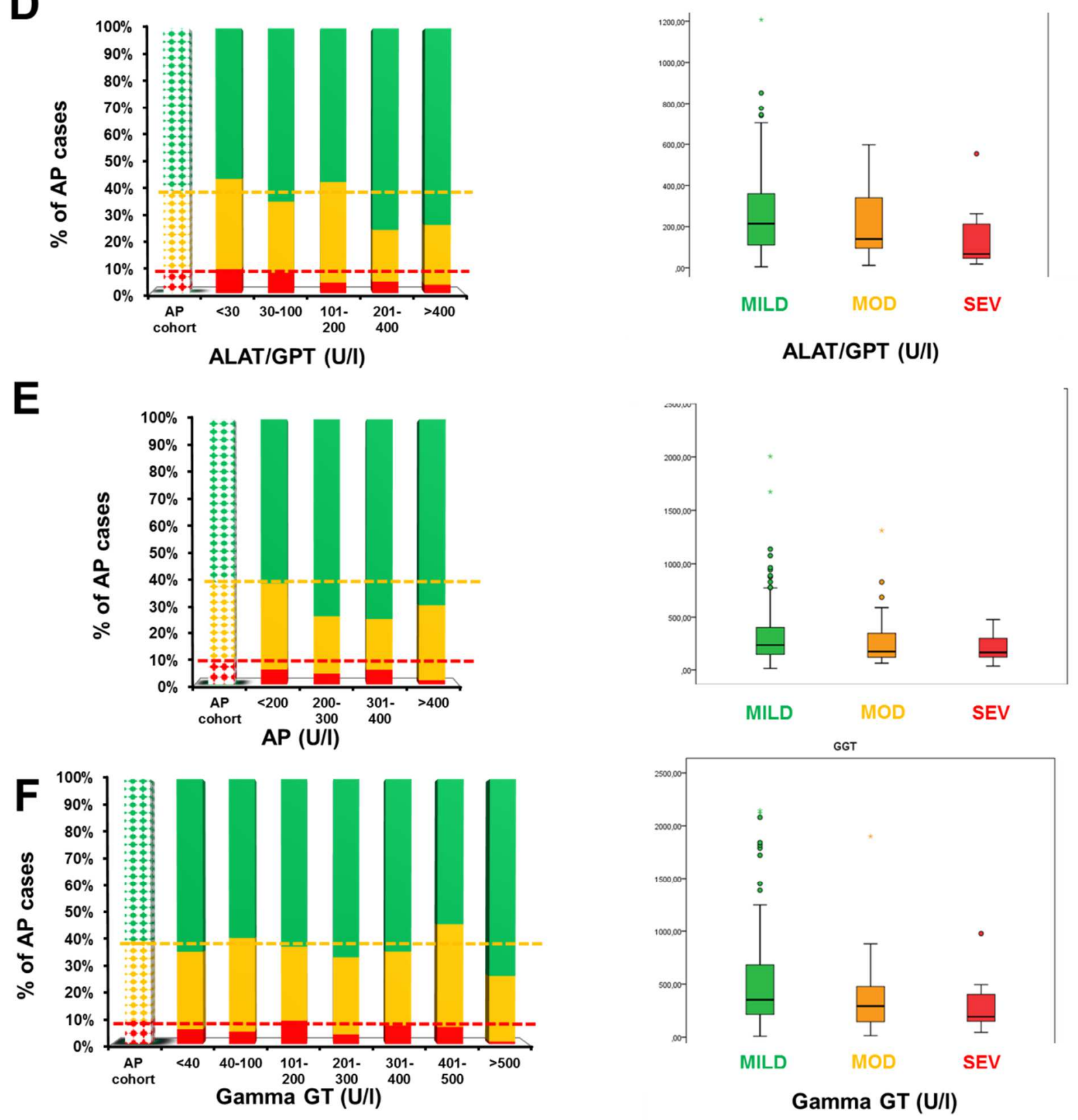

Figure 18. C, Alkaline phosphatase (ALP, n=9-165), D, Gamma-glutamyl transferase (GGT, n=31-109). E, Direct bilirubin (diBi, $n=11-31)$, F, Creatinine (n=6-230). 

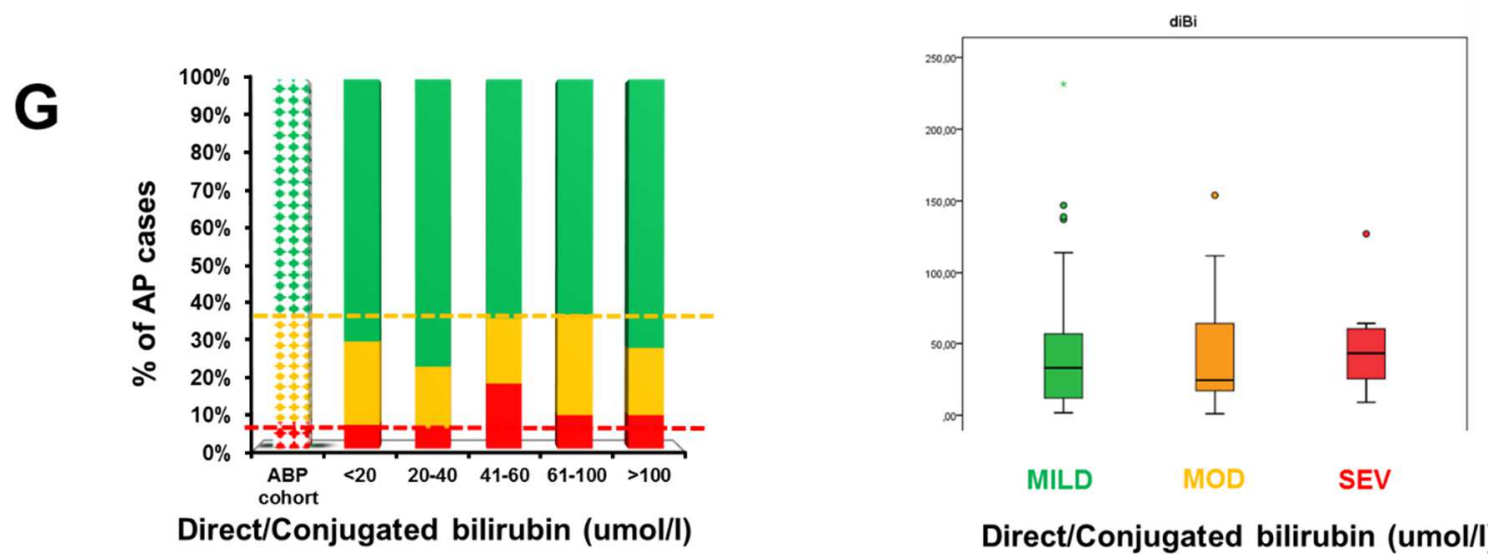

Direct/Conjugated bilirubin (umol/l)

Figure 18. G, Blood urea nitrogen (BUN) $(n=59-226)$.

\subsubsection{Complications}

The most common organ complication in severe AP was of pancreatic origin (87.5\%), followed by lung (68.1\%), cardiac (47.7\%), kidney (36.4\%) and brain $(11.1 \%)$ injury (Figure 19). Mortality in severe AP without respiratory failure was $6.7 \%$, whereas it increased to $50 \%$ if lung injury persisted for more than 24 hours. Mortality in severe AP with no cardiac failure was $8.7 \%$, while it was elevated to $57.1 \%$ if cardiac failure lasted for more than 24 hours. The lack of kidney failure did not decrease mortality in severe AP; however, if kidney failure persisted for more than 24 hours, the mortality rate was 50\% (Figure 19). The rate of pancreatic local complications increased from mild to severe AP. The most common local complication was peripancreatic fluid (mild AP: 2.8\%; moderate AP: 53.9\%; severe AP: $52.1 \%$ ). Importantly, local complications during AP had no effect on the risk of mortality (Figure 19).

A

\begin{tabular}{|c|c|c|c|c|}
\hline $\begin{array}{c}\text { ORGAN COMPLICATION } \\
\text { IN SEVERE AP }\end{array}$ & Frequency & Mortality & $\begin{array}{c}\text { Frequency } \\
\text { no compl. }\end{array}$ & $\begin{array}{c}\text { Mortality } \\
\text { no compl. }\end{array}$ \\
\hline PANCREAS & $\mathbf{8 7 , 5} \%$ & $28,6 \%$ & $12,5 \%$ & $16,7 \%$ \\
\hline LUNG & $68,1 \%$ & $\mathbf{4 0 . 6} \%^{\mathbf{a}}$ & $31,9 \%$ & $6,7 \%$ \\
\hline CARDIAC & $47,7 \%$ & $\mathbf{5 2 . 4} \%^{\mathbf{b}}$ & $52,3 \%$ & $8,7 \%$ \\
\hline KIDNEY & $36,4 \%$ & $43,8 \%$ & $63,6 \%$ & $21,4 \%$ \\
\hline BRAIN & $11,1 \%$ & $\mathbf{5 0 . 0} \%^{\mathbf{c}}$ & $88,9 \%$ & $21,9 \%$ \\
\hline
\end{tabular}

\begin{tabular}{|c|c|c|c|c|}
\hline $\begin{array}{c}\text { COMBINED ORGAN COMPLICATION } \\
\text { IN SEVERE AP }\end{array}$ & Frequency of COF & Mortality & $\begin{array}{c}\text { Frequency } \\
\text { without COF }\end{array}$ & $\begin{array}{c}\text { Mortality } \\
\text { without COF }\end{array}$ \\
\hline LUNG+CARDIAC & $44,2 \%$ & $\mathbf{5 2 . 6} \%^{\mathbf{d}}$ & $55,8 \%$ & $12,5 \%$ \\
\hline LUNG+KIDNEY & $34,1 \%$ & $46,7 \%$ & $65,9 \%$ & $20,7 \%$ \\
\hline LUNG + KIDNEY + CARDIAC & $31,0 \%$ & $\mathbf{5 3 . 8} \%{ }^{\text {e }}$ & $69,0 \%$ & $17,2 \%$ \\
\hline
\end{tabular}

\begin{tabular}{c|c|c|c|c|c|}
\hline $\begin{array}{c}\text { PANCREATIC COMPLICATIONS } \\
\text { IN AP }\end{array}$ & MILD & MODERATE & $\begin{array}{c}\text { SEVERE } \\
\text { MERTALITY }\end{array}$ & $\begin{array}{c}\text { MORTALITY } \\
\text { YES }\end{array}$ \\
\hline NECROSIS & $0,3 \%$ & $26,2 \%$ & $62,2 \%$ & $23,5 \%$ & $32,1 \%$ \\
\hline DIABETES & $2,2 \%$ & $7,1 \%$ & $22,0 \%$ & $29,0 \%$ & $11,1 \%$ \\
\hline PSEUDOCYST & $1,1 \%$ & $19,1 \%$ & $35,4 \%$ & $23,5 \%$ & $16,7 \%$ \\
\hline PERIPANCREATIC FLUID & $2,8 \%$ & $53,9 \%$ & $52,1 \%$ & $16,7 \%$ & $32,0 \%$ \\
\hline
\end{tabular}


Figure 19. Frequency of organ failure and mortality in AP. A. Frequency of individual organ failure (pancreas, lung, cardiac, kidney and brain) and mortality in severe AP. B. Frequency of combined organ failure and mortality in severe AP. C. Frequency of pancreatic complications and mortality in AP. Mortality was only calculated in severe AP. a: $p=0.020$ (Fisher's exact test); b: $\mathrm{p}=0.002$ (Chi-square test); $\mathbf{c}: \mathrm{p}=0.043$ (Fisher's exact test); $\mathbf{d}: \mathrm{p}=0.003$ (Chi-square test); $\mathbf{e}: \mathrm{p}=0.030$ (Fisher's exact test).

\subsubsection{Conservative therapy}

Statistical analyses of fluid resuscitation practices in the first 24 hours showed that both severity and mortality are affected by the amount of fluid administered. The optimal fluid amount was between 1500 and $3500 \mathrm{~mL}$ (Figure 20).
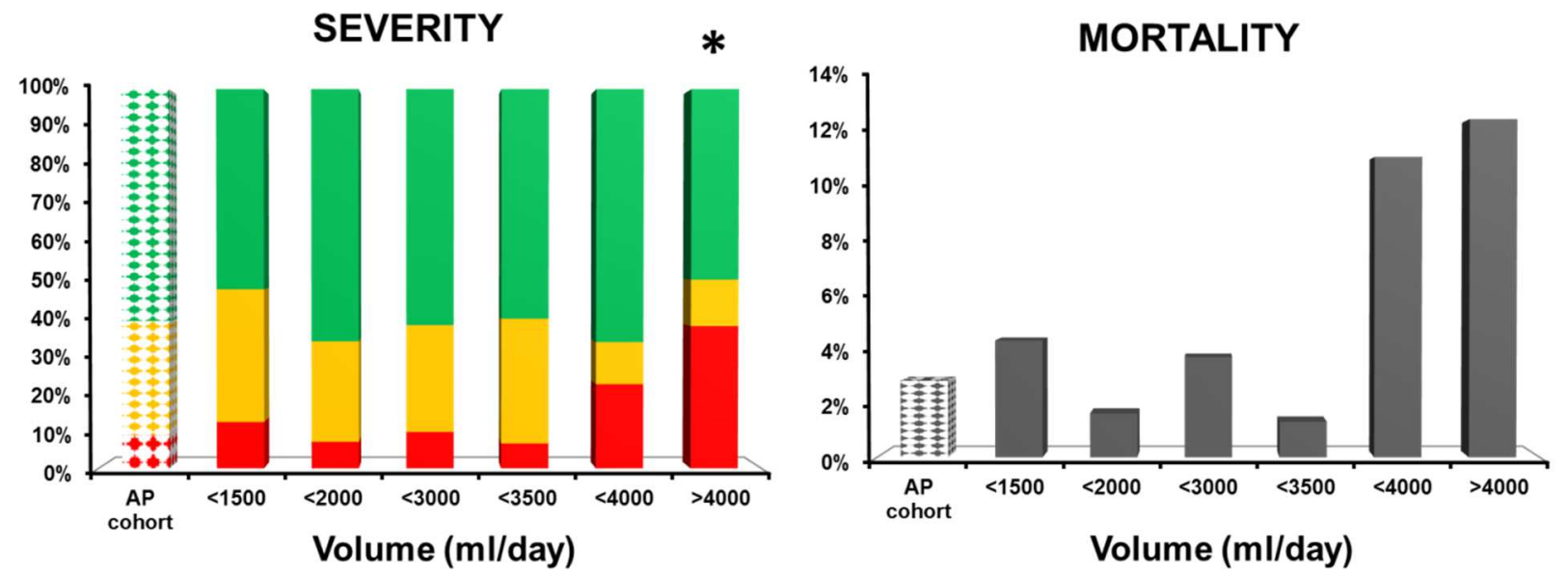

Figure 20. Conservative therapy in AP. Effect of fluid resuscitation on severity and mortality in the first 24 hours. The first dotted column represents the AP severity groups and mortality for each group in the entire cohort. Green: mild AP; yellow: moderate AP; red: severe AP; *: $\mathrm{p}=0.030$ (Fisher's exact test on severity) versus the cohort $(n=8-185)$.

(85.4\%) of the patients with severe AP received enteral feeding. In severe AP, the mortality rate rose from $27 \%$ to $57 \%$ when enteral feeding was not administered (Figure 21). Parenteral feeding was only employed in $4 \%$ of the cases. 


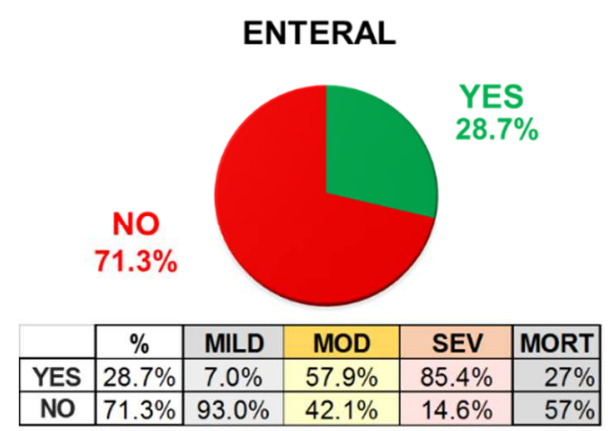

TYPE OF ENTERAL

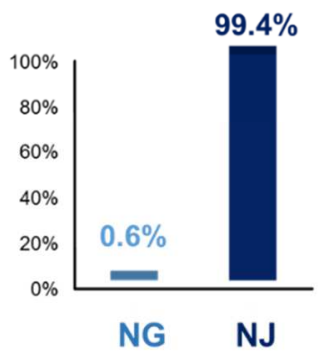

PARENTERAL

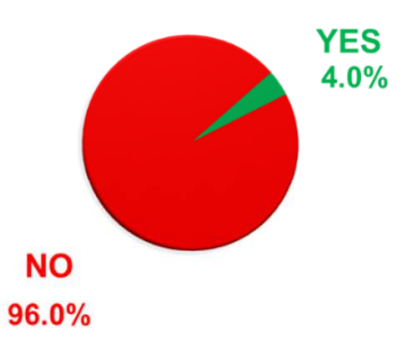

$4.0 \%$

Figure 21. Enteral and parenteral feeding in AP. Mortality is shown for the severe AP group. NG: nasogastric feeding; NJ: nasojejunal feeding.

The practice of antibiotic therapy was widespread in our cohort (77.1\% of the cases) (Figure 22A). In two-thirds of the cases, the indication was for the prevention of infectious complications. There were no relevant differences in mortality or severity between patients who received antibiotics for prevention and those who were treated with antibiotics for infection. Since preventive antibiotics did not appear to be beneficial in our cohort, we can agree with the notion that use of preventive antibiotics is not beneficial (Figure 22A). The most common therapy was a combination of a cephalosporin and metronidazole (42.5\%), whereas imipenem was only initiated in $5.5 \%$ of the patients. Antibiotic therapy was changed from cephalosporin/metronidazole or other combinations to imipenem in $6.9 \%$ of the cases. Although probiotics and proton pump inhibitors (PPIs) are not recommended by the guidelines, $4.6 \%$ of the patients received probiotics and 64.5\% were administered PPIs (Figure 22B).

\section{ANTIBIOTIC THERAPY}

A

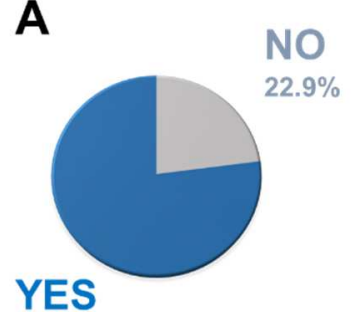

$77.1 \%$

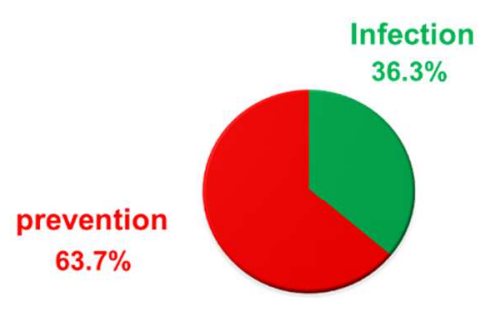

PROBIOTIC THERAPY

B

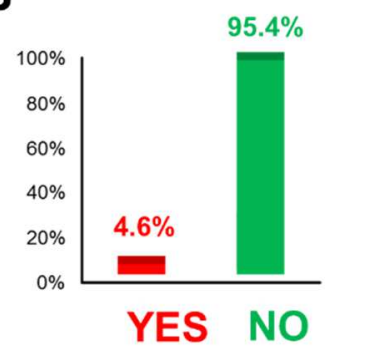

Figure 22. A. Antibiotic therapy and its indications in AP. Table shows the indications for antibiotic therapy in the three severity groups. B. Probiotic therapy in AP. 


\subsubsection{Endoscopic therapy}

The cause of AP was biliary in $43.8 \%$ of the cases. In $18.8 \%$ of the cases, the diagnosis was based on laboratory alterations only (predicted AP) with no sign of obstruction. In $80.6 \%$ of the patients with biliary aetiology, ERCP was performed (Figure 23A). In 91.9\% of the cases, the endoscopic intervention was carried out within the first 48 hours after the diagnosis of AP (Figure 23B). In 33.1\% of the patients, cholangitis was present (Figure 23C), 81.3\% had obstruction (Figure 23D), and 35.3\% had severe or moderate AP (Figure 23E). Most ERCP procedures were conducted when cholangitis was present, whereas the fewest were performed when obstruction was not visible. Only $3.8 \%$ of the 212 ERCPs were unjustified (mild AP with neither cholangitis nor obstruction). Endoscopic biliary sphincterotomy was carried out in $71.8 \%$ of the cases, while endoscopic pancreatic sphincterotomy was conducted in only $7 \%$. A biliary stent was placed in $11.2 \%$ of the cases, and $11.5 \%$ of the patients received a pancreatic stent. 
A ERCP IN BILIARY AP

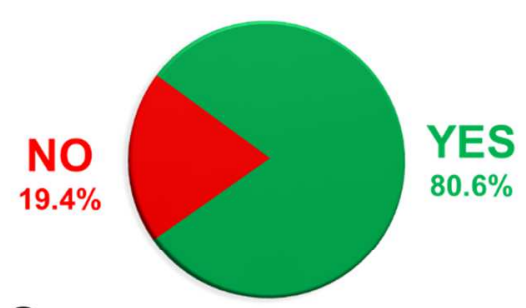

C

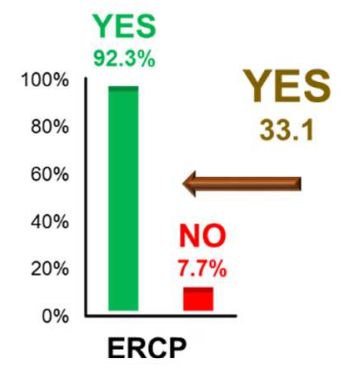

D

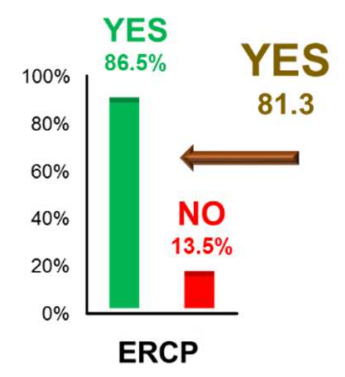

B

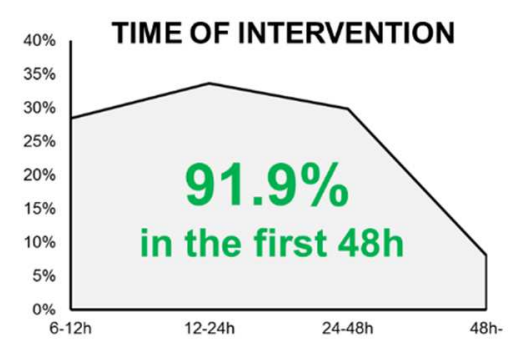

CHOLANGITIS

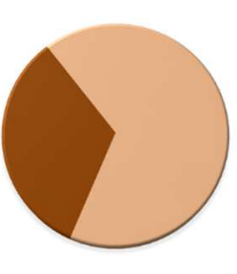

OBSTRUCTION

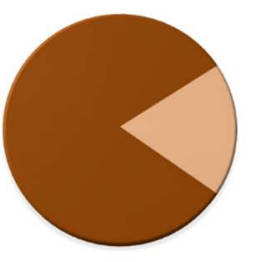

MODERATE - SEVERE
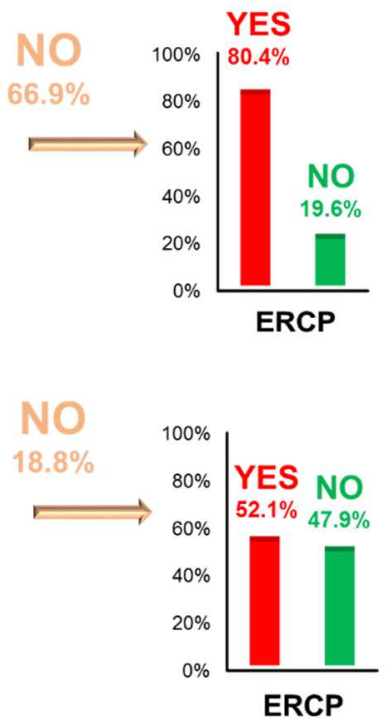

E
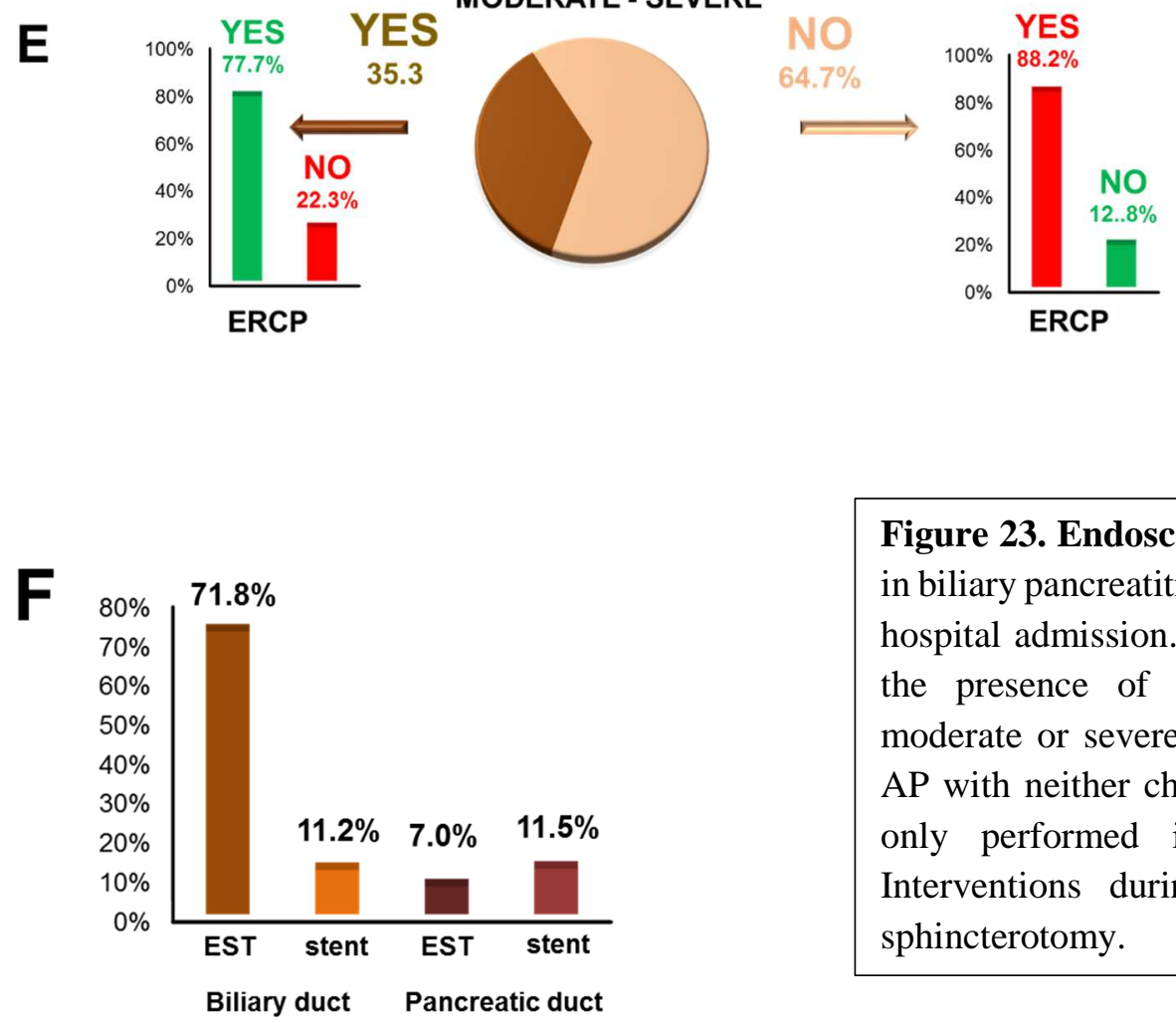

Figure 23. Endoscopic therapy in AP. A. ERCP in biliary pancreatitis. B. Time of intervention after hospital admission. C-E. Indication for ERCP in the presence of cholangitis, obstruction, and moderate or severe AP. Unjustified ERCP (mild AP with neither cholangitis nor obstruction) was only performed in $3.8 \%$ of the cases. F. Interventions during ERCP. EST: endoscopic sphincterotomy. 


\subsubsection{Interventions}

Interventions were performed in 26 cases $(4.3 \%)$ in our cohort, of which $62 \%$ were surgical operations, 19\% endoscopic procedures and 19\% radiological interventions (Figure 24).

\begin{tabular}{|c|c|c|c|c|c|c|}
\hline No & \begin{tabular}{|c|} 
TYPE OF \\
INTERVENTION \\
\end{tabular} & SEVERITY & INDICATION & $\begin{array}{l}\text { TIME OF INTERVENTION } \\
\text { AFTER THE ONSET OF AP }\end{array}$ & OUTCOME & \\
\hline 1 & radiological & severe & persisting MOF & 2 & death & \multirow{2}{*}{$\begin{array}{l}\text { MORTALITY IN THE } \\
\text { FIRST } 4 \text { WEEKS }\end{array}$} \\
\hline 2 & surgical & moderate & suspected infected necrosis & 4 & discharge & \\
\hline 3 & surgical & severe & persisting MOF & 8 & death & \\
\hline 4 & endoscopical & moderate & other less common indications & 8 & discharge & \multirow{4}{*}{$37.5 \%$} \\
\hline 5 & surgical & mild & other less common indications & 9 & discharge & \\
\hline 6 & surgical & severe & other less common indications & 16 & death & \\
\hline 7 & surgical & severe & suspected infected necrosis & 19 & discharge & \\
\hline 8 & radiological & moderate & persisting MOF & 23 & discharge & \\
\hline 9 & surgical & moderate & other less common indications & 28 & discharge & \multirow{2}{*}{$\begin{array}{l}\text { MORTALITY AFTER } \\
\text { THE FIRST } 4 \text { WEEKS }\end{array}$} \\
\hline 10 & endoscopical & severe & persisting MOF & 28 & discharge & \\
\hline 11 & radiological & moderate & suspected infected necrosis & 30 & discharge & \\
\hline 12 & endoscopical & severe & persisting MOF & 30 & death & \multirow{4}{*}{$11.1 \%$} \\
\hline 13 & surgical & severe & suspected infected necrosis & 30 & discharge & \\
\hline 14 & endoscopical & moderate & persisting MOF & 36 & discharge & \\
\hline 15 & radiological & severe & suspected infected necrosis & 37 & death & \\
\hline 16 & surgical & severe & persisting MOF & 37 & discharge & \\
\hline 17 & surgical & moderate & other less common indications & 38 & discharge & \\
\hline 18 & surgical & severe & persisting MOF & 39 & discharge & \\
\hline 19 & surgical & severe & persisting MOF & 42 & discharge & \\
\hline 20 & surgical & moderate & persisting MOF & 45 & discharge & \\
\hline 21 & endoscopical & severe & suspected infected necrosis & 53 & discharge & \\
\hline 22 & surgical & severe & suspected infected necrosis & 71 & discharge & \\
\hline 23 & surgical & moderate & suspected infected necrosis & 74 & discharge & \\
\hline 24 & radiological & moderate & suspected infected necrosis & 82 & discharge & \\
\hline 25 & surgical & severe & confirmed infected necrosis & 102 & discharge & \\
\hline 26 & surgical & severe & other less common indications & 118 & discharge & \\
\hline
\end{tabular}

Figure 24. Type, indication and outcome of interventions in AP. Data show the mortality differences between early and late interventions in AP.

\subsection{Pediatric pancreatitis}

Our APPLE trial is currently running. Until now we have enrolled 75 acute, 32 recurrent acute and 14 chronic pancreatitis cases to the APPLE-R study: Concerning the etiology, biliary and drug-induced 9-9\%, trauma, acohol2-2\%, post-ERCP and anatomic 5-5\%, other 14\% were identified however $54 \%$ of the cases still remained idiopathic. In 121 cases, genetic analyses of PRSS1, SPINK1, CFTR and CTRC genes have been completed. 48,8\% (59/121) of the patients have pathogenic variants. Genetic alterations in PRSS1 were found in 4 cases, SPINK1 in 13 
cases, CPA1 in 2 cases, CFTR in 15 case and CTRC in 51 cases. Pathogenic variants in two genes were observed: 2 PRSS1-CTRC, 1 PRSS1-SPINK1, 6 SPINK1-CTRC, 1 SPINK1-CFTR, 7 CTRC-CFTR, 1 CPA1-CFTR. There were no pathogenic variants in 62 cases.

APPLE-P: We have already enrolled 18 patients with AP. More data is necessary for detailed analysis (67).

\subsection{SPINK1 Promoter Variants in Chronic Pancreatitis}

\subsubsection{Sequence Analysis of the SPINK1 Promoter Region}

In the approximately 1.2-kb SPINK1 promoter region, 6 different variants were detected (Figure 25; Table 1). Two common polymorphisms (c.-253T $>\mathrm{C}$ and c.-807C $>\mathrm{T}$ ) were present in cases and controls. The $\mathrm{C}$-allele of the c.-253T $>\mathrm{C}$ polymorphism was significantly overrepresented in CP patients (19\%) compared with controls (10\%) (odds ratio [OR], 2.1; 95\% confidence interval $[95 \% \mathrm{CI}], 1.2-3.8 ; \mathrm{P}=0.015)$. In subgroup analysis, the variant was observed in similar frequency in ACP patients (13.3\%) and controls (10\%) (OR, 1.4; 95\% CI, 0.7-2.9; $\mathrm{P}=0.4)$ but occurred significantly more frequently in ICP patients $(24.5 \%)(\mathrm{OR}, 2.9$; 95\% CI, 1.5-5.6; $\mathrm{P}=0.002)$. The distribution of the c.-807C $>\mathrm{T}$ polymorphism in cases $(21 \%)$ and controls $(17.5 \%)$ did not differ significantly $(\mathrm{P}=0.45)$. Three novel heterozygous variants were identified in single cases in patients with ACP, c.-14G>A, c.-108G>T, and c.-246A>G, whereas the heterozygous c.-215G>A variant occurred in 3 patients ( 2 ACP and 1 ICP). None of these 4 promoter variants was detected in controls.

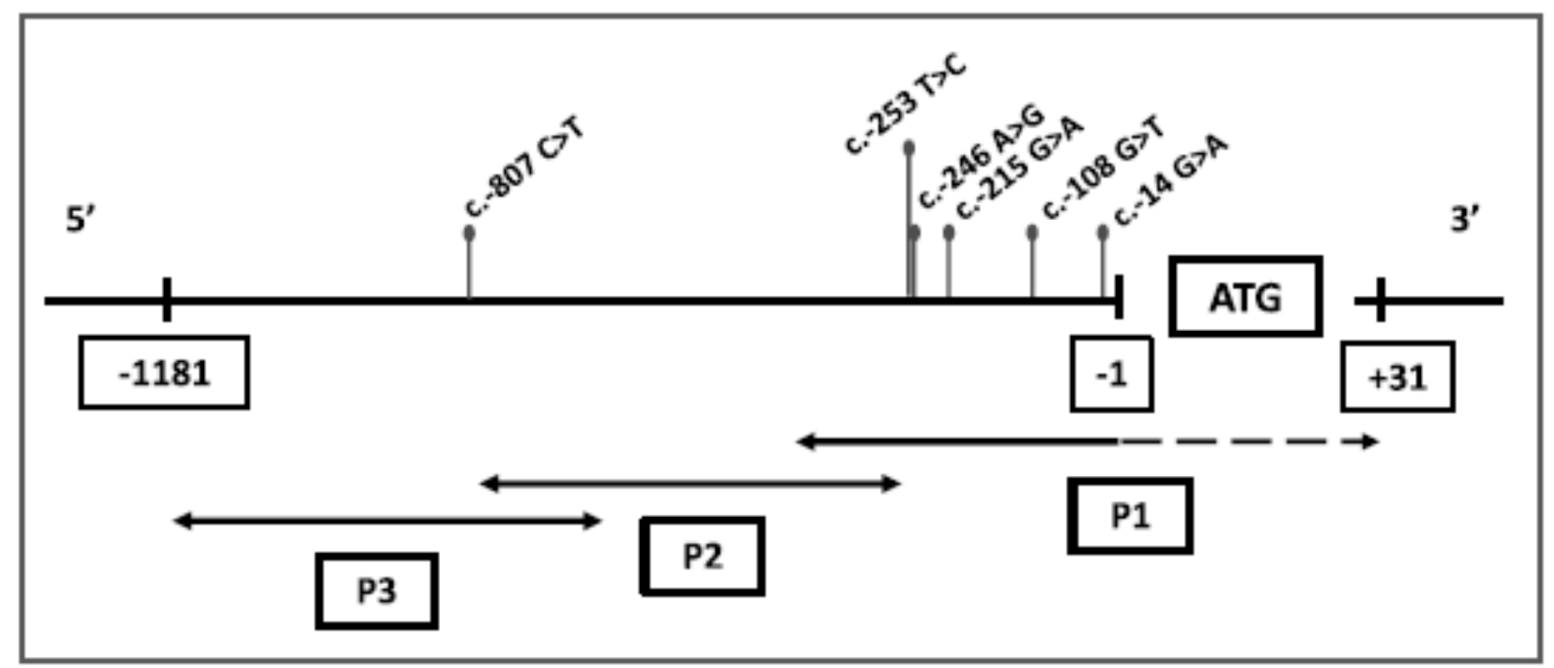

Figure 25. SPINK1 promoter variants found in this study. Three primer pairs (P1, P2, P3) were designed for the amplification of the approximately 1.2-kb SPINK1 region spanning c.-1181 to c. +31 with an amplicon overlap of $127 \mathrm{bp}(\mathrm{P} 1-\mathrm{P} 2)$ and $153 \mathrm{bp}$ (P2-P3). The location of the identified variants within the promoter region is indicated. ATG, translation initiation codon. 


\begin{tabular}{lcccccc}
\hline Variant & ACP & \multicolumn{1}{c}{ ICP } & Total CP & Controls & OR (95\% CI) & $P$ \\
\hline c. $-14 \mathrm{G}>\mathrm{A}$ & $1 / 98(1 \%)$ & $0 / 102$ & $1 / 200(0.5 \%)$ & $0 / 200$ & - & - \\
c. $-108 \mathrm{G}>\mathrm{T}$ & $1 / 98(1 \%)$ & $0 / 102$ & $1 / 200(0.5 \%)$ & $0 / 200$ & - & - \\
c. $-215 \mathrm{G}>\mathrm{A}$ & $2 / 98(2 \%)$ & $1 / 102(1 \%)$ & $3 / 200(1.5 \%)$ & $0 / 200$ & - & - \\
c. $-246 \mathrm{~A}>\mathrm{G}$ & $1 / 98(1 \%)$ & $0 / 102$ & $1 / 200(0.5 \%)$ & $0 / 200$ & - & - \\
c. $-253 \mathrm{~T}>\mathrm{C}$ & $13 / 98(13.3 \%)$ & $25 / 102(24.5 \%)$ & $38200(19 \%)$ & $20 / 200(10 \%)$ & $2.1(1.2-3.8)$ & 0.015 \\
c. $-807 \mathrm{C}>\mathrm{T}$ & $23 / 98(23.5 \%)$ & $19 / 102(18.6 \%)$ & $42200(21 \%)$ & $35 / 200(17.5 \%)$ & $0.8(0.5-1.3)$ & 0.45 \\
\hline
\end{tabular}

\section{Table 1. Allele Frequencies of SPINK1 Promoter Variants in Patients and Controls.}

The c.-253T>C variant was present in 5/100 cases in homozygous and in $28 / 100$ cases in heterozygous state compared with $20 / 100$ heterozygous controls. The c.-807C $>\mathrm{T}$ was present in $6 / 100$ cases in homozygous and 30/100 cases in heterozygous state compared with 3/100 homozygous and 29/100 heterozygous controls. OR and P value were calculated for total CP versus controls.

\subsubsection{Sequence Analysis of the SPINK1 Coding Region}

In cases with promoter variants c. $-14 \mathrm{G}>\mathrm{A}, \mathrm{c} .-108 \mathrm{G}>\mathrm{T}$, c. $-215 \mathrm{G}>\mathrm{A}$, and c. $-246 \mathrm{~A}>\mathrm{G}$, the entire SPINK1 coding region with exon-intron boundaries was sequenced to determine a possible linkage with other variants. The c.-14G>A variant was not associated with other SPINK1 variants. In the case with the c. $108 \mathrm{G}>\mathrm{T}$ variant, 3 common polymorphisms were detected, the intron 3 variant c. $195-323 \mathrm{C}>\mathrm{T}$ in the heterozygous state and the 3 prime region variants c. $* 318 \mathrm{~A}>\mathrm{T}$ and c. $* 407 \mathrm{C}>\mathrm{G}$ in the homozygous state. In all 3 patients carrying the c.$215 \mathrm{G}>\mathrm{A}$ variant, the c.194+2T $>\mathrm{C}$ mutation in intron 3 was confirmed. Two of these also had the c. $* 318 \mathrm{~A}>\mathrm{T}$ and $\mathrm{c} . * 407 \mathrm{C}>\mathrm{G}$ polymorphisms in the heterozygous state. The patient with the c.-246A $>$ G variant carried also a heterozygous variant c.88-23A $>$ T of unknown significance in intron 2.

\subsubsection{Functional Analysis of Promoter Variants Using Luciferase Reporter Gene Assay}

To determine their functional significance, promoter variants c. $-14 \mathrm{G}>\mathrm{A}$, c. $-108 \mathrm{G}>\mathrm{T}$, c.$215 \mathrm{G}>\mathrm{A}$, c. $-246 \mathrm{~A}>\mathrm{G}$, and c.-253T $>\mathrm{C}$ were introduced into a luciferase reporter plasmid carrying the SPINK1 promoter and AR42J cells were transfected with the constructs. Compared with the wild type, 3 variants (c.-14G>A, c. $-108 \mathrm{G}>\mathrm{T}$, and c. $-246 \mathrm{~A}>\mathrm{G}$ ) showed a statistically significant decrease in luciferase expression, with residual activities of $80 \%, 31 \%$, and $47 \%$, respectively (Figure 26). Variant c.-253T $>\mathrm{C}$ had no appreciable effect on the promoter activity, whereas variant c. $-215 \mathrm{G}>\mathrm{A}$ increased luciferase activity to $201 \%$. 


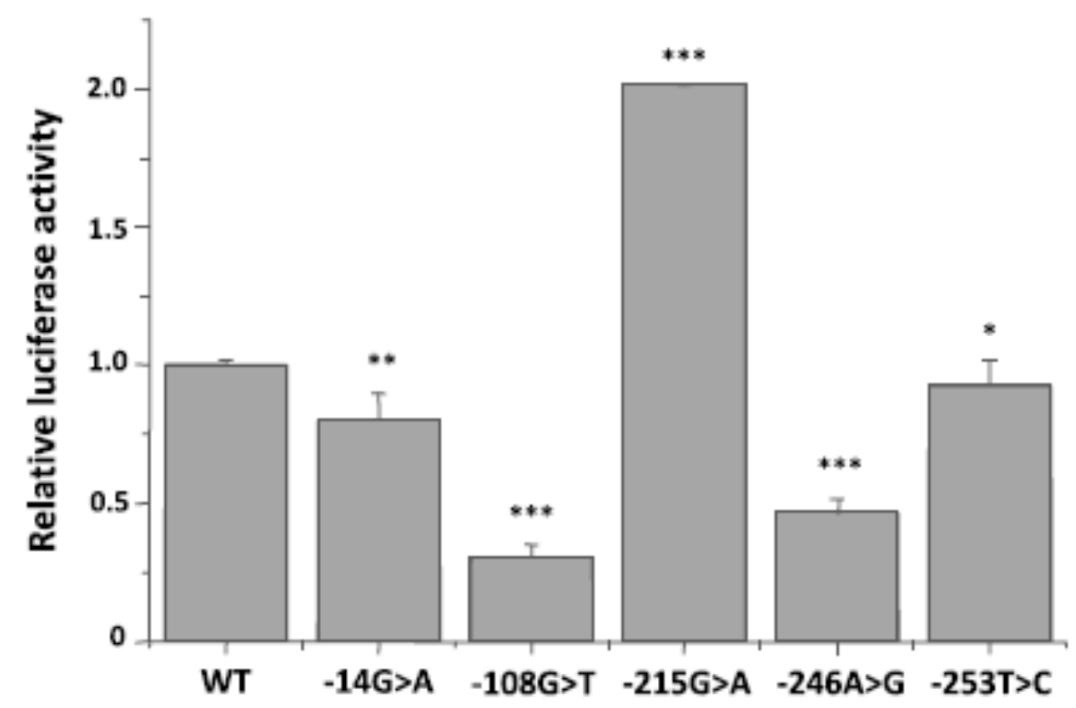

Figure 26.

Functional characterization of SPINK1 promoter variants.

Luciferase activity was determined by dividing the firefly and renilla luciferase luminescence results and expressing this firefly/renilla ratio relative to the WT pGL3SPINK1 value. The activity was determined as the mean of 3 to 8 transfections. Error bars indicate SD. $* \mathrm{P}<0.05, * * \mathrm{P}<0.001, * * * \mathrm{P}$ $<0.0001$.

WT, wild type. 


\section{DISCUSSION}

Our study in adults contain among the largest cohorts of any publication on prospectively collected clinical data in AP to date. With regard to epidemiology, our study confirmed findings from other cohorts showing that AP in women is more likely related to gallstones, alcohol-related pancreatitis is more common in men $(68,69)$, and age is a risk factor for AP (70). The role of dietary factors in the risk for AP is unclear. In experimental animal models, fatty acids, alcohol and fatty acid ethyl esters can cause AP; therefore, we separated "alcohol plus high-fat diet" as a distinct etiological group from alcohol-induced AP (71-73). However, no difference was found in the severity of AP between cases associated with alcohol plus high-fat diet versus alcohol only.

Cigarette smoking has been linked to AP $(74,75)$; however, the exact mechanism is unknown. Smoking also heightens the risk for recurrent AP (76). In our study, we observed that smoking was connected with greater mortality in severe AP.

Hypertriglyceridaemia was an etiological factor of AP in our cohort, as described for other cohorts (77-80). However, it is always a question whether elevation of serum triglyceride level is the cause of AP or merely a consequence of alcohol consumption and/or the hypertriglyceridaemia is just a coincidence. A rise in a serum triglyceride level above 11.3 $\mathrm{mmol} / \mathrm{L}$ in a patient with AP is considered diagnostic, whereas above $5.6 \mathrm{mmol} / \mathrm{L}$ considered suspicion for hypertriglyceridemia-induced AP (78). In our study, an increase in serum triglycerides above $5.6 \mathrm{mmol} / \mathrm{L}$ was considered as causative whenever no other obvious aetiology of AP was apparent. Experimental data have suggested that hypertriglyceridaemia can heighten the risk of severe AP (81); however, the role of hypertriglyceridaemia in the risk for severe AP has been unclear so far (78). One of the most important new observations of this study is that hypertriglyceridaemia is associated with severe AP. It has recently been shown that lipolysis of visceral adipocyte triglyceride converts mild AP to severe AP, independent of necrosis and inflammation (82). Moreover, data suggest that the unsaturated fatty acids in the triglycerides used in intravenous lipids may contribute to the development of organ failure in AP (83).

Obesity has been shown to be associated with an elevated systemic inflammatory response and increased risk for systemic complications and mortality (84-87). Although we could see a tendency between the rise in BMI and risk of severe AP, statistical analyses could not confirm the literature data. 
With regard to laboratory parameters, a WBC count above $23,000 / \mu \mathrm{L}, \mathrm{CRP}$ evels above $200 \mathrm{mg} / \mathrm{L}$, PCT levels above $10 \mathrm{U} / \mathrm{L}$, calcium levels below $2 \mathrm{mmol} / \mathrm{L}$ and triglyceride levels above $40 \mathrm{mmol} / \mathrm{L}$ were all associated with severe AP. Average glucose levels differed significantly between the three AP severity groups. Although others have reported that a haematocrit value above $44 \%$ and a rise in BUN are associated with persistent organ failure (88), our results could not confirm these findings. Our study support the recommendations in the IAP/APA guidelines. The first 24 hours were found to be the "golden hours" in AP $(89,90)$. Recommendations D9-10 highlight the importance of fluid resuscitation at admission. In our cohort, fluid volume below $1500 \mathrm{~mL}$ or above $3500 \mathrm{~mL}$ raised the risk of mortality and AP severity. In the current study, $71.7 \%$ of the patients received the recommended amount of fluid. In this group, the severity rate was only $7.8 \%$, whereas it increased to $14.1 \%$ in patients who were given less than $1500 \mathrm{~mL}$ or more than $3500 \mathrm{~mL}$. Moreover, the mortality rate was also elevated from $2.3 \%$ to $5.1 \%$. If we consider that around 7,000 new AP cases are diagnosed in Hungary in a year, hypothetically, we would prevent 124 patients from developing severe AP if fluid therapy were administered according to the IAP/APA guidelines. This would result in cost savings of HUF 200 million (about 672,000 euros) and could save 57 lives in a country of 10 million people. Projection of these calculations to the entire Eastern European region, with a population of about 200 million people, indicates that implementation of the EBM guidelines could save over a thousand lives.

Although there is no clear evidence for the efficacy of preventive antibiotic therapy ( 91 , 92), recent meta-analyses of six randomized clinical trials point to reduced mortality and lower incidence of infected pancreas necrosis (93). The recent Japanese guidelines suggest that in severe AP prophylactic antibiotic therapy may improve prognosis if started in the early phases of AP (94). Recommendations F17-18 in the IAP/APA guidelines do not endorse prophylactic antibiotic therapy. Our data have provided further support for the latter recommendation since there was no difference seen in severity and mortality between groups who received preventive and therapeutic antibiotic treatments. Meta-analyses have shown that probiotics have neither beneficial nor adverse effects in the outcome of AP (95). Our doctors generally followed recommendation F19 in the IAP/APA guidelines.

Recommendations on nutrition (G21) clearly suggest the importance of enteral feeding in severe and predicted severe AP. Recent meta-analyses have revealed that gut barrier dysfunction is present in three out of five patients in AP (96), thus raising the question whether enteral feeding is recommended in all types of AP. Although enteral feeding via a nasogastric tube is efficacious in severe AP (97-101), it is not among the preferred therapeutic tools in 
Hungary. In our cohort, we found that lack of enteral feeding was associated with mortality. Since the BISAP score has limitations $(70,102)$, our observation also highlights the need for a severity index in AP that could be employed at admission (103).

There is a lack of consensus on the role of ERCP in acute biliary AP (104). It has been generally agreed that early ERCP should be performed in biliary AP with cholangitis $(6,105-$ 107); however, there is only limited evidence available whether early ERCP should be conducted when only duct obstruction is present $(105,108)$. The strongest controversy concerns the predicted severe biliary pancreatitis without cholangitis and obstruction (104). The IAP/APA guidelines suggest that ERCP is most probably not indicated in the latter case (6). In our cohort, most of the endoscopists followed the guidelines when cholangitis was observed; however, they used a defensive attitude in cases of obstruction and predicted severe AP.

An unexpectedly large number $(30.7 \%)$ of the interventions were performed within the first four weeks after the onset of AP. Although the clinical necessity (which was not investigated in this cohort) could have indicated the procedure, our cohort suggests a lack of awareness of recommendation $\mathrm{J} 31$ on the necessity of delaying the intervention for at least four weeks.

In summary, a number of important determinants and associations of severity and mortality in AP were identified in our large, prospectively collected, nationwide cohort. The results also highlight that the evidence-based IAP/APA guidelines should be followed strictly to improve outcomes in AP.

Secondly, we wanted to investigate the situation is children. Inflammatory disorders of the exocrine pancreas are among the most challenging and expensive gastroenterological disorders in adults. While acute inflammation of the gland can lead to severe disease with a mortality rate of $30-50 \%$, the chronic form is usually not life-threatening but can diminish the patients' quality of life and can promote the development of pancreatic cancer (66). Although the incidence of AP in children is only 2-3 times less than in adults, our knowledge in pediatric AP is very limited. The current situation is difficult for the following reasons: (i) there is a limited number of scientists working in the field, genetic tests for pancreatic patients are unavailable or testing is not organized at the national level in most of the countries, (ii) there is a big and unacceptable high difference in disease recognition and outcome among the countries, (iii) limited number of biobanks or patient registers are available; those that exist are mostly organized on national levels with no links to international consortia and (iv) funding is often refused because of the low importance. Therefore, multinational efforts are crucially needed (109). There are clear evidences that the disease development in children is different than in 
adults. For example, the etiology of pediatric AP compared to adults is more diverse. The most common etiological factors in children are idiopathic and biliary causes, followed by trauma, systemic disease, medication, viral infections, metabolic disorders, diabetes mellitus, hypertryglyceridemia and hypercalcemia $(9,10,12)$. No specific etiological factor was found in $13-34 \%$ of all pediatric AP cases $(9-12,110]$. Results from the Danish population-based cohort study showed that genetic mutations that elevate the risk of pancreatitis can occur in $32 \%$ of idiopathic acute cases in young patients (111). Early onset and/or recurrent episodes of AP can further elevate the possibility of genetic alterations $(14,111,112)$. The INSPPIRE consortium highlighted that the current diagnostic practice is also differ between children and adults. Trans-abdominal ultrasonography is more commonly used than $\mathrm{CT}$ in the initial presentation of children with AP in order to limit radiation. MRI is also more frequently performed in cases of recurrent AP or chronic pancreatitis (16). Concerning the diagnosis, the key predicting signs in adult for pancreatitis are vomiting and nausea; however, it appears only in $74 \%$ of the cases in children (113). Predicting the severity of pancreatitis needs to be improved in children. For adults, the Ranson criteria (114, 115), Modified Glasgow (116) and the Acute Physiology and Chronic Health Evaluation II $(115,117)$ score have been developed for predicting the severity. Three studies have confirmed that the above-mentioned clinical scoring systems had low sensitivity in children and cannot be used as a predictors of outcome for pediatric pancreatitis (118-120). DeBanto et al. (121) published the first pediatric-specific AP severity score. This score requires 48 hours to be completed and has not been validated in prospective studies. There is a need for an easy, simple, pediatric-specific, clinically oriented novel models to further improve predictive accuracy of severity in AP (122). Concerning the treatment of AP in children, the situation is even worse. Almost only adult experiences are available for pediatricians to order treatment in everyday practice $(15,109)$.

In summary, here we propose a multinational observational clinical trial (APPLE) to collect a critical mass of clinical data from children suffering from AP in an uniform prospective manner to help fill the knowledge gap and provide simple, pediatric-specific, clinical scoring system that can stratify patients with AP on presentation. It is important to mention that after the APPLE study, we plan to design a follow-up longitudinal study for better understanding of PP.

Thirdly, In the present thesis we choose a gene which alterations can be found in both adult and children. Sequencing of the SPINK1 promoter region in a Hungarian cohort of CP patients revealed 6 different variants. Of these, the c.-807C $>\mathrm{T}$ variant was found in both cases and controls with comparable frequencies and could be considered as a common polymorphism with no clinical significance. The c.-253T $>\mathrm{C}$ variant occurred significantly more frequently in 
ICP patients than in controls; however, a similar enrichment was not observed in ACP patients. Previous studies from France, Germany, and Japan showed no association between this variant and $\mathrm{CP}$ and, based on these findings, the c.-253T $>\mathrm{C}$ variant was classified as a common nonpathogenic polymorphism $(27,28,39)$ Nevertheless, it is important to note that, in a Brazilian study of 82 patients with $\mathrm{CP}$, the $-253 \mathrm{C}$ allele occurred also significantly more frequently in CP patients (22\%) than in the control group (10\%) (37). Because there was a significant difference between the incidence of the c.-253T $>C$ variant in patients and controls in our cohort, we conducted functional characterization of this variant by luciferase reporter gene assay. This variant had no considerable effect on promoter activity, suggesting that c.$253 \mathrm{~T}>\mathrm{C}$ is a harmless variant. Clearly, additional studies are needed to resolve this apparent contradiction between the genetic and functional results. The c.-215G>A variant was confirmed in 3 patients with CP. This variant is part of the c.194+2T >C (IVS3+2T>C)-associated haplotype, which was reported as the second most common SPINK1 haplotype after p.N34S $(28,29,39,56,59,123)$. In vivo and in vitro studies showed that the c. $194+2 \mathrm{~T}>\mathrm{C}$ variant causes exon 3 skipping, which results in a diminished trypsin inhibitor production $(46,124,125)$ Boulling et al. (57) reported an increased promoter activity of the c.-215G>A variant compared with wild type. Our functional data also indicate that this variant increases promoter activity. However, this effect on SPINK1 expression would be completely masked in vivo by the impact of the c.194+2T>C mutation on mRNA expression (57). The relatively high frequency of the c.194+2T>C variant in our ACP cohort is surprising because this variant has been typically found in idiopathic cohorts so far. Although SPINK1 variants do not associate with sporadic pancreatic cancer, $(126,127)$ variant $\mathrm{c} .194+2 \mathrm{~T}>\mathrm{C}$ was detected in a patient with pancreatic adenocarcinoma who also had histologically defined CP (127). We found 3 novel promoter variants exclusively in the patient group. In functional assays, all variants exhibited reduced promoter activity. Based on the extent of the functional defect, we propose that variants c.$108 \mathrm{G}>\mathrm{T}$ ( $31 \%$ of wild type) and c. $-246 \mathrm{~A}>\mathrm{G}$ (47\% of wild type) should be considered as potential risk factors for $\mathrm{CP}$. In contrast, the slight decrease in activity observed with variant c.$14 \mathrm{G}>\mathrm{A}$ ( $80 \%$ of wild type) has likely no biological significance. Functional characterization by the luciferase reporter gene assay is a widely used method for the determination of potential pathogenicity of promoter variants. A comprehensive analysis of SPINK1 promoter variants was last performed in 2011, when Boulling et al. (57) reported sequencing data and the functional analysis of 11 SPINK1 promoter variants using the luciferase reporter gene assay and the electrophoretic mobility shift assay. Limitations of the luciferase reporter approach include the arbitrary nature of the promoter region selected for study, which may exclude 
important regulatory regions and the choice of cell line that may or may not harbor the same transcriptional factor complement as the human pancreatic acinar cells. In this regard, Boulling et al used a $1.17-\mathrm{kB}$ promoter fragment and the human pancreatic adenocarcinoma cell line COLO-357 whereas, in the present study, we used a $0.57-\mathrm{kB}$ promoter region and dexamethasone-differentiated AR42J rat acinar cells. The only variant that was analyzed in both studies is c.-215G>A, which in both systems exhibited increased activity.

In summary, our study identified 2 new potentially pathogenic SPINK1 promoter variants in a Hungarian cohort and confirmed linkage of the c.-215G>A variant with the pathogenic intronic variant c. $194+2 \mathrm{~T}>\mathrm{C}$. The observed association of the common variant c. $-253 \mathrm{~T}>\mathrm{C}$ with $\mathrm{ICP}$ is intriguing but needs independent confirmation in other populations. 


\section{NEW DISCOVERIES}

\subsection{Prospective, Multicentre, Nationwide Clinical Data from 600 Cases of Acute Pancreatitis}

The first report about the epidemiology, risk factors, management of AP from Hungary on a prospectively collected cohort. The article highlights the importance of evidence based guidelines. Following results have not been published before:

-Hyperlipidaemia is a risk factor for severity.

-Lack of serum enzyme elevation posed a risk for severe AP.

-Lack of abdominal pain at admission demonstrated a risk for mortality.

-Deviation from the recommendations in the IAP/APA evidence-based guidelines on fluid replacement, enteral nutrition and timing of interventions increased severity and mortality.

\subsection{Analysis of Pediatric Pancreatitis (APPLE Trial)}

This is the first worldwide study on the field of childhood onset pancreatitis for earlier (APPLER) and ongoing episodes (APPLE-P) of pancreatitis to collect a critical mass of clinical data and biomedical research samples in uniform prospective manner.

\subsection{SPINK1 Promoter Variants in Chronic Pancreatitis}

The common SPINK1 promoter variant c. $-253 \mathrm{~T}>\mathrm{C}$ was associated with $\mathrm{CP}$ in this cohort. Two of 3 newly identified SPINK1 promoter variants seem to exhibit significant functional defects and should be considered potential risk factors for $\mathrm{CP}$. 


\section{ACKNOWLEDGEMENTS}

I would like to express my most sincere gratitude to my mentor and supervisor, Professor Péter Hegyi, at the First Department of Medicine, University of Szeged and Institute for Translational Medicine, University of Pécs who supports my improvement with his guidance, criticism day by day and trusts in my ability unshakeably. Without his outstanding supervision, this $\mathrm{Ph} . \mathrm{D}$ thesis would not have been possible.

I am grateful to Professor Miklós Sahin-Tóth who guided me in the labirinth of the basic science and gave me the opportunity to have international experience.

These great scientist have served as a role model for me.

I would like to express my gratitude also to my other supervisor, Dr. István Hritz at the Endoscopic Unit, First Department of Surgery, University of Semmelweis, who supported me with his valuable advices and comments.

I am grateful to the leadership of the Heim Pál Children's Hospital, especially Dr. Anikó Nagy, Dr. Ferenc Fekete and Dr. András Kiss, who made me possible to work on this project. Special thanks to Dr. Judit B. Kovács, Dr. Margit Lőrincz, to attract my attention to the pediatric gastroenterology and to Dr. Natália Lásztity, who encourage me to get deeper knowledge on field of pancreatology.

This work would not have been possible to accomplish without the support and active participation of all the members of the Hungarian Pancreatic Study Group and the Pancreas Laboratory at the University of Szeged, especially Zsuzsa Miklósné Árva, Márta Bába, Erika Darvasi, Dr. Csilla Andorka, Dr. Anita Balázs, Dr. Renáta Bor, Dr. László Czakó, Cr. Judit Czelecz, Dr. Alexandra Demcsák, Dr. László Gárdos, Dr. Szilárd Gódi, Dr. Ildikó Guthy, Dr. Adrienn Halász, Dr. Eszter Hegyi, Dr. Emese Horváth, Dr. Judit Gervain, Dr. Imre Ignáth, Dr. Veronika Ila, Dr. Dóra Illés, Dr. Nelli Farkas, Dr. Ferenc Izbéki, Dr. Balázs Kui, Dr. Gábor Lakatos, Dr. József Maléth, Dr. Katalin Márta, Dr. Tímea Molnár, Dr. Dóra Mosztbacher, Dr. Balázs Németh, Dr. Petra Pallagi, Dr. Gabriella Pár, Dr. Dániel Pécsi, Dr. Zoltán Rakonczay, Dr. Anikó Nóra Szabó, Dr. Zoltán Szepes, Dr. Ákos Szücs, Dr. Tamás Takács, Dr. István Tokodi, Dr. Erika Tomsits, Dr. Anna Tóth, Dr. Péter Varjú, Dr. Ibolya Vass, Dr. Viktória Venglovecz, Dr. Fanni Zsoldos, Rea Fritz, Erzsébet Zoltánné Fuksz, Krisztina Harth, Ágnes Kocsisné Halas, Enikő Horváth, Kinga Kaán, Klaudia Kárász, Balázs Koncz, Félix Márk Juhász, Tünde Pritz, Zsuzsanna Répásy, Lajos Szakó, Andrea Szentesi and all the contributors to the Registry for Pancreatic Patients, a very special thanks to them. 
I am greatful to Andrea Talabér, Fabiola Zsuppán, Dr. Zsolt Bognár, Dr. Éva Rimanóczy for their help.

Thanks to the international professional advisory team: Maisam Abu-el Haija, Aliye Uc, Mark Lowe, Flóra Szabó, Micheal Wilschanski, Heiko Witt, Grzegorz Oracz, David Whitcomb.

Last but not least, I owe warm thanks to my parents, Csilla and Péter Párniczky, who thaught me to be brave and tenacious. Thank you, my brother Peti for your patience.

\section{FINANCIAL SUPPORT}

The studies in this thesis were supported by the Hungarian Academy of Sciences University of Szeged, Momentum Gastroenterology Multidisciplinary Research Group (LP2014-10/2014 to Péter Hegyi), the National Research, Development and Innovation Office (K116634 to Péter Hegyi) and the Economic Development and Innovation Operational Program (GINOP-2.3.2-15, University of Pécs). Functional studies in the laboratory of Miklós SahinTóth were supported by NIH grants R01DK058088, R01DK082412, and R01DK095753. 


\section{REFERENCES}

1. Gompertz M, Lara I, Fernandez L, Miranda JP, Mancilla C, Watkins G, et al. Mortality of acute pancreatitis in a 20 years period]. Rev Med Chil. 2013 May;141(5):562-7.

2. Roberts SE, Akbari A, Thorne K, Atkinson M, Evans PA. The incidence of acute pancreatitis: impact of social deprivation, alcohol consumption, seasonal and demographic factors. Aliment Pharmacol Ther. 2013 Sep;38(5):539-48.

3. Peery AF, Dellon ES, Lund J, Crockett SD, McGowan CE, Bulsiewicz WJ, et al. Burden of gastrointestinal disease in the United States: 2012 update. Gastroenterology. 2012 Nov;143(5):1179-87 e1-3.

4. McKay CJ, Evans S, Sinclair M, Carter CR, Imrie CW. High early mortality rate from acute pancreatitis in Scotland, 1984-1995. Br J Surg. 1999 Oct;86(10):1302-5.

5. Nawaz H, Mounzer R, Yadav D, Yabes JG, Slivka A, Whitcomb DC, et al. Revised Atlanta and determinant-based classification: application in a prospective cohort of acute pancreatitis patients. Am J Gastroenterol. 2013 Dec;108(12):1911-7.

6. IAP/APA evidence-based guidelines for the management of acute pancreatitis. Pancreatology. 2013 Jul-Aug;13(4 Suppl 2):e1-15.

7. Lopez MJ: The changing incidence of acute pancreatitis in children: a single-institution perspective. J Pediatr 2002; 140: 622-624.

8. Morinville VD, Barmada MM, Lowe ME: Increasing incidence of acute pancreatitis at an American pediatric tertiary care center: is greater awareness among physicians responsible? Pancreas 2010; 39: 5-8.

9. Nydegger A, Heine RG, Ranuh R, Gegati- Levy R, Crameri J, Oliver MR: Changing incidence of acute pancreatitis: 10-year experience at the Royal Children's Hospital, Melbourne. J Gastroenterol Hepatol 2007; 22: 1313-1316.

10. Park A, Latif SU, Shah AU, Tian J, Werlin S, Hsiao A, Pashankar D, Bhandari V, Nagar A, Husain SZ: Changing referral trends of acute pancreatitis in children: a 12-year single-center analysis. J Pediatr Gastroenterol Nutr 2009; 49: 316-322.

11. Sánchez-Ramírez CA, Larrosa-Haro A, Flores-Martínez S, Sánchez-Corona J, Villa-Gómez A, Macías Rosales R: Acute and recurrent pancreatitis in children: etiological factors. Acta Paediatr 2007; 96:534-537.

12. Werlin SL, Kugathasan S, Frautschy BC: Pancreatitis in children. J Pediatr Gastroenterol Nutr 2003; 37: 591-595.

13. Pant C, Deshpande A, Olyaee M, Anderson MP, Bitar A, Steele MI, Bass PF 3rd, Sferra TJ: Epidemiology of acute pancreatitis in hospitalized children in the United States from 2000-2009. PLoS One 2014; 9:e95552.

14. Meyer A, Coffey MJ, Oliver MR, Ooi CY: Contrasts and comparisons between childhood and adult onset acute pancreatitis. Pancreatology 2013; 13: 429-435.

15. Párniczky A, Czakó L, Dubravcsik Z, Farkas G, Hegyi P, Hritz I, Kelemen D, Morvay Z, Oláh A, Pap Á, Sahin-Tóth M, Szabó F, Szentkereszti Z, Szmola R, Takács T, Tiszlavicz L, Veres G, Szücs Á, Lásztity N; Magyar Hasnyálmirigy Munkacsoport, Hungarian Pancreatic Study Group: [Pediatric pancreatitis. Evidence based management guidelines of the Hungarian Pancreatic Study Group]. Orv Hetil 2015; 156: 308-325.

16. Morinville VD, Husain SZ, Bai H, Barth B, Alhosh R, Durie PR, Freedman SD, Himes R, Lowe ME, Pohl J, Werlin S, Wilschanski M, Uc A; INSPPIRE Group: Definitions of pediatric pancreatitis and survey of present clinical practices. J Pediatr Gastroenterol Nutr 2012; 55: 261-265.

17. Hritz I, Czakó L, Dubravcsik Z, Farkas G, Kelemen D, Lásztity N, Morvay Z, Oláh A, Pap Á, Párniczky A, Sahin-Tóth M, Szentkereszti Z, Szmola R, Szücs Á, Takács T, Tiszlavicz L, Hegyi P; Magyar Hasnyálmirigy Munkacsoport, Hungarian Pancreatic Study Group: [Acute pancreatitis. Evidence-based practice guidelines, prepared by the Hungarian Pancreatic Study Group]. Orv Hetil 2015; 156: 244-261.

18. Dubravcsik Z, Farkas G, Hegyi P, Hritz I, Kelemen D, Lásztity N, Morvay Z, Oláh A, Pap Á, Párniczky A, Sahin-Tóth M, Szentkereszti Z, Szmola R, Takács T, Tiszlavicz L, Szüics Á, Czakó L; Magyar Hasnyálmirigy Munkacsoport, Hungarian Pancreatic Study Group: [Autoimmune pancreatitis. 
Evidence based management guidelines of the Hungarian Pancreatic Study Group]. Orv Hetil 2015; 156: $292-307$.

19. Szmola R, Farkas G, Hegyi P, Czakó L, Dubravcsik Z, Hritz I, Kelemen D, Lásztity N, Morvay Z, Oláh A, Párniczky A, Rubovszky G, Sahin-Tóth M, Szentkereszti Z, Szücs Á, Takács T, Tiszlavicz L, Pap Á; Magyar Hasnyálmirigy Munkacsoport, Hungarian Pancreatic Study Group: [Pancreatic cancer. Evidence based management guidelines of the Hungarian Pancreatic Study Group]. Orv Hetil 2015; 156: 326-339.

20. Hritz I, Hegyi P: Early Achievable Severity (EASY) index for simple and accurate expedite risk stratification in acute pancreatitis. J Gastrointestin Liver Dis 2015; 24: 177-182.

21. Dubravcsik Z, Madácsy L, Gyökeres T, Vincze Á, Szepes Z, Hegyi P, Hritz I, Szepes A; Hungarian Pancreatic Study Group: Preventive pancreatic stents in the management of acute biliary pancreatitis (PREPAST trial): pre-study protocol for a multicenter, prospective, randomized, interventional, controlled trial. Pancreatology 2015; 15: 115-123.

22. Singer MV, Gyr K, Sarles H. Revised classification of pancreatitis. Report of the Second International Symposium on the Classification of Pancreatitis in Marseille, France, March 28-30, 1984. Gastroenterology. 1985;89:683-685.

23. Witt H, Apte MV, Keim V, et al. Chronic pancreatitis: challenges and advances in pathogenesis, genetics, diagnosis, and therapy. Gastroenterology. 2007;132:1557-1573.

24. Comfort MW, Steinberg AG. Pedigree of a family with hereditary chronic relapsing pancreatitis. Gastroenterology. 1952;21:54-63.

25. Whitcomb DC, Gorry MC, Preston RA, et al. Hereditary pancreatitis is caused by a mutation in the cationic trypsinogen gene. Nat Genet. 1996;14:141-145.

26. Szabó A, Sahin-Tóth M. Increased activation of hereditary pancreatitis-associated human cationic trypsinogen mutants in presence of chymotrypsin C. J Biol Chem. 2012;287:20701-20710.

27. Chen JM, Mercier B, Audrezet MP, et al. Mutational analysis of the human pancreatic secretory trypsin inhibitor (PSTI) gene in hereditary and sporadic chronic pancreatitis. J Med Genet. 2000;37:6769.

28. Witt H, Luck W, Hennies HC, et al. Mutations in the gene encoding the serine protease inhibitor Kazal type 1 are associated with chronic pancreatitis. Nat Genet. 2000;25:213-216.

29. Pfützer RH, Barmada MM, Brunskill AP, et al. SPINK1/PSTI polymorphisms act as disease modifiers in familial and idiopathic chronic pancreatitis. Gastroenterology. 2000;119:615-623.

30. Rosendahl J,Witt H, Szmola R, et al. Chymotrypsin C (CTRC) variants that diminish activity or secretion are associated with chronic pancreatitis. Nat Genet. 2008;40:78-82.

31. Beer S, Zhou J, Szabó A, et al. Comprehensive functional analysis of chymotrypsin C (CTRC) variants reveals distinct loss-of-function mechanisms associated with pancreatitis risk. Gut. 2013;62:1616-1624.

32. Witt H, Beer S, Rosendahl J, et al. Variants in CPA1 are strongly associated with early onset chronic pancreatitis. Nat Genet. 2013;45:1216-1220.

33. SharerN, Schwarz M, Malone G, et al. Mutations of the cystic fibrosis gene in patients with chronic pancreatitis. N Engl J Med. 1998;339:645-652.

34. Rosendahl J, Landt O, Bernadova J, et al. CFTR, SPINK1, CTRC and PRSS1 variants in chronic pancreatitis: is the role of mutated CFTR overestimated? Gut. 2013;62:582-592.

35. Rinderknecht H. Activation of pancreatic zymogens. Normal activation, premature intrapancreatic activation, protective mechanisms against inappropriate activation. Dig Dis Sci. 1986;31:314-321.

36. Horii A, Kobayashi T, Tomita N, et al. Primary structure of human pancreatic secretory trypsin inhibitor (PSTI) gene. Biochem Biophys Res Commun. 1987;149:635-641.

37. Chen JM, Mercier B, Audrezet MP, et al. Mutations of the pancreatic secretory trypsin inhibitor (PSTI) gene in idiopathic chronic pancreatitis. Gastroenterology. 2001;120:1061-1064.

38. Bhatia E, Choudhuri G, Sikora SS, et al. Tropical calcific pancreatitis: strong association with SPINK1 trypsin inhibitor mutations. Gastroenterology. 2002;123:1020-1025.

39. Kume K, Masamune A, Mizutamari H, et al. Mutations in the serine protease inhibitor Kazal type 1 (SPINK1) gene in Japanese patients with pancreatitis. Pancreatology. 2005;5:354-360.

40. Aoun E, Chang CC, Greer JB, et al. Pathways to injury in chronic pancreatitis: decoding the role of the high-risk SPINK1 N34S haplotype using meta-analysis. PloS One. 2008;3:e2003. 
41. Mahurkar S, Reddy DN, Rao GV, et al. Genetic mechanisms underlying the pathogenesis of tropical calcific pancreatitis. World J Gastroenterol. 2009;15:264-269.

42. Kuwata K, Hirota M, Shimizu H, et al. Functional analysis of recombinant pancreatic secretory trypsin inhibitor protein with amino-acid substitution. J Gastroenterol. 2002;37:928-934.

43. Király O, Wartmann T, Sahin-Tóth M. Missense mutations in pancreatic secretory trypsin inhibitor (SPINK1) cause intracellular retention and degradation. Gut. 2007;56:1433-1438.

44. Boulling A, Le Maréchal C, Trouvé P, et al. Functional analysis of pancreatitis-associated missense mutations in the pancreatic secretory trypsin inhibitor (SPINK1) gene. Eur J Hum Genet. 2007;15:936-942.

45. Masamune A, Kume K, Takagi Y, et al. N34S mutation in the SPINK1 gene is not associated with alternative splicing. Pancreas. 2007;34:423-428.

46. Kereszturi E, Király O, Sahin-Tóth M. Minigene analysis of intronic variants in common SPINK1 haplotypes associated with chronic pancreatitis. Gut. 2009;58:545-549.

47. Chen JM, Férec C. The true culprit within the SPINK1 p. N34S-containing haplotype is still at large. Gut. 2009;58: 478-480.

48. Gaia E, Salacone P, Gallo M, et al. Germline mutations in CFTR and PSTI genes in chronic pancreatitis patients. Dig Dis Sci. 2002;47:2416-2421.

49. Le Maréchal C, Chen JM, Le Gall C, et al. Two novel severe mutations in the pancreatic secretory trypsin inhibitor gene (SPINK1) cause familial and/or hereditary pancreatitis. Hum Mutat. 2004;23:205.

50. Masson E, Le Maréchal C, Chen JM, et al. Detection of a large genomic deletion in the pancreatic secretory trypsin inhibitor (SPINK1) gene. Eur J Hum Genet. 2006;14:1204-1208.

51. Boulling A,Keiles S, Masson E, et al. Functional analysis of eight missense mutations in the SPINK1 gene. Pancreas. 2012;41:329-330.

52. Masson E, Chen JM, Scotet V, et al. Association of rare chymotrypsinogen C (CTRC) gene variations in patients with idiopathic chronic pancreatitis. Hum Genet. 2008;123:83-91.

53. Cooper DN. Human gene mutation in pathology and evolution. J Inherit Metab Dis. 2002;25:157-182.

54. Wapenaar MC, Monsuur AJ, Poell J, et al. The SPINK gene family and celiac disease susceptibility. Immunogenetics. 2007;59:349-357.

55. Chandak GR, Idris MM, Reddy DN, et al. Mutations in the pancreatic secretory trypsin inhibitor gene (PSTI/SPINK1) rather than the cationic trypsinogen gene (PRSS1) are significantly associated with tropical calcific pancreatitis. J Med Genet. 2002;39:347-351.

56. Kaneko K, Nagasaki Y, Furukawa T, et al. Analysis of the human pancreatic secretory trypsin inhibitor (PSTI) gene mutations in Japanese patients with chronic pancreatitis. J Hum Genet. 2001;46:293-297.

57. Boulling A, Witt H, Chandak GR, et al. Assessing the pathological relevance of SPINK1 promoter variants. Eur J Hum Genet. 2011;19: 1066-1073.

58. Bernardino AL, Guarita DR, Mott CB, et al. CFTR, PRSS1 and SPINK1 mutations in the development of pancreatitis in Brazilian patients. JOP J Pancreas. 2003;4:169-177.

59. Keiles S, Kammesheidt A. Identification of CFTR, PRSS1, and SPINK1 mutations in 381 patients with pancreatitis. Pancreas. 2006;33:221-227.

60. Audrézet MP, Chen JM, Le Maréchal C, et al. Determination of the relative contribution of three genes - the cystic fibrosis transmembrane conductance regulator gene, the cationic trypsinogen gene, and the pancreatic secretory trypsin inhibitor gene-to the etiology of idiopathic chronic pancreatitis. Eur J Hum Genet. 2002;10:100-106.

61. Szmola R, Farkas G, Hegyi P, Czako L, Dubravcsik Z, Hritz I, et al. [Pancreatic cancer. Evidence based management guidelines of the Hungarian Pancreatic Study Group]. Orv Hetil. 2015 Feb 22;156(8):326-39.

62. Parniczky A, Czako L, Dubravcsik Z, Farkas G, Hegyi P, Hritz I, et al. [Pediatric pancreatitis. Evidence based management guidelines of the Hungarian Pancreatic Study Group]. Orv Hetil. 2015 Feb 22;156(8):308-25.

63. Dubravcsik Z, Farkas G, Hegyi P, Hritz I, Kelemen D, Lasztity N, et al. [Autoimmune pancreatitis. Evidence based management guidelines of the Hungarian Pancreatic Study Group]. Orv Hetil. 2015 Feb 22;156(8):292-307. 
64. Takacs T, Czako L, Dubravcsik Z, Farkas G, Hegyi P, Hritz I, et al. [Chronic pancreatitis. Evidence based management guidelines of the Hungarian Pancreatic Study Group]. Orv Hetil. 2015 Feb 15;156(7):262-88.

65. Hritz I, Czako L, Dubravcsik Z, Farkas G, Kelemen D, Lasztity N, et al. [Acute pancreatitis. Evidence-based practice guidelines, prepared by the Hungarian Pancreatic Study Group]. Orv Hetil. 2015 Feb 15;156(7):244-61.

66. Banks PA, Bollen TL, Dervenis C, Gooszen HG, Johnson CD, Sarr MG, et al. Classification of acute pancreatitis--2012: revision of the Atlanta classification and definitions by international consensus. Gut. 2013 Jan;62(1):102-11.

67. A. Párniczky, D. Mosztbacher, A Tóth, B Cs Németh, A Demcsak, N Lásztity, et al. Protocols and early results of an internatinal clinical trial on peditaric pancreatitis (APPLE). Pancreatology. 2016 June; 3S1(16):S117

68. Yadav D, Lowenfels AB. The epidemiology of pancreatitis and pancreatic cancer. Gastroenterology. 2013 Jun;144(6):1252-61.

69. Lankisch PG, Lowenfels AB, Maisonneuve P. What is the risk of alcoholic pancreatitis in heavy drinkers? Pancreas. 2002 Nov;25(4):411-2.

70. Wu BU, Johannes RS, Sun X, Tabak Y, Conwell DL, Banks PA. The early prediction of mortality in acute pancreatitis: a large population-based study. Gut. 2008 Dec;57(12):1698-703.

71. Maleth J, Balazs A, Pallagi P, Balla Z, Kui B, Katona M, et al. Alcohol disrupts levels and function of the cystic fibrosis transmembrane conductance regulator to promote development of pancreatitis. Gastroenterology. 2015 Feb;148(2):427-39 e16.

72. Hegyi P, Petersen OH. The exocrine pancreas: the acinar-ductal tango in physiology and pathophysiology. Rev Physiol Biochem Pharmacol. 2013;165:1-30.

73. Hegyi P, Pandol S, Venglovecz V, Rakonczay Z, Jr. The acinar-ductal tango in the pathogenesis of acute pancreatitis. Gut. 2011 Apr;60(4):544-52.

74. Alexandre M, Pandol SJ, Gorelick FS, Thrower EC. The emerging role of smoking in the development of pancreatitis. Pancreatology. 2011;11(5):469-74.

75. Yuhara H, Ogawa M, Kawaguchi Y, Igarashi M, Mine T. Smoking and risk for acute pancreatitis: a systematic review and meta-analysis. Pancreas. 2014 Nov;43(8):1201-7.

76. Majumder S, Gierisch JM, Bastian LA. The association of smoking and acute pancreatitis: a systematic review and meta-analysis. Pancreas. 2015 May;44(4):540-6.

77. Click B, Ketchum AM, Turner R, Whitcomb DC, Papachristou GI, Yadav D. The role of apheresis in hypertriglyceridemia-induced acute pancreatitis: A systematic review. Pancreatology. 2015 Jul-Aug;15(4):313-20.

78. Scherer J, Singh VP, Pitchumoni CS, Yadav D. Issues in hypertriglyceridemic pancreatitis: an update. J Clin Gastroenterol. 2014 Mar;48(3):195-203.

79. Valdivielso P, Ramirez-Bueno A, Ewald N. Current knowledge of hypertriglyceridemic pancreatitis. Eur J Intern Med. 2014 Oct;25(8):689-94.

80. Czako L, Szabolcs A, Vajda A, Csati S, Venglovecz V, Rakonczay Z, Jr., et al. Hyperlipidemia induced by a cholesterol-rich diet aggravates necrotizing pancreatitis in rats. Eur J Pharmacol. 2007 Oct 15;572(1):74-81.

81. Baranyai T, Terzin V, Vajda A, Wittmann T, Czako L. [Acute pancreatitis caused by hypertriglyceridemia]. Orv Hetil. 2010 Nov 7;151(45):1869-74.

82. Patel K, Trivedi RN, Durgampudi C, Noel P, Cline RA, DeLany JP, et al. Lipolysis of visceral adipocyte triglyceride by pancreatic lipases converts mild acute pancreatitis to severe pancreatitis independent of necrosis and inflammation. Am J Pathol. 2015 Mar;185(3):808-19.

83. Patel KS, Noel P, Singh VP. Potential influence of intravenous lipids on the outcomes of acute pancreatitis. Nutr Clin Pract. 2014 Jun;29(3):291-4.

84. Premkumar R, Phillips AR, Petrov MS, Windsor JA. The clinical relevance of obesity in acute pancreatitis: targeted systematic reviews. Pancreatology. 2015 Jan-Feb;15(1):25-33.

85. Martinez J, Sanchez-Paya J, Palazon JM, Suazo-Barahona J, Robles-Diaz G, Perez-Mateo M. Is obesity a risk factor in acute pancreatitis? A meta-analysis. Pancreatology. 2004;4(1):42-8.

86. Porter KA, Banks PA. Obesity as a predictor of severity in acute pancreatitis. Int J Pancreatol. 1991 Nov-Dec;10(3-4):247-52. 
87. Shin KY, Lee WS, Chung DW, Heo J, Jung MK, Tak WY, et al. Influence of obesity on the severity and clinical outcome of acute pancreatitis. Gut Liver. 2011 Sep;5(3):335-9.

88. Koutroumpakis E, Wu BU, Bakker OJ, Dudekula A, Singh VK, Besselink MG, et al. Admission Hematocrit and Rise in Blood Urea Nitrogen at $24 \mathrm{~h}$ Outperform other Laboratory Markers in Predicting Persistent Organ Failure and Pancreatic Necrosis in Acute Pancreatitis: A Post Hoc Analysis of Three Large Prospective Databases. Am J Gastroenterol. 2015 Nov 10.

89. Fisher JM, Gardner TB. The "golden hours" of management in acute pancreatitis. Am J Gastroenterol. 2012 Aug;107(8):1146-50.

90. Schepers NJ, Besselink MG, van Santvoort HC, Bakker OJ, Bruno MJ. Early management of acute pancreatitis. Best Pract Res Clin Gastroenterol. 2013 Oct;27(5):727-43.

91. Wittau M, Mayer B, Scheele J, Henne-Bruns D, Dellinger EP, Isenmann R. Systematic review and meta-analysis of antibiotic prophylaxis in severe acute pancreatitis. Scand J Gastroenterol. 2011 Mar;46(3):261-70.

92. Villatoro E, Mulla M, Larvin M. Antibiotic therapy for prophylaxis against infection of pancreatic necrosis in acute pancreatitis. Cochrane Database Syst Rev. 2010(5):CD002941.

93. Ukai T, Shikata S, Inoue M, Noguchi Y, Igarashi H, Isaji S, et al. Early prophylactic antibiotics administration for acute necrotizing pancreatitis: a meta-analysis of randomized controlled trials. J Hepatobiliary Pancreat Sci. 2015 Apr;22(4):316-21.

94. Yokoe M, Takada T, Mayumi T, Yoshida M, Isaji S, Wada K, et al. Japanese guidelines for the management of acute pancreatitis: Japanese Guidelines 2015. J Hepatobiliary Pancreat Sci. 2015 Jun;22(6):405-32.

95. Gou S, Yang Z, Liu T, Wu H, Wang C. Use of probiotics in the treatment of severe acute pancreatitis: a systematic review and meta-analysis of randomized controlled trials. Crit Care. 2014;18(2):R57.

96. Wu LM, Sankaran SJ, Plank LD, Windsor JA, Petrov MS. Meta-analysis of gut barrier dysfunction in patients with acute pancreatitis. Br J Surg. 2014 Dec;101(13):1644-56.

97. Nally DM, Kelly EG, Clarke M, Ridgway P. Nasogastric nutrition is efficacious in severe acute pancreatitis: a systematic review and meta-analysis. Br J Nutr. 2014 Dec 14;112(11):1769-78.

98. Petrov MS, Correia MI, Windsor JA. Nasogastric tube feeding in predicted severe acute pancreatitis. A systematic review of the literature to determine safety and tolerance. JOP. 2008;9(4):4408.

99. Eatock FC, Chong P, Menezes N, Murray L, McKay CJ, Carter CR, et al. A randomized study of early nasogastric versus nasojejunal feeding in severe acute pancreatitis. Am J Gastroenterol. 2005 Feb;100(2):432-9.

100. Eckerwall GE, Axelsson JB, Andersson RG. Early nasogastric feeding in predicted severe acute pancreatitis: A clinical, randomized study. Ann Surg. 2006 Dec;244(6):959-65; discussion 65-7.

101. Kumar A, Singh N, Prakash S, Saraya A, Joshi YK. Early enteral nutrition in severe acute pancreatitis: a prospective randomized controlled trial comparing nasojejunal and nasogastric routes. $\mathbf{J}$ Clin Gastroenterol. 2006 May-Jun;40(5):431-4.

102. Gao W, Yang HX, Ma CE. The Value of BISAP Score for Predicting Mortality and Severity in Acute Pancreatitis: A Systematic Review and Meta-Analysis. PLoS One. 2015;10(6):e0130412.

103. Hritz I, Hegyi P. Early Achievable Severity (EASY) index for simple and accurate expedite risk stratification in acute pancreatitis. J Gastrointestin Liver Dis. 2015 Jun;24(2):177-82.

104. van Geenen EJ, van Santvoort HC, Besselink MG, van der Peet DL, van Erpecum KJ, Fockens $\mathrm{P}$, et al. Lack of consensus on the role of endoscopic retrograde cholangiography in acute biliary pancreatitis in published meta-analyses and guidelines: a systematic review. Pancreas. 2013 Jul;42(5):774-80.

105. Neoptolemos JP, Carr-Locke DL, London NJ, Bailey IA, James D, Fossard DP. Controlled trial of urgent endoscopic retrograde cholangiopancreatography and endoscopic sphincterotomy versus conservative treatment for acute pancreatitis due to gallstones. Lancet. 1988 Oct 29;2(8618):979-83.

106. Nowak A, Marek TA, Nowakowska-Dulawa E, Rybicka J, Kaczor R. Biliary pancreatitis needs endoscopic retrograde cholangiopancreatography with endoscopic sphincterotomy for cure. Endoscopy. 1998 Nov;30(9):A256-9. 
107. Folsch UR, Nitsche R, Ludtke R, Hilgers RA, Creutzfeldt W. Early ERCP and papillotomy compared with conservative treatment for acute biliary pancreatitis. The German Study Group on Acute Biliary Pancreatitis. N Engl J Med. 1997 Jan 23;336(4):237-42.

108. Sharma VK, Howden CW. Metaanalysis of randomized controlled trials of endoscopic retrograde cholangiography and endoscopic sphincterotomy for the treatment of acute biliary pancreatitis. Am J Gastroenterol. 1999 Nov;94(11):3211-4.

109. Abu-El-Haija M, Lin TK, Palermo J: Update to the management of pediatric acute pancreatitis: highlighting areas in need of research. J Pediatr Gastroenterol Nutr 2014; 58: 689-693.

110. Bai HX, Lowe ME, Husain SZ: What have we learned about acute pancreatitis in children? J Pediatr Gastroenterol Nutr 2011; 52: 262-

270.

111. Joergensen M, Brusgaard K, Cruger DG, Gerdes AM, Schaffalitzky de Muckadell OB: Incidence, etiology and prognosis of firsttime acute pancreatitis in young patients: a population based cohort study. Pancreatology 2010; 10: 453-461.

112. Lucidi V, Alghisi F, Dall'Oglio L, D'Apice MR, Monti L, De Angelis P, Gambardella S, Angioni A, Novelli G: The etiology of acute recurrent pancreatitis in children: a challenge for pediatricians. Pancreas 2011; 40:517-521

113. Park AJ, Latif SU, Ahmad MU, Bultron G, Orabi AI, Bhandari V, Husain SZ: A comparison of presentation and management trends in acute pancreatitis between infants/toddlers and older children. $\mathrm{J}$ Pediatr Gastroenterol Nutr 2010; 51: 167-170.

114. Ranson JH, Rifkind KM, Roses DF, Fink SD, Eng K, Localio SA: Objective early identification of severe acute pancreatitis. Am J Gastroenterol 1974; 61: 443-451.

115. Ranson JH: Etiological and prognostic factors in human acute pancreatitis: a review. Am J Gastroenterol 1982; 77: 633-638.

116. Blamey SL, Imrie CW, O’Neill J, Gilmour WH, Carter DC: Prognostic factors in acute pancreatitis. Gut 1984; 25: 1340-1346.

117. Knaus WA, Draper EA, Wagner DP, Zimmerman JE: APACHE II: a severity of disease classification system. Crit Care Med 1985; 13: 818-829.

118. Suzuki M, Fujii T, Takahiro K, Ohtsuka Y, Nagata S, Shimizu T: Scoring system for the severity of acute pancreatitis in children. Pancreas 2008; 37: 222-223.

119. Lautz TB, Chin AC, Radhakrishnan J: Acute pancreatitis in children: spectrum of disease and predictors of severity. J Pediatr Surg 2011; 46: 1144-1149.

120. Fabre A, Petit P, Gaudart J, Mas E, Vial J, Olives JP, Sarles J: Severity scores in children with acute pancreatitis. J Pediatr Gastroenterol Nutr 2012; 55: 266-267.

121. DeBanto JR, Goday PS, Pedroso MR, Iftikhar R, Fazel A, Nayyar S, Conwell DL, Demeo MT, Burton FR, Whitcomb DC, Ulrich CD 2nd, Gates LK Jr; Midwest Multicenter Pancreatic Study Group: Acute pancreatitis in children. Am J Gastroenterol 2002; 97: 1726- 1731.

122. Uc A: Predicting the severity of pediatric acute pancreatitis: are we there yet? J Pediatr Gastroenterol Nutr 2013; 56: 584-585.

123. Shimosegawa T, Kume K, Masamune A. SPINK1 gene mutations and pancreatitis in Japan. J Gastroenterol Hepatol. 2006;21(suppl 3): S47-S51.

124. Kume K, MasamuneA, Kikuta K, et al. [-215G $>$ A; IVS3 $+2 \mathrm{~T}>\mathrm{C}]$ mutation in the SPINK1 gene causes exon 3 skipping and loss of the trypsin binding site. Gut. 2006;55:1214.

125. Kume K, Masamune A, Ariga H, et al. Do genetic variants in the

SPINK1 gene affect the level of serum PSTI? J Gastroenterol. 2012;47: 1267-1274.

126. Teich N, Schulz HU,Witt H, et al. N34S, a pancreatitis associated SPINK1 mutation, is not associated with sporadic pancreatic cancer. Pancreatology. 2003;3:67-68.

127. Matsubayashi H, Fukushima N, Sato N, et al. Polymorphisms of SPINK1 N34S and CFTR in patients with sporadic and familial pancreatic cancer. Cancer Biol Ther. 2003;2:652-655. 